Aus dem Institut Neuroanatomie

(Prof. Dr. med. J. Staiger)

im Zentrum Anatomie

der Medizinischen Fakultät der Universität Göttingen

\title{
Neuroligin-4: Einfluss auf die synaptische Übertragung exzitatorischer Neurone der Schicht IV des Barrel-Kortex
}

\author{
INAUGURAL - DISSERTATION \\ zur Erlangung des Doktorgrades \\ der Medizinischen Fakultät der Georg-August-Universität zu Göttingen
}

vorgelegt von

Stephen Olt

aus Basel/Schweiz

Göttingen 2013 
Dekan:

Prof. Dr. rer. nat. H. K. Kroemer

I. Berichterstatter:

II. Berichterstatter/in:

III. Berichterstatter/in:

Tag der mündlichen Prüfung:
Prof. Dr. med. J. Staiger

Prof. Dr. Rizzoli

Prof. Dr. rer. nat. Virsik-Köpp
20. November 2013 



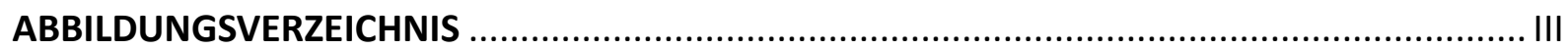

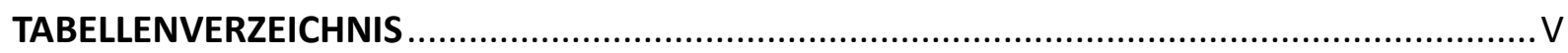

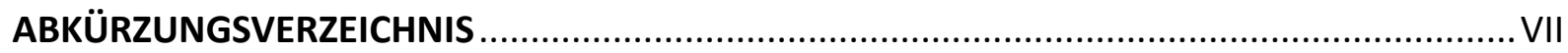

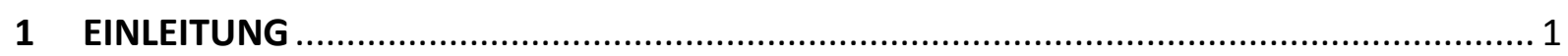

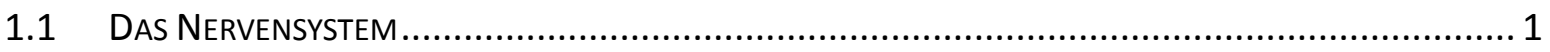

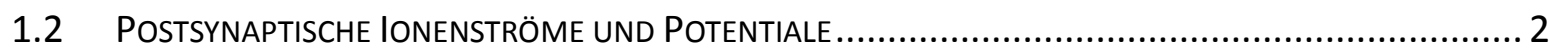

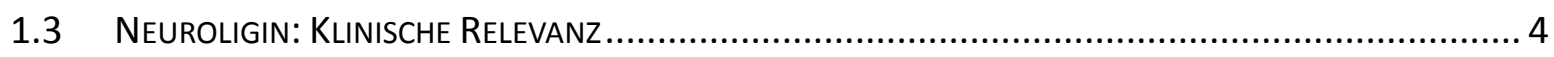

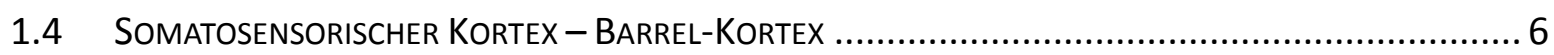

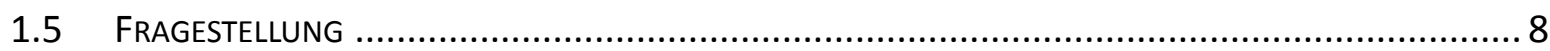

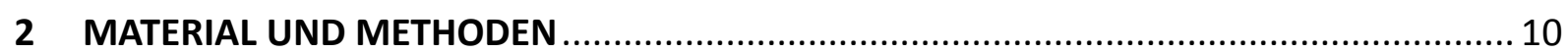

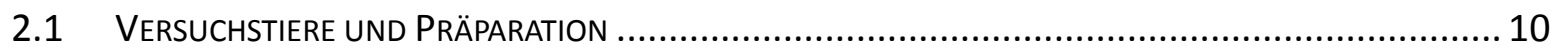

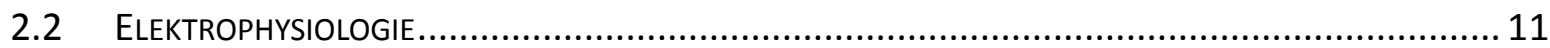

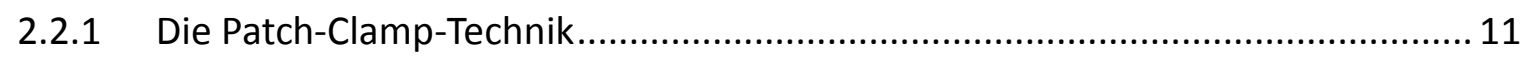

2.2.2 Elektrophysiologischer Versuchsaufbau...................................................... 13

2.2.3 Elektrophysiologische Charakterisierung abgeleiteter Zellen ............................ 15

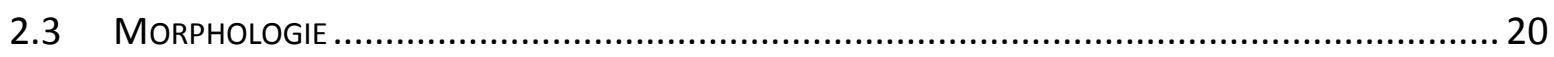

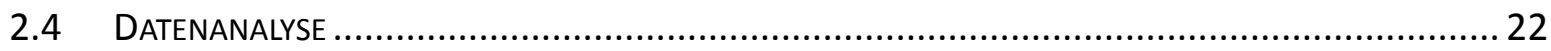

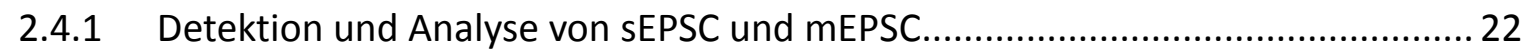

2.4.2 Analyse der Netzwerkaktivität - Detektion und Analyse TTX-sensitiver EPSC .... 28

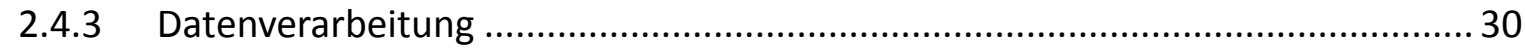

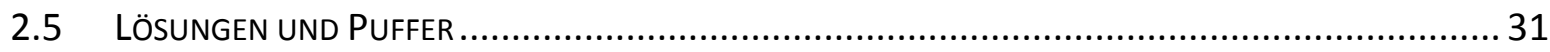

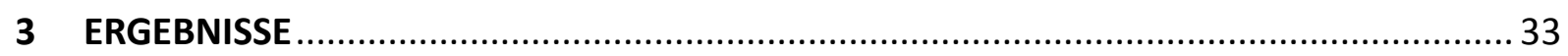

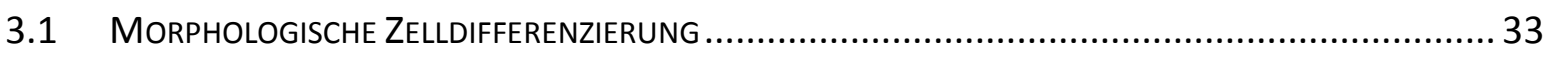

3.2 ANALYSE DER SYNAPTISCHEN ÜBERTRAGUNG - AUSWERTUNG DER SEPSC UND MEPSC ................ 39

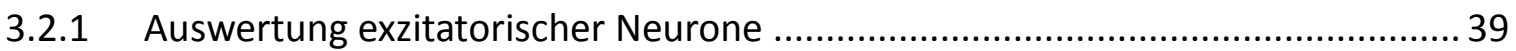

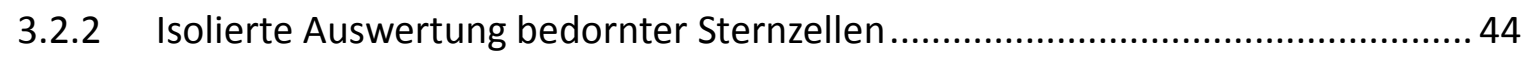




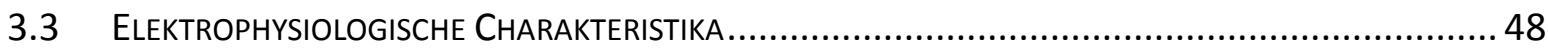

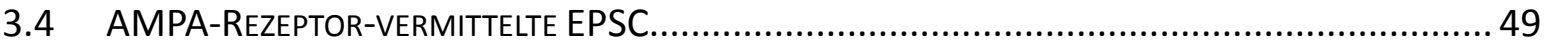

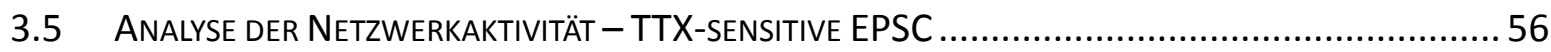

4 DISKUSSION

4.1 EINFLUSS VON NL-4 AUF DIE AMPA-REZEPTOR-VERMITTELTE SYNAPTISCHE ÜBERTRAGUNG AUF EXZITATORISCHE NEURONE DER SCHICHT IV DES BARREL-KoRTEX.......................................... 59

4.2 FUNKTIONELLE KONSEQUENZ EINER VERÄNDERTEN SYNAPTISCHEN ÜBERTRAGUNG .......................66

4.3 EINFLUSS VON NL-4 AUF DIE PRÄSYNAPTISCHE NETZWERKAKTIVITÄT ................................... 67

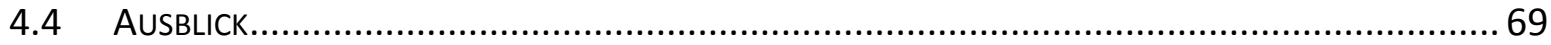

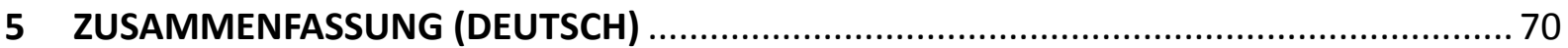

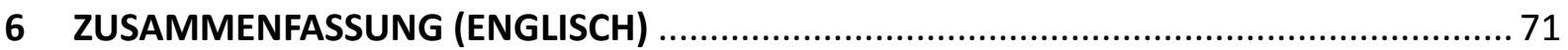

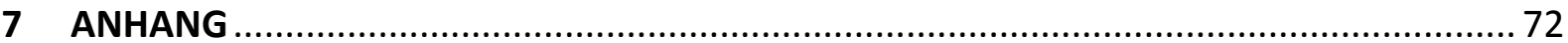

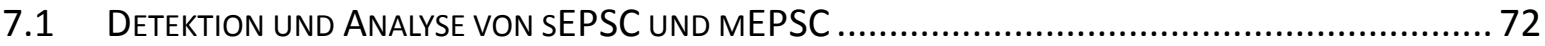

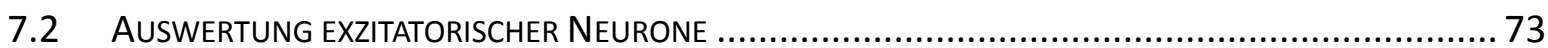

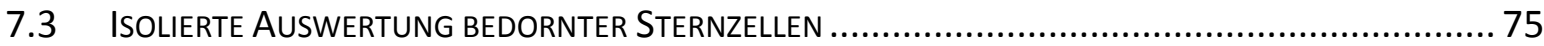

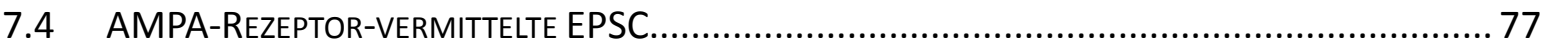

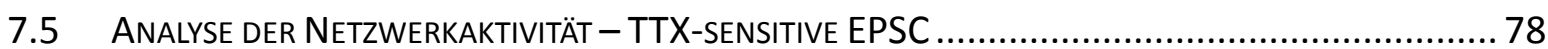

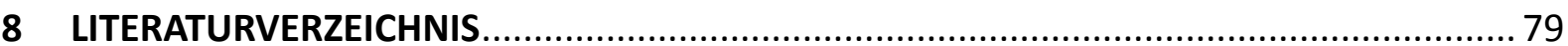




\section{ABBILDUNGSVERZEICHNIS}

AbBILdUng 1.1: $\quad$ EXZITATORISCHE POSTSYNAPTISCHE MEMBRANSTRÖME (EPSC) .................................... 3

AbBILDUNG 1.2: LOKALISATION VON NL-4 IM BARREL-KORTEX .................................................. 6

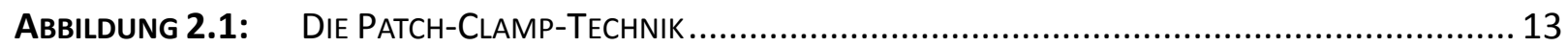

AbBILdUng 2.2: $\quad$ ÜBeRSICHTSAUfNAHME EINES THALAMO-KORTIKALEN HIRNSCHNITTS ........................... 14

Abbildung 2.3: MembranpotentialVerlauf in AbHÄngigkeit ZUR StimulationsStärkE ................... 16

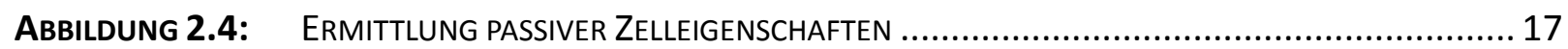

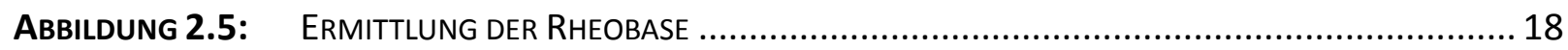

AbBiLdUng 2.6: $\quad$ ERMITtLUNG AKTIVER ZeLLEIGENSCHAFTEN ....................................................... 19

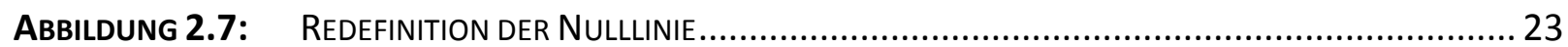

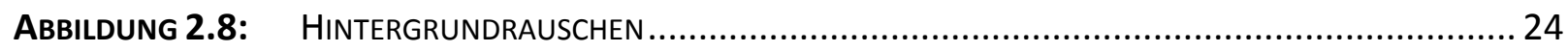

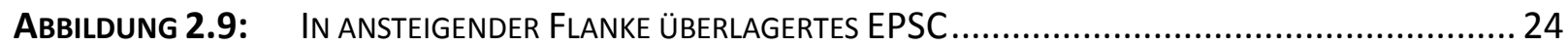

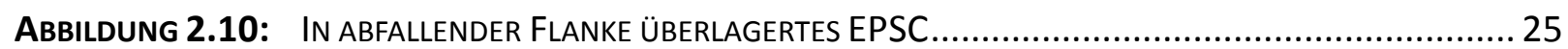

Abbildung 2.11: Rauschendes Signal in Abfallender Flanke ERreicht Vorzeitig Nulluinie .............. 25

AbBildUng 2.12: STREUdiagramm DETEKTIERTER SEPSC IN ABHÄNGIGKEIT VON ANSTIEGS- UND

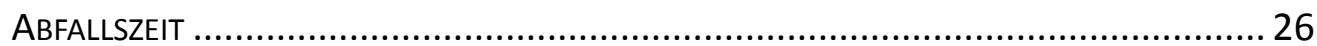

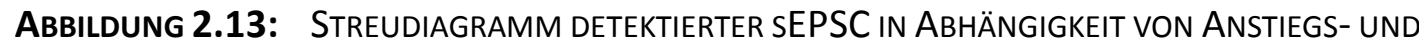
ABFALLSZEIT

AbBILDUNG 2.14: EXEMPLARISCHE DARSTELLUNG DER AUSGEWERTETEN MEPSC- UND SEPSC-AMPLITUDEN EINER ZELLE.......

ABbildung 2.15: $\quad$ BOXPLOT-DARSTELLUNG 30

Abbildung 3.1: Verteilung deR EXZITATORISChen NeURONe IN NL-4-WT UND NL-4-KO fÜR DIE ABLEITBEDINGUNGEN SEPSC UND MEPSC

AbBildung 3.2: $\quad$ LiCHTMIKROSKOPISCHES Bild UND ReKONSTRUKTION BEDORNTER STERNZELLEN IM WT 35

AbBILDUNg 3.3: LICHTMIKROSKOPISCHES BILD UND REKONSTRUKTION EINER BEDORNTEN STERNZELLE IM KO 36

AbBildDUng 3.4: LICHTMIKROSKOPISCHES BILD UND REKONSTRUKTION EINER STERNPYRAMIDENZELLE IM WT 
ABBILDUNG 3.5: LICHTMIKROSKOPISCHES BILD UND REKONSTRUKTION EINER STERNPYRAMIDENZELLE IM KO

Abbildung 3.6: AbFallszeit und Maximales Gefälle Von sEPSC und MEPSC aller KLASSEN EXZITATORISCHER NEURONE.

Abbildung 3.7: Anstiegszeit und maximale Steigung von sEPSC Und mEPSC aller KLASSEn EXZITATORISCHER NEURONE.

AbBildung 3.8: Amplitude Und FreQuenz VON SEPSC Und MEPSC ALLER KLASSEN EXZITATORISCHER

NEURONE

Abbildung 3.9: Abfallszeit, maximales Gefälle, HalbWertszeit und maximale Steigung von SEPSC UND MEPSC DER BEDORNTEN STERNZELLEN.

Abbildung 3.10: ORIGINALSPUREN EINES NL-4-WT- Und NL-4-KO-NeURONS UNTER KONTROLLBEDINGUNGEN UND NACH EINWASCHEN VON NBQX 50

AbBILDUNG 3.11: EPSC-AMPLITUDE EINES NL-4-WT- UND EINES NL-4-KO-NEURONS UNTER KONTROLLBEDINGUNGEN UND NACH EINWASCHEN VON GABAZINE 53

Abbildung 3.12: EPSC-AnStIEgSzeIt Und MAXIMALE SteIgUNG EINES NL-4-WT- UND EINES NL-4-KONeURONS UNTER Kontrollbedingungen UND NACH EINWASCHEN VON GABAZINE 54

Abbildung 3.13: EPSC-AbfallsZeIt Und MAXIMALES GeFÄLle EINES NL-4-WT- UND EINES NL-4-KONEURONS UNTER KONTROLLBEDINGUNGEN UND NACH EINWASCHEN VON GABAZINE 55

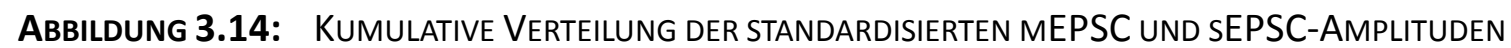
EXZITATORISCHER NL-4-WT- UND NL-4-KO-NEURONE 57

Abbildung 3.15: Frequenz Und INTERVAll TTX-Sensitiver EPSC. 58

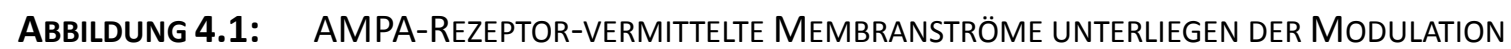
DURCH TARP

Abbildung 4.2: Interaktion ZWischen Neuroligin und AMPA-Rezeptoren ÜBer Proteine DER PSD. 


\section{TABELLENVERZEICHNIS}

TABelle 3.1: STATISTIK: P-WERTE

TABELle 3.2: STATISTISCHER VERGLEICH AKTIVER UND PASSIVER ELEKTROPHYSIOLOGISCHER

EIGENSCHAFTEN ZWISCHEN BEDORNTEN STERNZELLEN DES GENOTYPS NL-4-WT

UND NL-4-KO 48

TABelle 7.1: ÜBBerblick ÜBER DIE ANZAHL DeR AUSGEWERTETEN EPSC, ABHÄNGIG VON ABLEITUNGSMODUS (SEPSC/MEPSC), GENOTYP (NL-4-WT/NL-4-KO) UND EPSC-PARAMETER 72

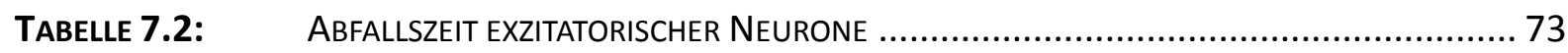

TABelle 7.3: Maximales Gefälle eXZitatorischer NeURone .............................................. 73

TAbelle 7.4: Maximale Steigung eXZitatorischer Neurone .............................................. 73

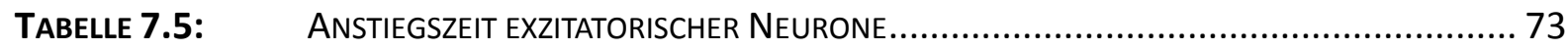

TABELle 7.6: AMPLITUdE EXZITATORISCHER NeURONE ......................................................... 74

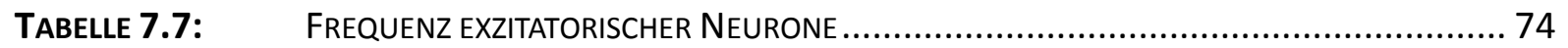

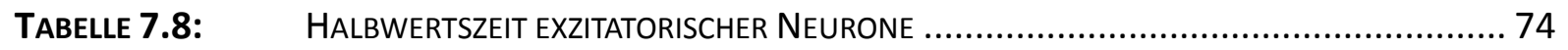

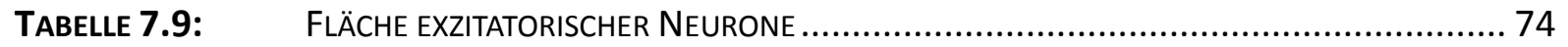

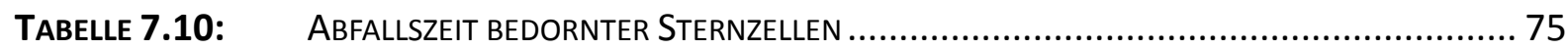

TABelle 7.11: HalbWertSZeit Bedornter SteRnZellen........................................................ 75

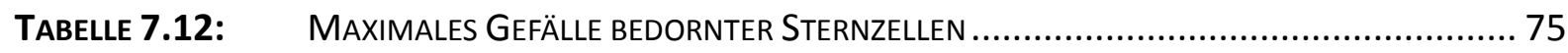

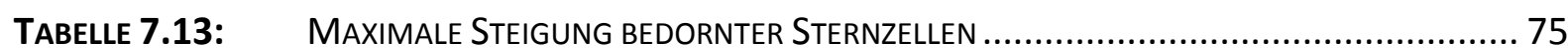

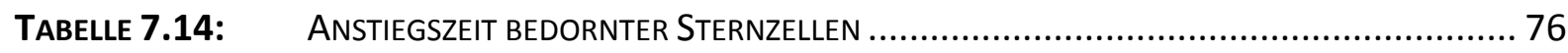

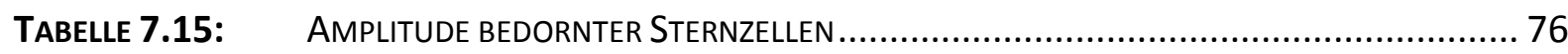

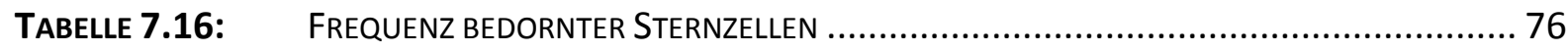

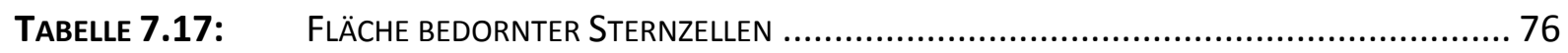


TABelle 7.18: MittelWerte Und Verteilung der EPSC-Amplitude Unter KontrollBEDINGUNGEN UND NACH EINWASCHEN VON GABAZINE FÜR JE EIN NL-4-WTUND EIN NL-4-KO-NEURON.

TABelle 7.19: MitTelWerte Und Verteilung Der EPSC-ANSTIEgSZEIT UNTER KontrollBEDINGUNGEN UND NACH EINWASCHEN VON GABAZINE FÜR JE EIN NL-4-WTUND EIN NL-4-KO-NEURON 77

Tabelle 7.20: Mittelwerte und Verteilung der maximalen Steigung Unter KontrollBEDINGUNGEN UND NACH EINWASCHEN VON GABAZINE FÜR JE EIN NL-4-WTUND EIN NL-4-KO-NEURON.....

Tabelle 7.21: MittelWerte Und Vertellung der EPSC-Abfallszeit Unter KontrollBEDINGUNGEN UND NACH EINWASCHEN VON GABAZINE FÜR JE EIN NL-4-WTUND EIN NL-4-KO-NEURON.....

Tabelle 7.22: MittelWerte und Verteilung des maximalen Gefälles unter KontrollBEDINGUNGEN UND NACH EINWASCHEN VON GABAZINE FÜR JE EIN NL-4-WTUND EIN NL-4-KO-NEURON

TABeLle 7.23: FREQUENZ UND EPSC-INTERVALL TTX-SENSITIVER EPSC. 78 


\section{ABKÜRZUNGSVERZEICHNIS}

ABC-Methode Avidin-Biotin-Komplex-Methode; avidin-biotin-complex-method

ACSF künstliche Zerebrospinalflüssigkeit; artificial cerebrospinal fluid

ADP

Nachdepolarisation; afterdepolarisation

AHP

Nachhyperpolarisation; afterhyperpolarisation

AMPA

$\alpha$-amino-3-hydroxy-5-methyl-4-isoxazol-Propionsäure: Spezifischer

Glutamat-Rezeptoragonist

AMPAR

AMPA-Rezeptor

AP

Aktionspotential

ATP

Adenosintriphosphat

CO

Cytochrom-C-Oxidase

DAB

3,3'-Diamino-benzidin-tetrahydrochlorid

DIgA

Drosophila disc large tumor suppressor $A$

EGTA

Ethylenglycol-bis-( $\beta$-aminoethylether)-N,N,N',N'-tetraessigsäure

EPSC

exzitatorischer postsynaptischer Strom; excitatory postsynaptic current

EPSP

exzitatorisches postsynaptisches Potential; excitatory postsynaptic potential

FS

schnelles Feuermuster; fast-spiking

GABA $\quad$-Aminobuttersäure

Gabazine 4-[6-imino-3-(4-methoxyphenyl)pyridazin-1-yl]-Butansäure-Hydrobromid:

$\mathrm{GABA}_{\mathrm{A}}$-Rezeptorantagonist

GluR Glutamat-Rezeptor

GluR1 - GluR4 Glutamat-Rezeptoruntereinheit 1-4

GlyRa1 Glycin-Rezeptoruntereinheit $\alpha 1$

GTP Guanosintriphosphat 
v

HEPES

IB

IPSC

IPSP

ISI

KO

MEPSC

n.s.

NBQX

NL

NL-1

NL-2

NL-3

NL-4

NL-4-KO

NL-4-WT

NL-4X

NL-4Y

NMDA

NRCAM
Bezeichnung für Transmembrane-AMPA-Rezeptor-Protein-Untereinheiten $\left(\gamma^{2}, \gamma^{3}, \gamma^{4}\right.$ und $\left.\gamma 8\right)$

$\mathrm{N}$-(2-Hydroxyethyl)-piperazin-N'-2-ethansulfonsäure

intrinsisch-burstendes Feuermuster; intrinsic-bursting

inhibitorischer postsynaptischer Strom; inhibitory postsynaptic current

inhibitorisches postsynaptisches Potential; inhibitory postsynaptic potential

Interspike Intervall

Knockout

exzitatorischer postsynaptischer Miniatur-Strom; miniature excitatory postsynaptic current

inihibitorischer postsynaptischer Miniatur-Strom; miniature inhibitory postsynaptic current

nicht signifikant

2,3-dihydroxy-6-nitro-7-sulfamoylbenzo(f)chinoxalin: AMPA- und KainatRezeptorantagonist

Neuroligin

Neuroligin-1

Neuroligin-2

Neuroligin-3

Neuroligin-4

Neuroligin-4-Knockout

Neuroligin-4-Wildtyp

Neuroligin-4 X-chromosomal

Neuroligin-4 Y-chromosomal

N-Methyl-D-Aspartat: Spezifischer Glutamat-Rezeptoragonist neuronales Zelladhäsionsmolekül; neuronal cell adhesion molecule 
NX Neurexin

PB

PDZ

PSD

PSD-95

RS

SD

SE

sEPSC

SIPSC

S-SCAM

STP

TARP

TB

TBS

TRIS

TTX

WT

ZNS

ZO-1
Phosphat-Puffer; phosphate buffer

post synaptic density protein-95/Drosophila disc large tumor

suppressorA/zonula occludens-1 protein

postsynaptische Dichte

Postsynaptische Dichte-95; post synaptic density protein-95

regelmäßiges Feuermuster; regular-spiking

Standardabweichung

Standardfehler

spontan gemessener exzitatorischer postsynaptischer Strom; spontaneous excitatory postsynaptic current

spontan gemessener inhibitorischer postsynaptischer Strom; spontaneous inhibitory postsynaptic current

Synaptisches Gerüstprotein; synaptic-scaffolding molecule

Aktionspotential-Präzision; spike-time-precison

Transmembranes-AMPA-Rezeptor-Regulator-Protein

TRIS Puffer, tris buffer

TRIS-gepufferte Saline; tris buffered saline

Tris(hydroxymethyl)-aminomethan

Tetrodotoxin: Antagonist spannungsgesteuerter Natrium-Kanäle

Wildtyp

Zentrales Nervensystem

Zonula occludens-1 protein 


\section{Physikalische und chemische Messgrößen und Einheiten:}

\begin{tabular}{|c|c|c|c|c|}
\hline C & Kapazität & - & {$[\mathrm{F}]$} & Farad \\
\hline c & Stoffmengenkonzentration & - & [M; mol/l] & Mol pro Liter \\
\hline $\mathbf{E}$ & $\begin{array}{l}\text { lonenspezifisches Gleichgewichtspotential } \\
\text { nach Nernst }\end{array}$ & - & [V] & Volt \\
\hline I & Stromstärke & - & {$[\mathrm{A}]$} & Ampere \\
\hline m & Masse & - & [g] & Gramm \\
\hline $\mathbf{R}$ & Widerstand & - & {$[\Omega]$} & Ohm \\
\hline $\mathbf{T}$ & Temperatur & - & {$\left[{ }^{\circ} \mathrm{C}\right]$} & Grad Celsius \\
\hline & & & {$[\mathrm{K}]$} & Kelvin \\
\hline $\mathbf{t}$ & Zeit & - & [s] & Sekunde \\
\hline & & & [min] & Minute \\
\hline$\tau$ & Membranzeitkonstante & - & [s] & Sekunde \\
\hline $\mathbf{U}$ & Spannung & - & [V] & Volt \\
\hline V & Volumen & - & [I] & Liter \\
\hline
\end{tabular}

Physikalische Konstanten:

$\begin{array}{llll}\mathbf{R} \text { universelle Gaskonstante } & =8,31 & {\left[\frac{\mathrm{J}}{\mathrm{mol} * \mathrm{~K}}\right]} & \text { Joule pro Mol pro Kelvin } \\ \mathbf{F} \text { Faradaykonstante } & =96485,33 & {\left[\frac{\mathrm{C}}{\mathrm{mol}}\right]} & \text { Coulomb pro Mol }\end{array}$

Dekadische Vorsilben:

$\begin{array}{llllll}\mathbf{m} & \text { (milli) } & 10^{-3} & \mathbf{k} & \text { (kilo) } & 10^{3} \\ \boldsymbol{\mu} & \text { (mikro) } & 10^{-6} & \mathbf{M} & \text { (mega) } & 10^{6} \\ \mathbf{n} & \text { (nano) } & 10^{-9} & \mathbf{G} & \text { (giga) } & 10^{9} \\ \mathbf{p} & \text { (pico) } & 10^{-12} & & & \end{array}$




\section{EINLEITUNG}

\subsection{Das Nervensystem}

Das Nervensystem zählt zu den komplexesten funktionellen Systemen des Organismus. Topographisch lässt es sich in einen zentralen und einen peripheren Anteil untergliedern. Das zentrale Nervensystem (ZNS) besteht dabei aus Gehirn und Rückenmark und erfüllt Funktionen einer übergeordneten Kontrollinstanz, welche einerseits sensible Informationen aus afferenten Nervenfasern integriert, wahrnimmt und bewertet und andererseits motorische Aktionen und Reaktionen plant, koordiniert und über efferente Nervenfasern auslöst. Gegenüber dem ZNS stellt das periphere Nervensystem das Rezeptor- und Effektororgan dar und umfasst den Anteil des Nervensystems außerhalb von Gehirn und Rückenmark, wozu, neben autonomen Ganglien mit ihren Verschaltungen, auch Hirn- und Spinalnerven samt ihrer Rezeptoren zählen (Kugler 2004).

Neurone bilden die funktionelle Grundeinheit des Nervensystems. Ihre Strukturierung und Vernetzung ist die Grundlage, auf der das Gehirn funktioniert. Neurone bestehen aus einem Zellkörper (Soma) und Zellfortsätzen, die dem Erregungsempfang (dendritische Zellfortsätze) und der Erregungsweiterleitung (axonale Zellfortsätze) dienen. Sie zeichnen sich durch die Fähigkeit aus, elektrische Signale zu integrieren, in Form von Aktionspotentialen (AP) weiterzuleiten und auf andere Neurone oder Effektororgane zu übertragen. Diese Übertragung erfolgt an Synapsen (Bear et al. 2007).

Die klassische chemische Synapse besteht aus einer präsynaptischen Endigung, dem synaptischen interzellulären Spalt und der postsynaptischen Membran. Jedes dieser drei Kompartimente zeichnet sich durch besondere Strukturen aus, welche es ermöglichen, eine Erregung der präsynaptischen Zelle, über den synaptischen Spalt hinweg, auf die postsynaptische Zelle zu übertragen. Ein komplexes Zusammenspiel spezifischer präsynaptischer Proteine steuert und reguliert dabei an der sogenannten aktiven Zone die Ausschüttung von chemischen Botenstoffen, den Neurotransmittern, welche durch Diffusion den synaptischen Spalt überwinden und durch Bindung an postsynaptischen transmitterspezifischen Rezeptoren den Aktivitätszustand der postsynaptischen Zelle verändern können (Kandel und Siegelbaum 2013). 
Die am häufigsten vorkommenden Neurotransmitter-Rezeptoren des ZNS sind ionotrope Glutamat-Rezeptoren. Zu dieser Gruppe zählen AMPA-, NMDA- und Kainat-Rezeptoren, die als Bestandteil der postsynaptischen Dichte (PSD) - einem korrespondierend zu der aktiven Zone lokalisierten Netzwerk postsynaptischer Proteine - die Funktion ligandengesteuerter transmembraner lonenkanäle erfüllen. Die Rezeptoren vermitteln durch Interaktion mit dem Neurotransmitter Glutamat bzw. den individuellen, spezifischen, namensgebenden, synthetisch hergestellten Agonisten AMPA ( $\alpha$-amino-3-hydroxy-5-methyl-4-isoxazolPropionsäure), NMDA (N-Methyl-D-Aspartat) oder Kainat, erregende (exzitatorische) postsynaptische Membranströme über Veränderungen ihrer Leitfähigkeiten für spezifische Ionen. Dabei unterscheiden sich die einzelnen Rezeptorklassen (AMPA-, NMDA- und KainatRezeptoren) in ihren biophysikalischen Rezeptoreigenschaften und auf diese Weise in der Kinetik der durch sie vermittelten postsynaptischen Membranströme (Hille 2001).

\subsection{Postsynaptische lonenströme und Potentiale}

Die durch kurzzeitig geöffnete transmembrane Rezeptorkanäle fließenden Ionen werden, entsprechend dem Nettofluss an Ladungsträgern, als exzitatorischer postsynaptischer Strom (excitatory postsynaptic current; EPSC) (Abb. 1.1) oder als inhibitorischer postsynaptischer Strom (inhibitory postsynaptic current; IPSC) bezeichnet. Analog hierzu wird die Veränderung des dabei anliegenden Membranpotentials als exzitatorisches postsynaptisches Potential (excitatory postsynaptic potential; EPSP) bzw. inhibitorisches postsynaptisches Potential (inhibitory postsynaptic potential; IPSP) benannt. Mit Hilfe elektrophysiologischer Methoden wie der Patch-Clamp-Technik (siehe Abschnitt 2.2.1) können diese postsynaptischen Ströme und Potentialveränderungen gemessen werden.

Es lassen sich dabei zwei Klassen von EPSC/IPSC anhand ihrer zugrundeliegenden Entstehungsmechanismen unterscheiden und durch experimentell veränderbare Ableitbedingungen aufzeichnen. Hierzu zählen die spontan gemessenen EPSC/IPSC (spontaneous EPSC/IPSC; sEPSC/SIPSC) sowie die miniatur EPSC/IPSC (miniature EPSC/IPSC; $\mathrm{mEPSC} / \mathrm{mIPSC}$ ). 


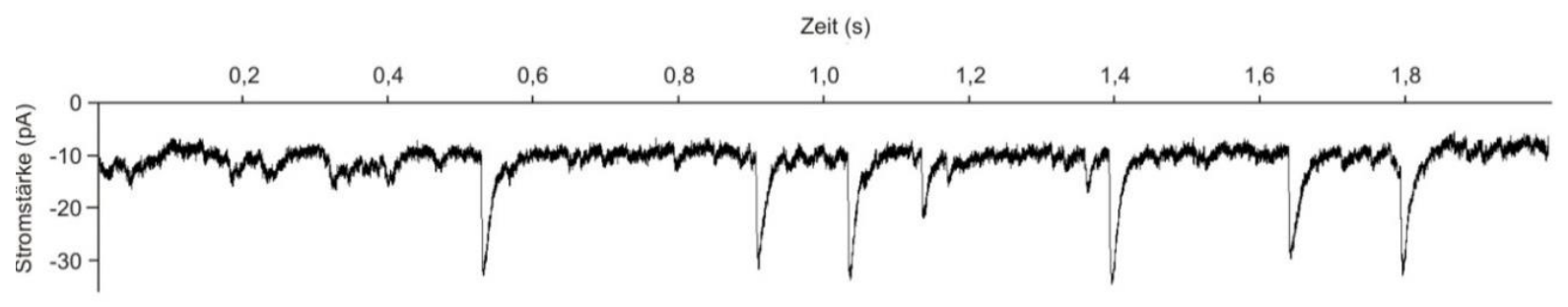

\section{Abbildung 1.1: Exzitatorische postsynaptische Membranströme (EPSC)}

Mit Hilfe der Patch-Clamp-Technik können durch kurzzeitiges Öffnen von Ionenkanälen ausgelöste Membranströme registriert werden. Diese zeichnen sich durch den charakteristischen steilen Signalaufstrich mit verhältnismäßig langsamer Rückkehr auf Nullinienniveau (bei I $\approx-10 p A$ ) aus. Per Definition entsprechen negative Amplitudenausschläge, bei extrazellulär anliegender Referenzelektrode (Erdung), exzitatorischen Ionenströmen (EPSC), positive Amplitudenausschläge inhibitorischen lonenströmen (IPSC).

Zur Registrierung der sEPSC/sIPSC werden mit Hilfe einer Messelektrode Veränderungen im postsynaptischen Membranstromverlauf unter Kontrollbedingungen, also ohne weitere externe Manipulation, gemessen. Die auf diese Weise registrierten SEPSC/SIPSC werden dementsprechend durch eine spontane synaptische „Ruhe-Aktivität“ hervorgerufen, welche sich aus einer AP-abhängigen und AP-unabhängigen Komponente zusammensetzt: Neben der AP-induzierten Depolarisation der präsynaptischen Zellmembran führen spontane und unabhängig von Aktionspotentialen stattfindende Fusionen einzelner transmittergefüllter Vesikel mit der präsynaptischen Zellmembran zur Freisetzung von Neurotransmittern und auf diese Weise zu postsynaptischen Membranströmen (Fatt und Katz 1952; Kuffler et al. 1984).

Die Klasse der mEPSC/mIPSC beschreibt isoliert diese durch AP-unabhängige Transmitterfreisetzung hervorgerufenen postsynaptischen Membranströme. Sie werden nach Einwaschen von Tetrodotoxin (TTX), einem Pharmakon, welches spannungsgesteuerte $\mathrm{Na}^{+}$-Kanäle hemmt und auf diese Weise die AP-abhängige Neurotransmitterfreisetzung unterdrückt, gemessen (Narahashi et al. 1960; Narahashi et al. 1964).

Neben den genannten Klassen lässt sich eine weitere Gruppe, die sogenannten TTX-sensitiven EPSC, definieren. Dabei handelt es sich um Membranströme, welche nach Applikation von TTX nicht mehr detektierbar sind. Im Gegensatz zu den zuvor beschriebenen EPSC-Klassen sind diese nicht direkt experimentell messbar, sondern nur indirekt durch eine vergleichende Analyse von SEPSC und mEPSC ermittelbar. Da es sich bei den TTX-sensitiven EPSC um 
postsynaptische Ströme handelt, die isoliert den durch TTX unterdrückten (AP-abhängigen) Anteil der synaptischen Aktivität repräsentieren, erlaubt ihre Auswertung eine Beurteilung der präsynaptischen Netzwerkaktivität.

\subsection{Neuroligin: Klinische Relevanz}

Entsprechend der hohen hierarchischen Stellung und der komplexen, bislang nur in Teilen verstandenen Funktionsweise des Nervensystems, können bereits kleine Irritationen zu Fehlleistungen mit teilweise schwerwiegenden, den Gesamtorganismus betreffenden Beeinträchtigungen führen. Solche Beeinträchtigungen können sich klinisch in Form tiefgreifender Entwicklungsstörungen manifestieren. Autismus-Spektrum-Störungen, wie der frühkindliche Autismus, das Asperger-Syndrom und der atypische Autismus, gehören zur Gruppe der tiefgreifenden Entwicklungsstörungen. „Diese Gruppe von Störungen ist gekennzeichnet durch qualitative Abweichungen in den wechselseitigen sozialen Interaktionen und Kommunikationsmustern und durch ein eingeschränktes, stereotypes, sich wiederholendes Repertoire von Interessen und Aktivitäten“ (WHO 2011 - ICD-10; F84 Tiefgreifende Entwicklungsstörungen; S. 311). Die Ätiologie der Autismus-Spektrum-Störungen ist nicht vollständig verstanden. Epidemiologische, zytogenetische und molekulargenetische Studien belegen jedoch, dass die Erkrankungen im Wesentlichen genetisch determiniert sind (Freitag 2007). Beim Menschen konnten einzelne Gene identifiziert werden, deren Mutationen mit Autismus-Spektrum-Störungen assoziiert sind. Hierzu zählen unter anderem Mutationen von neuronalen, für die synaptische Funktion notwendigen Proteinen wie Shank (Durand et al. 2007; Moessner et al. 2007; Peca et al. 2011; Wang et al. 2011), NRCAM (neuronales Zelladhäsionsmolekül, neuronal cell adhesion molecule) (Bonora et al. 2005; Hutcheson et al. 2004), Neurexin (Feng et al. 2006; Kim et al. 2008) sowie Neuroligin-3 und Neuroligin-4 (Blasi et al. 2006; Jamain et al. 2003; Laumonnier et al. 2004; Yan et al. 2005).

Neuroligine (NL) bilden eine Proteinfamilie, welche beim Menschen und höheren Primaten aus fünf Isoformen besteht (NL-1, NL-2, NL-3, NL-4X und NL-4Y). Bei Nagetieren, wie beispielsweise der Maus existieren vier Neuroligin-Isoformen NL-1, NL-2, NL-3 und NL-4 (Krueger et al. 2012). Sie interagieren als vorwiegend postsynaptisch lokalisierte Typ-1Transmembranproteine (Bolliger et al. 2001; Ichtchenko et al. 1995; Ichtchenko et al. 1996) in 
Wechselwirkung mit dem präsynaptisch lokalisierten Protein Neurexin (Ushkaryov et al. 1992; Ushkaryov et al. 1994), indirekt mit Proteinen der aktiven Zone (Biederer und Südhof 2000; Hata et al. 1996) und durch ihr intrazelluläres C-terminales Ende direkt mit Proteinen der PSD (Bolliger et al. 2001; lida et al. 2004; Irie et al. 1997; Sumita et al. 2007). Neuroligine übernehmen auf diese Weise Funktionen transsynaptischer Adhäsionsproteine (Nguyen und Südhof 1997) und spielen eine wichtige Rolle in der Reifung und Funktion von Synapsen (Varoqueaux et al. 2006). Dabei unterscheiden sich die einzelnen NL-Isoformen in ihrer Assoziation zu exzitatorischen und inhibitorischen Synapsen wie folgt:

Die Isoform NL-1 ist exklusiv an exzitatorischen Synapsen (Song et al. 1999) lokalisiert, wohingegen NL-2 exklusiv mit inhibitorischen Synapsen (Graf et al. 2004) assoziiert vorkommt. Für NL-3 konnte keine einheitliche, synapsenspezifische Assoziation nachgewiesen werden. Es ist sowohl an exzitatorischen als auch an inhibitorischen Synapsen lokalisiert (Budreck und Scheiffele 2007). Untersuchungen der Isoform NL-4 weisen auf eine in unterschiedlichen Hirnregionen divergente Expression an inhibitorischen und auch exzitatorischen Synapsen hin: In der Retina, dem Globus Pallidus, der Vierhügelplatte oder dem Thalamus konnte NL-4 exklusiv mit inhibitorischen glycinergen Synapsen assoziiert nachgewiesen werden. Im Gegensatz dazu war im Hippokampus und dem Kortex eine Assoziation des exprimierten NL-4 mit inhibitorischen Synapsen nicht nachweisbar (Hoon et al. 2011).

Daten der Arbeitsgruppe um Prof. Dr. N. Brose des Göttinger Max-Planck-Instituts für Experimentelle Medizin (Abteilung Molekulare Neurobiologie), auf deren Ergebnisse im Rahmen einer Kooperation für die vorliegende Arbeit zurückgegriffen werden konnte, zeigen eine besonders ausgeprägte Expression von NL-4 in Schicht IV des Barrel-Kortex (Abb. 1.2), welche mit inhibitorischen Synapsen nicht assoziiert werden konnte (Hoon et al. 2011). 

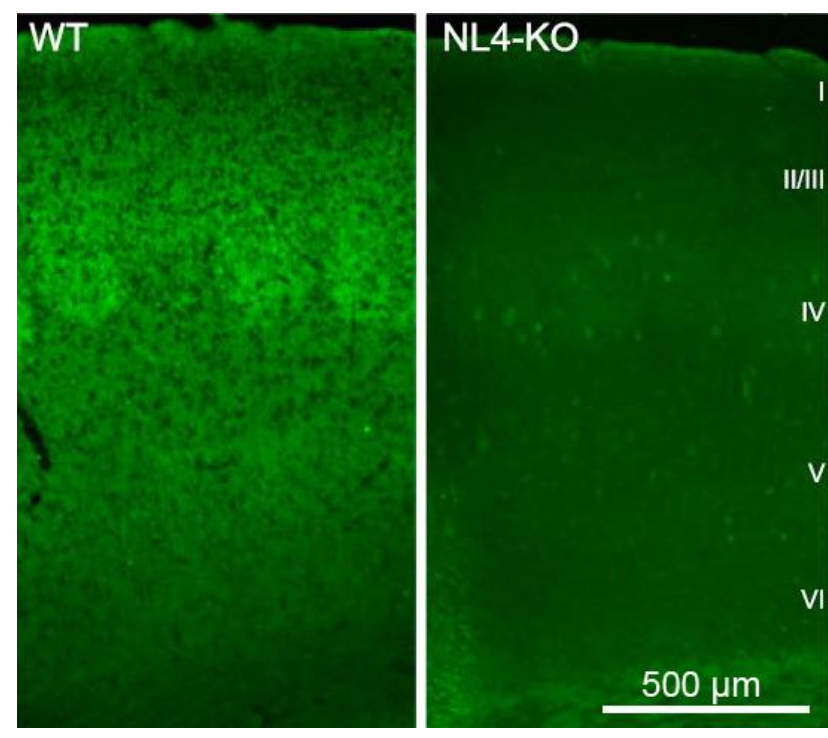

\section{Abbildung 1.2: Lokalisation von NL-4 im Barrel-Kortex}

Die immunhistochemische, NL-4-spezifische Färbung des Barrel-Kortex zeigt im Wildtyp (WT, links) eine erhöhte Reaktivität insbesondere in Schicht IV und Schicht II/III des Barrel-Kortex verglichen zur Hintergrunddarstellung im Knockout (NL-4-KO, rechts). Abbildung modifiziert nach Hoon et al. (2011); Supporting Information S. 6.

\subsection{Somatosensorischer Kortex - Barrel-Kortex}

In Säugetieren bildet der Neokortex als Bestandteil der Großhirnrinde (Cortex cerebri) den phylogenetisch jüngst entwickelten und höchst organisierten Anteil des ZNS. Der Neokortex lässt sich strukturell in sechs, parallel zur pialen Oberfläche orientierte Schichten und funktionell in umschriebene Funktionsareale gliedern. Eines jener Funktionsareale bildet den primären somatosensorischen Kortex, welcher als primäres Rindengebiet direkte Efferenzen des lemniskalen Thalamus empfängt und dadurch zentrale Bedeutung für die Wahrnehmung und Weiterverarbeitung aus der Peripherie stammender taktiler Reize einnimmt (Bear et al. 2007).

Einen besonderen, vorwiegend in Nagetieren identifizierbaren Anteil des somatosensorischen Kortex stellt der Barrel-Kortex dar, der sich durch in Schicht IV (Lamina granularis interna, innere Körnerschicht) abgrenzbare, regelmäßig angeordnete, fassförmige Strukturen - die namensgebenden Barrels - auszeichnet (Welker C 1971; Woolsey und Van der Loos 1970). Funktionell erhält die Schicht IV des Barrel-Kortex, wie andere neokortikale Areale seine subkortikalen Hauptafferenzen aus dem Thalamus (Bernardo und Woolsey 1987; Killackey 1973; Killackey und Leshin 1975; Lu und Lin 1993; Staiger et al. 1996). Wie in anderen 
primären neokortikalen Arealen existiert eine zentrale topographisch organisierte Repräsentation der peripheren rezeptiven Felder, die hier als Somatotopie bezeichnet wird (Welker C 1971; Welker C und Woolsey 1974). Im Barrel-Kortex werden die großen Gesichtsvibrissen (Tasthaare), die den Nagetieren zur räumlichen Orientierung und Wahrnehmung ihrer Umwelt dienen, repräsentiert. Die einzelnen Barrels korrespondieren im Verhältnis 1:1 mit den Gesichtsvibrissen und sind analog zur Vibrissenanordnung auf der Schnauze der Tiere zueinander gruppiert. Diese somatotope Repräsentation bleibt nicht nur auf Schicht IV begrenzt, sondern erstreckt sich darüber hinaus säulenartig vertikal durch alle Kortexschichten (Armstrong-James et al. 1992; Simons 1978; Welker E et al. 1993).

Auf diese Weise bilden die Barrels ein strukturelles Korrelat funktioneller, vertikal alle Kortexschichten überspannender Funktionseinheiten, den kortikalen Kolumnen, an welchen das aktuell favorisierte Modell einer modularen kolumnenassoziierten Informationsverarbeitung nachvollzogen werden kann (Feldmeyer et al. 2012; Petersen 2007; Schubert et al. 2007).

Die zellulären Elemente der kortikalen Kolumnen des Barrel-Kortex lassen sich auf Basis unterschiedlicher, z.B. neurochemischer Merkmale charakterisieren. Grundsätzlich lassen sich dabei exzitatorische/glutamaterge Neurone von inhibitorischen/GABAergen Neuronen unterscheiden (GABA: $y$-Aminobuttersäure) und anhand morphologischer Charakteristika in verschiedene Klassen differenzieren (Fox 2008). In Schicht IV des Barrel-Kortex lassen sich morphologisch drei exzitatorische Neuronenklassen voneinander unterscheiden. Zu diesen zählen die bedornten Sternzellen, die Sternpyramidenzellen und die Pyramidenzellen:

Die bedornten Sternzellen zeichnen sich durch die Abwesenheit eines apikalen Dendriten aus. Ihre dendritischen Fortsätze beschränken sich auf ihr Ursprungs-Barrel. Typischerweise tritt ihr axonaler Zellfortsatz an der Somabasis aus, verläuft Richtung weiße Substanz, ohne diese dabei zu erreichen, und gibt in seinem Verlauf zahlreiche rekurrent verlaufende Kollateralen ab, die in den Schichten II/III und IV ein dichtes axonales Geflecht bilden, dabei aber weitestgehend auf die zugehörige Kolumne begrenzt bleiben (Lübke et al. 2000; Simons und Woolsey 1984; Staiger et al. 2004).

Im Unterschied dazu zeichnen sich die Klassen der Sternpyramidenzellen und der Pyramidenzellen durch einen apikalen, sich in supragranuläre Schichten erstreckenden 
Dendriten aus (Jones 1975; Simons und Woolsey 1984; Staiger et al. 2004). Untereinander differenzieren lassen sich Sternpyramiden- und Pyramidenzellen anhand der räumlichen Orientierung ihrer nicht apikalen Dendriten, welche in Pyramidenzellen als basale Dendriten nur aus der Somabasis austreten, wohingegen sie in Sternpyramidenzellen, abgesehen von einer Polarisierung in Richtung Barrel-Zentrum, keiner speziellen polarisierten Ausrichtung unterliegen (Jones 1975; Staiger et al. 2004). Der axonale Zellfortsatz von Sternpyramidenzellen verläuft sehr variabel, von streng vertikal kolumnenbegrenzt bis weit horizontal transkolumnär verzweigt. Die axonale Ausbreitung von Pyramidenzellen erstreckt sich dagegen typischerweise horizontal über mehrerer Kolumnen (Staiger et al. 2004).

\subsection{Fragestellung}

Die vorliegende Arbeit entstand in Kooperation mit der Arbeitsgruppe von Herrn Prof. Dr. N. Brose, am Göttinger Max-Planck-Institut für Experimentelle Medizin, Abteilung Molekulare Neurobiologie. Durch das gezielte Ausschalten des human-orthologen NL-4-Gens der Maus (Neuroligin-4 Knockout; NL-4-KO) gelang es der Arbeitsgruppe um Prof. Dr. Brose, ein Tiermodell zum Studium der nicht syndromatisch, monogenetisch vererbbaren AutismusSpektrum-Störungen zu generieren, bei dem die genetisch veränderten Mäuse Verhaltensabweichungen in wechselseitigen sozialen Interaktionen und Kommunikationsmustern aufweisen, die an Beeinträchtigungen der humanen AutismusSpektrum-Störungen erinnern (Jamain et al. 2008).

Anhand dieses Tiermodells konnte bereits der Einfluss der in der Retina beobachteten Lokalisation von NL-4 (siehe Abschnitt 1.3) auf die inhibitorische glycinerge synaptische Übertragung nachgewiesen werden. Hoon et al. (2011) zeigten in retinalen Ganglienzellen, dass NL-4-KO mit einer verminderten Expression der Glycin-Rezeptoruntereinheit GlyRa1 einhergeht, was zu einer veränderten Kinetik inhibitorischer postsynaptischer Membranströme führt. Inwiefern die (immunhistochemisch) beobachtete Lokalisation des NL-4-Proteins in der Schicht IV des Barrel-Kortex für die synaptische Übertragung relevant ist, ist gegenwärtig unbekannt. Aufgrund der dominierenden exzitatorischen Verschaltungen (gegenüber der meist lokalen inhibitorischen Projektion) von thalamischen Projektionen (Haupteingangsschicht somatosensorischer Information aus der Peripherie) und 
kolumnenassoziierten Rückverschaltungen innerhalb des Neokortex kann eine Interaktion des NL-4-Proteins mit exzitatorischen Synapsen in Schicht IV vermutet werden.

Im Rahmen dieser Arbeit soll deshalb die exzitatorische synaptische Übertragung auf die exzitatorischen Neurone der Schicht IV des Barrel-Kortex der NL-4-KO-Maus untersucht werden. Hierfür wurden mit Hilfe der Patch-Clamp-Technik abgeleitete, netzwerkunabhängige mEPSC und spontan generierte, netzwerkabhängige sEPSC von bedornten Sternzellen, Sternpyramiden- und Pyramidenzellen der Schicht IV ausgewertet und deren Amplitude, Frequenz und Kinetik-Parameter zwischen NL-4-Wildtyp- (NL-4-WT) und NL-4-KO-Neuronen verglichen. Darüber hinaus wurde die präsynaptische Netzwerkaktivität, und auf diese Weise indirekt das präsynaptische Verhältnis von Exzitation zu Inhibition der abgeleiteten NL-4-WTund NL-4-KO-Neuronen, durch die Auswertung TTX-sensitiver EPSC untersucht.

Veränderungen in der exzitatorischen synaptischen Übertragung auf Neurone dieses neokortikalen Areals und die daraus resultierende Modifikation ihrer Aktivität könnten weitreichende Auswirkungen auf die weiterführende somatosensorische Informationsverarbeitung haben und letztendlich mit den in NL-4-KO-Mäusen beobachteten Autismus-assoziierten Verhaltensauffälligkeiten in Zusammenhang stehen. Sie könnten ferner Modellcharakter für alle neokortikalen Areale, oder zumindest deren Schicht-IV-exzitatorische Synapsen, aufweisen. 


\section{MATERIAL UND METHODEN}

Die elektrophysiologischen Experimente, die in Patch-Clamp-Ableitungen der zu untersuchenden Zellen bestanden, wurden durch Herrn Dr. rer. nat. Mirko Witte und Herrn Dr. rer. nat. Martin Möck aus der Abteilung Neuroanatomie der Universitätsmedizin Göttingen durchgeführt. Die aufgenommenen Originaldaten und die fixierten Schnitte wurden durch den Autor im Rahmen dieser Arbeit ausgewertet und statistisch untersucht.

Alle tierexperimentellen Untersuchungen erfolgten unter strenger Einhaltung des deutschen Tierschutzgesetzes (Stand 2010).

\subsection{Versuchstiere und Präparation}

Die tierexperimentellen Untersuchungen wurden an 23 bis 32 Tage alten, NL-4-WT- $(n=11)$ und NL-4-KO-Mäusen $(n=10)$ beiderlei Geschlechts durchgeführt, welche freundlicherweise von der Arbeitsgruppe um Prof. Dr. Brose für die vorliegende Arbeit zur Verfügung gestellt wurden. Die Tiere wurden mit Isofluran betäubt und anschließend durch Dekapitation getötet. Nach der Schädeleröffnung wurde das Gehirn herauspräpariert und in eiskalte Carbogen-gesättigte Präparationslösung $\left(95 \% \mathrm{CO}_{2}+5 \% \mathrm{O}_{2}\right)$ überführt. Im Bereich des Barrel-Kortex wurden je Hemisphäre drei bis vier thalamokortikale Schnitte in einer Dicke von $300 \mu \mathrm{m}$ mit Hilfe des Vibratoms (Leica VT 1200S, Leica Microsystems, Wetzlar, Deutschland) hergestellt. Bis zum Versuchsbeginn (mindestens 30 Minuten) wurden die Schnitte in Carbogen-begaster künstlicher Zerebrospinalflüssigkeit (artificial cerebrospinal fluid; ACSF) bei $32^{\circ} \mathrm{C}$ gelagert. Für die Experimente wurden die einzelnen Schnitte in eine Versuchskammer überführt und nach Abschluss der elektrophysiologischen Messungen mit 4\%-Parafomaldehydlösung über Nacht fixiert. 


\subsection{Elektrophysiologie}

\subsubsection{Die Patch-Clamp-Technik}

Bei der Patch-Clamp-Technik handelt es sich um ein Verfahren der Elektrophysiologie, welches die Messung der bioelektrischen Leitfähigkeit von Membranen ermöglicht, um auf diese Weise Eigenschaften von Ionenkanälen und Transmitterrezeptoren zu untersuchen. Sie wurde ursprünglich durch Erwin Neher und Bert Sakmann (1976) zur Ableitung von Membranströmen auf Ebene einzelner lonenkanäle beschrieben und in der Folge von Hamill et al. (1981) durch die sogenannte tight-seal-Variante modifiziert (Abb. 2.1).

Die Patch-Clamp-Technik nutzt eine fein ausgezogene, mit Elektrolytlösung gefüllte Glaspipette als Messelektrode, deren Spitze (Durchmesser $\approx 2 \mu \mathrm{m}$ ) von extrazellulär auf einen Membranfleck (=patch) aufgesetzt wird. Der Kontakt zwischen Pipettenspitze und Zellmembran bildet dabei einen Widerstand, der den patch gegenüber der restlichen Membranoberfläche elektrisch isoliert. Dadurch wird gewährleistet, dass ein Strom, der durch einen Ionenkanal innerhalb des patchs fließt, von der angeschlossenen Messelektronik registriert werden kann und nicht als unspezifischer Leckstrom zwischen dem Pipetteninneren und dem Extrazellulärraum verloren geht. Bei der tight-seal-Modifikation wird der Kontakt zwischen Patchpipette und Zellmembran durch Ansaugen der Pipettenspitze an die Membranoberfläche zusätzlich abgedichtet. Hierdurch wird ein hochohmiger elektrischer Widerstand $(>1 G \Omega)$, der sogenannte giga-seal, erzeugt. Die Herstellung des giga-seal definiert den sogenannten cell-attached-Modus und ermöglicht weitere Patch-ClampAbleitkonfigurationen, wie beispielsweise die Ganzzellableitung (whole-cell-recording). Bei der Ganzzellableitung wird der patch durch einen kurzen Saugimpuls eröffnet und dadurch ein direkter, elektrisch leitender Zugang zum Zytoplasma erzeugt. Dieser Zugang eröffnet die Möglichkeit, den Intrazellulärraum gegenüber dem Extrazellulärraum abzuleiten, um auf diese Weise die durch lonenkanäle der gesamten Zellmembran fließenden Ströme zu messen.

Die über die Zellmembran fließenden Ionenströme werden mit Hilfe der sogenannten Spannungsklemm-Technik (voltage-clamp) gemessen. Hierbei legt der Versuchsleiter ein Haltepotential fest, welches bei der Ganzzellkonfiguration über die Patchpipette am Intrazellulärraum anliegt. Das Haltepotential wird dabei durch einen elektronischen Verstärker jederzeit aufrechterhalten. Diffundieren geladene Teilchen, ihrer elektrochemischen Triebkraft 
folgend durch offene lonenkanäle der Zellmembran, führen diese ihrem Nettofluss entsprechend zu einer Potentialauslenkung. Diese vom Haltepotential abweichende Veränderung wird durch einen Verstärker registriert und durch die Injektion eines kompensatorischen Stroms ausgeglichen. Der injizierte Strom dient dabei als Messgröße und repräsentiert in seinem Betrag den bei einem vorgegebenen Haltepotential als EPSC bzw. IPSC über die Zellmembran fließenden Ionenstrom.

Neben lonenströmen können mit der Patch-Clamp-Technik auch Veränderungen des Membranpotentials abgeleitet werden. Dafür verwendet man die sogenannte StromklemmTechnik (current-clamp). Bei dieser wird einem Neuron in Ganzzellkonfiguration über die Patchpipette ein konstanter Strom injiziert und die so ausgelösten Potentialveränderungen gemessen. Durch Injektionsströme, die das Membranpotential des abgeleiteten Neurons über dessen AP-Feuerschwelle depolarisieren, können AP ausgelöst werden. Nimmt der injizierte Strom den Wert Null an, kann das Ruhemembranpotential einer Zelle bestimmt werden. Die current-clamp-Technik ermöglicht auf diese Weise eine Analyse von AP und eine Charakterisierung der abgeleiteten Neurone (Molleman 2003). 


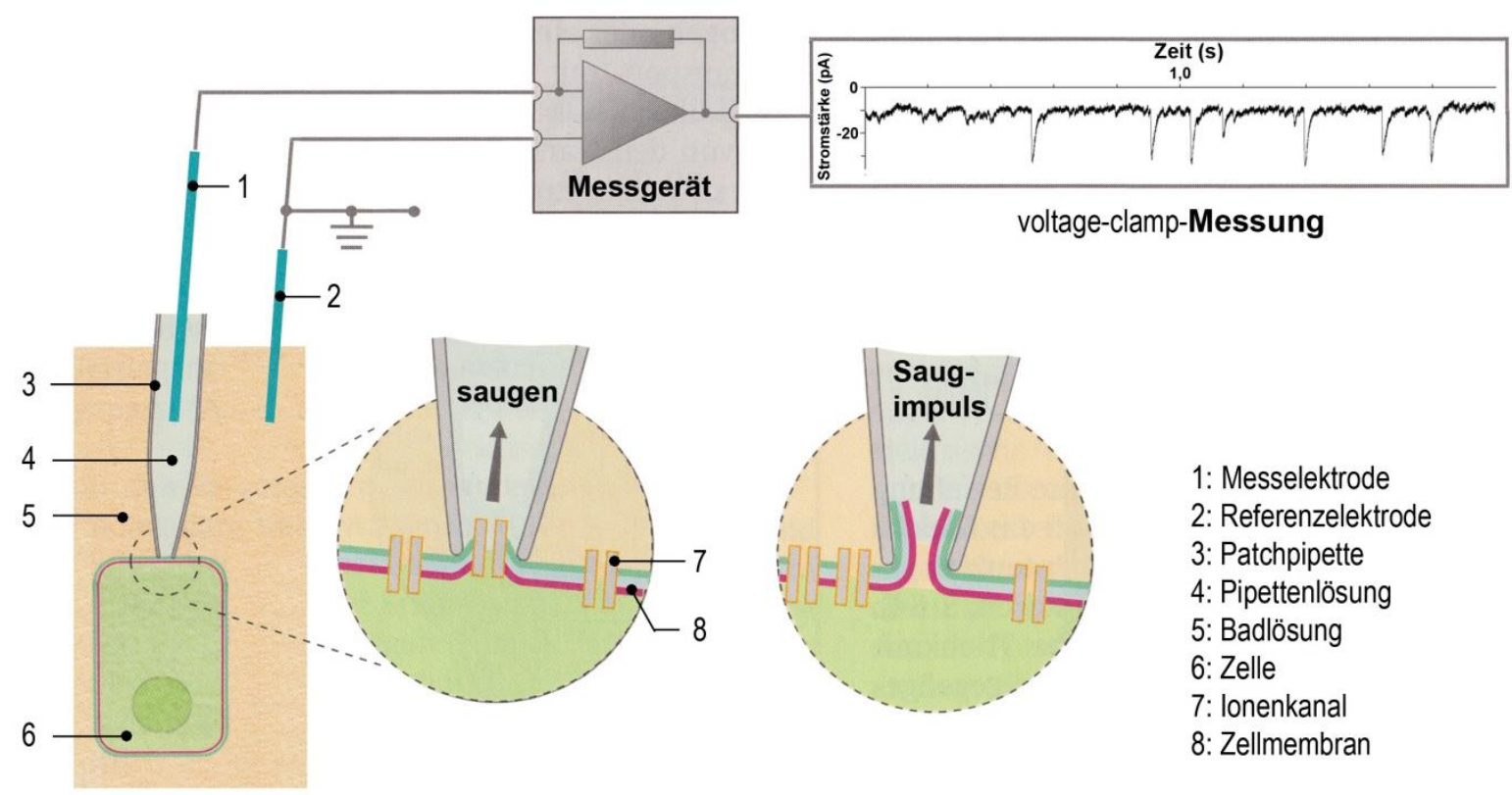

cell-attached-

Ableitungsmodus

whole-cell-

Ableitungsmodus

\section{Abbildung 2.1: Die Patch-Clamp-Technik}

Nach Aufsetzen der Patchpipette wird durch Ansaugen der Pipettenspitze an die Membranoberfläche der giga-seal hergestellt und der cell-attached-Ableitungsmodus erreicht. Davon ausgehend kann durch einen kurzen Saugimpuls die Zellmembran eröffnet und der whole-cell-Ableitungsmodus hergestellt werden. Dieser ermöglicht mit Hilfe der angeschlossenen Messelektronik den Intrazellulärraum gegenüber dem Extrazellulärraum abzuleiten und auf diese Weise, im voltage-clampModus, die über die Membran fließenden Ionenströme zu messen. Abbildung modifiziert nach Korbmacher und Greger (2005); S.26/27.

\subsubsection{Elektrophysiologischer Versuchsaufbau}

Für die Messungen wurden die Hirnschnitte in eine Ableitkammer überführt, welche auf dem Objekttisch eines aufrechten Durchlichtmikroskops (Zeiss Axio Examiner, Zeiss AG, Oberkochen, Deutschland) montiert war. Dort konnten die Schnitte mit Hilfe eines mit Nylonfaden bespannten Platinrings fixiert werden. Die Messkammer war mit einem regulierbaren $\mathrm{Zu}$ - und Ablauf $(1-3 \mathrm{ml} / \mathrm{min})$ ausgestattet, der eine kontinuierliche und vollständige Umspülung der Hirnschnitte mit ACSF ermöglichte. Durch ACSF konnten zusätzliche Substanzen und Pharmaka (wie TTX, NBQX oder Gabazine; siehe unten) unter kontrollierten Bedingungen in die Aufnahmekammer eingewaschen werden. Die verwendeten Patchpipetten bestanden aus Borosilikatglas und wurden mit Hilfe eines horizontalen Pipettenziehgeräts (P-97, Sutter Instrument Company, Novato, CA, USA) aus einer 
filamentierten Glaskapillare (Hilgenberg $\mathrm{GmbH}$, Malsfeld, Deutschland) automatisiert gezogen. Für die Messungen wurden sie mit Pipettenlösung gefüllt und mit Hilfe von in drei Raumebenen fernsteuerbaren Mikromanipulatoren an die Zelloberfläche eines Neurons herangeführt. Nach Aufsetzen der Pipette auf der Zellmembran wurden im Pipetteninneren negative Druckverhältnisse erzeugt und so die cell-attached-Position hergestellt. Der PipettenMembran Kontakt wurde als stabil erachtet, sobald der seal-Widerstand Werte größer als 1-2G $\Omega$ erreichte. Durch einen kurzen Saugimpuls wurde der patch durchbrochen und damit die whole-cell-Konfiguration erreicht.

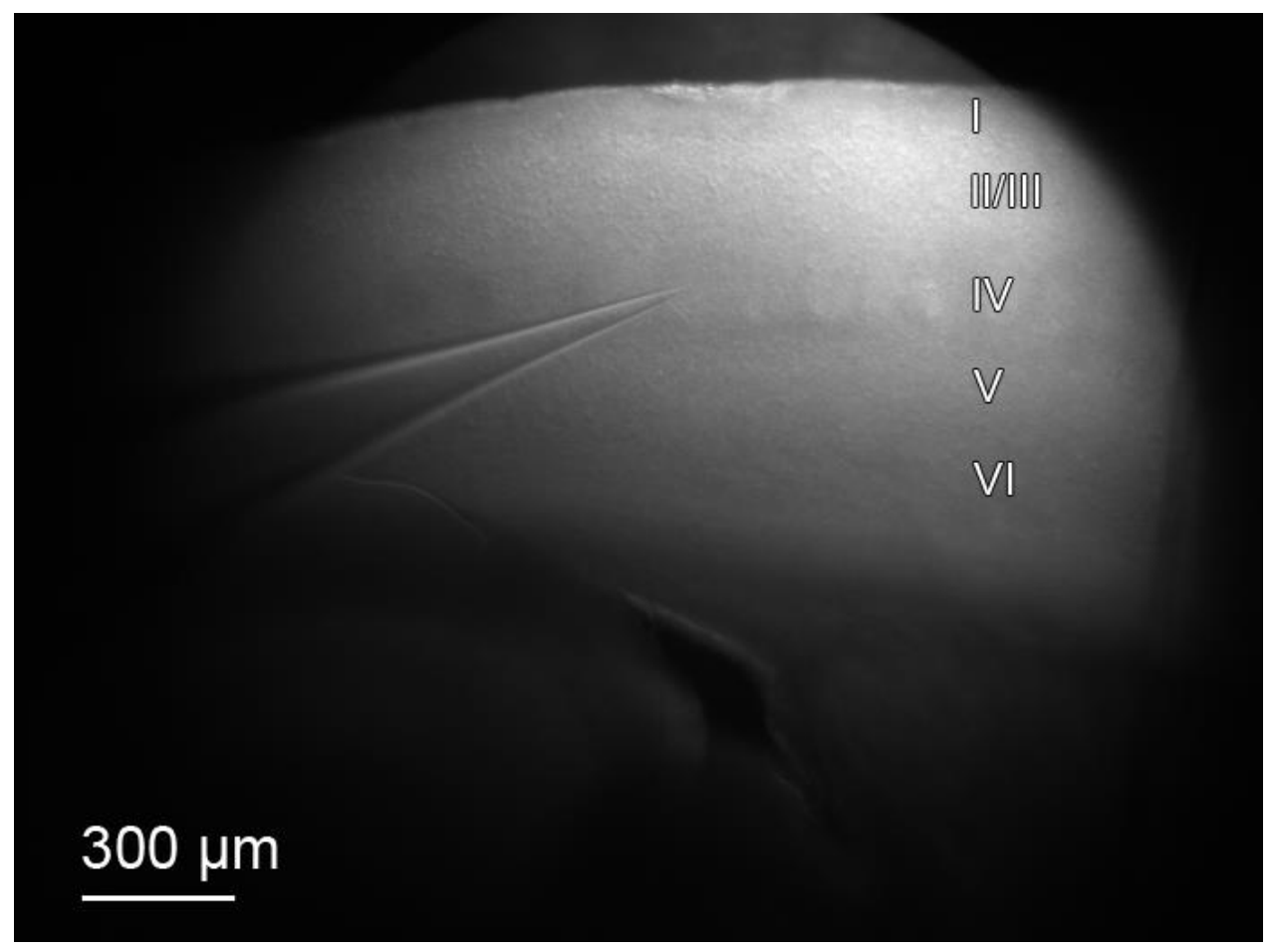

\section{Abbildung 2.2: Übersichtsaufnahme eines thalamo-kortikalen Hirnschnitts}

Nativ-Übersichtsaufnahme bei 2,5-facher Vergrößerung. Römische Zahlen (I-VI) markieren orientierend die kortikalen Schichten. Die Spitze der Patchpipette projiziert sich auf ein Barrel-Zentrum in Schicht IV des somatosensorischen Kortex.

Nach initialer elektrophysiologischer Charakterisierung und Identifizierung als exzitatorische Neurone im current-clamp-Modus wurden die Zellen im voltage-clamp-Modus auf eine Kommandospannung von -70mV geklemmt und der Membranstromverlauf (sEPSC) über eine Zeitspanne von 5-10 Minuten mit einem Verstärker (SEC-05L, NPI Electronics GmbH, Tamm, 
Deutschland) registriert und mit Hilfe der Software CED Signal (Version 4.08, Cambridge Electronic Design, Cambridge, UK) aufgezeichnet und gespeichert.

Zur Aufzeichnung von mEPSC wurde anschließend über einen Zeitraum von mindestens 6 Minuten 0,5 $\mu \mathrm{M}$ TTX (Sigma Aldrich, St. Louis, MO, USA) in die Badkammer eingewaschen und der Membranstromverlauf für weitere 5-10 Minuten aufgezeichnet. Instabile Ableitungen mit schlechtem Signal-Rauschverhältnis wurden verworfen.

Um zu prüfen, ob es sich bei den aufgezeichneten EPSC um AMPA-Rezeptor-vermittelte Membranströme handelt, wurden zusätzliche pharmakologische Experimente mit dem AMPARezeptorantagonisten NBQX (Sigma Aldrich, St. Louis, MO, USA) durchgeführt. Dabei wurden bei einem Haltepotential von $-70 \mathrm{mV}$ Membranstromverläufe unter Kontrollbedingungen und nach Einwaschen von 10 $\mu \mathrm{M}$ NBQX (Einwaschzeit 6-8 Minuten) abgeleitet.

Weiterhin wurde untersucht, ob die abgeleiteten EPSC durch zeitgleich auftretende, entgegen gerichtete, interferierende IPSC einem inhibitorischen Einfluss unterliegen. Dies geschah unter Verwendung von Gabazine (Sigma Aldrich, St. Louis, MO, USA), einem GABA $A^{-}$ Rezeptorantagonisten, der inhibitorische GABAerge Membranströme unterdrückt. Es wurden EPSC unter Kontrollbedingungen und nach Einwaschen von 20 $\mu \mathrm{M}$ Gabazine (Einwaschzeit 6-8 Minuten) abgeleitet und verglichen.

\subsubsection{Elektrophysiologische Charakterisierung abgeleiteter Zellen}

Im Rahmen dieser Arbeit wurden ausschließlich exzitatorische Neurone der Schicht IV des Barrel-Kortex untersucht. Versehentlich durchgeführte Ableitungen von inhibitorischen GABAergen Neuronen wurden nach elektrophysiologischer Identifizierung umgehend verworfen.

Anhand charakteristischer Zelleigenschaften, wie dem AP-Feuermuster und dessen Adaptationsverhalten sowie der Konfiguration der Nachhyperpolarisation, konnten die gepatchten Zellen im current-clamp-Modus unmittelbar als exzitatorische oder inhibitorische Neurone identifiziert werden (Abb. 2.3). Unterschiedliche AP-Feuermuster korrelieren mit den unterschiedlichen in Schicht IV des Barrel-Kortex vorkommenden Zelltypen. Exzitatorische Neurone zeichnen sich durch ein regelmäßiges Feuermuster (regular-spiking; RS) oder 
intrinsisch-burstendes (intrinsic-bursting; IB) Feuermuster aus und können von inhibitorischen, GABAergen Interneuronen, welche sich durch ein schnelles (fast-spiking; FS) Feuermuster auszeichnen, unterschieden werden. RS- und IB-Neurone weisen in ihrer AP-Feuer-Frequenz ein Adaptationsverhalten auf, welches sich in einem über die Zeit länger werdenden Interspike Intervall (ISI) äußert. Einer auf ein Aktionspotential folgenden langsamen Repolarisation schließt sich ein intrinsisch-generierter Komplex aus Nachhyperpolarisation (afterhyperpolarization; AHP) und Nachdepolarisation (afterdepolarization; ADP) an. FS-Neurone zeigen im Gegensatz zu RS- und IB-Neuronen eine schnellere Repolarisation mit einer kurzen und ausgeprägten Nachhyperpolarisation, eine höhere maximale Feuerfrequenz und kein bzw. ein sehr geringes Adaptationsverhalten (Connors und Gutnick 1990).
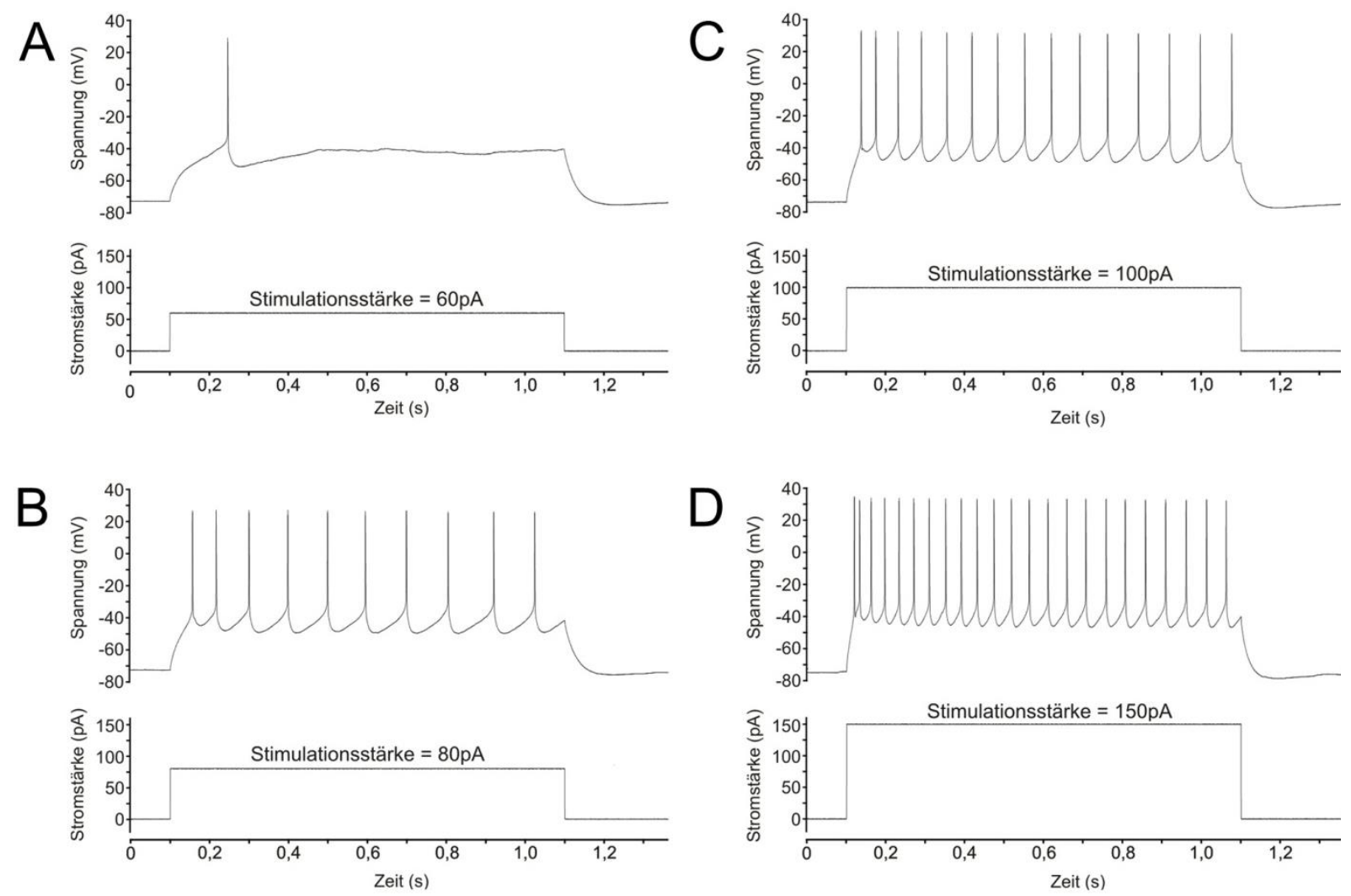

\section{Abbildung 2.3: Membranpotentialverlauf in Abhängigkeit zur Stimulationsstärke}

Im current-clamp-Modus wurden Membranpotentialverläufe bei steigenden Stimulationsstärken aufgezeichnet. Anhand des Feuermusters und der Charakteristika des Aktionspotentials und der darauffolgenden Nachhyperpolarisation konnten die gepatchten Zellen als exzitatorische Neurone identifiziert werden. Exemplarisch sind vier Membranpotentialverläufe einer Zelle bei Stimulationsstärken von 60 (A), 80 (B), 100 (C) und 150pA (D) abgebildet. Das dargestellte, sich über die Zeit verlängernde Interspike-Intervall, charakterisiert das RS-Feuermuster. 
Neben der Charakterisierung als exzitatorische Neurone wurden die Zellen hinsichtlich ihrer passiven und aktiven elektrophysiologischen Eigenschaften mit dem Programm CED Signal ausgewertet.

Die passiven Zelleigenschaften Ruhemembranpotential [mV], Membranzeitkonstante [ms], Eingangswiderstand $[\mathrm{M} \Omega$ ] und Membrankapazität $[\mathrm{pF}]$ wurden dafür aus zehn gemittelten current-clamp-Messungen mit einer Strominjektion (I) von -10pA über eine Dauer von einer Sekunde bestimmt (Abb. 2.4). Dabei wurde das Ruhemembranpotential als mittleres Membranpotential vor der Strominjektion und die Membranzeitkonstante als Zeit von Beginn der Strominjektion (0\%) bis 63\% der maximalen Potentialauslenkung (100\%) ermittelt. Der Eingangswiderstand (R) wurde mit Hilfe des ohmschen Gesetzes ( $R=U / I)$ bei bekanntem Strom $(I=-10 p A)$ und zum Zeitpunkt der maximalen Potentialauslenkung ( $U=100 \%)$ berechnet. Die Membrankapazität (C) konnte aus den zuvor bestimmten Parametern Membranzeitkonstante $(\tau)$ und Eingangswiderstand $(R)$ kalkuliert werden $(C=\tau / R)$.

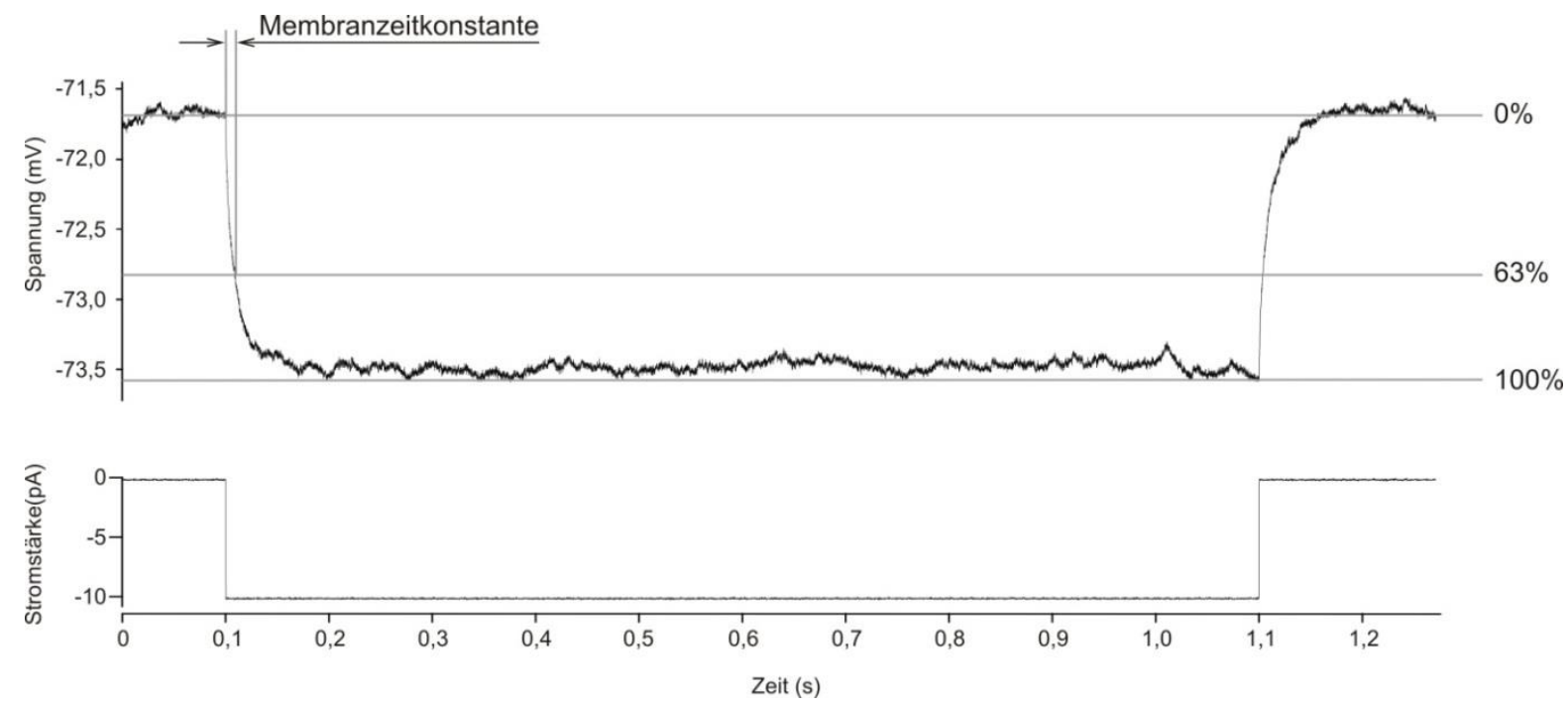

\section{Abbildung 2.4: Ermittlung passiver Zelleigenschaften}

Zusätzlich zur Charakterisierung als exzitatorische Neurone wurden die passiven Zelleigenschaften der abgeleiteten Neurone bestimmt. Aus zehn current-clamp-Messungen wurde der Membranpotentialverlauf gemittelt (obere Spur), wobei je Messung ein Strom von -10pA über 1s injiziert wurde (untere Spuren). Aus dem gemittelten Membranstromverlauf wurden das Ruhemembranpotential, die Membranzeitkonstante, der Eingangswiderstand und die Membrankapazität bestimmt. 
Die aktiven Zelleigenschaften Feuerschwelle [mV], AP-Latenzzeit [ms], AP-Amplitude [mV], Zeit bis zum Amplitudenmaximum [ms], maximale AP-Steigung $[\mathrm{V} / \mathrm{s}]$, AP-Weite [ms], Nachhyperpolarisations-Amplitude (AHP-Amplitude) [mV] und Nachhyperpolarisations-Weite (AHP-Weite) [ms] wurden ausschließlich an der Rheobase [pA], das heißt an der Schwelleninjektions-Stromstärke, ab welcher ein Neuron einzelne Aktionspotentiale generiert, untersucht. Zur Bestimmung der Rheobase wurden Ströme steigender Stärke injiziert und gleichzeitig der Membranpotentialverlauf registriert. Je Durchlauf wurde dabei bis zum Erreichen der Rheobase die Stromstärke um 2-5pA erhöht (Abb. 2.5).
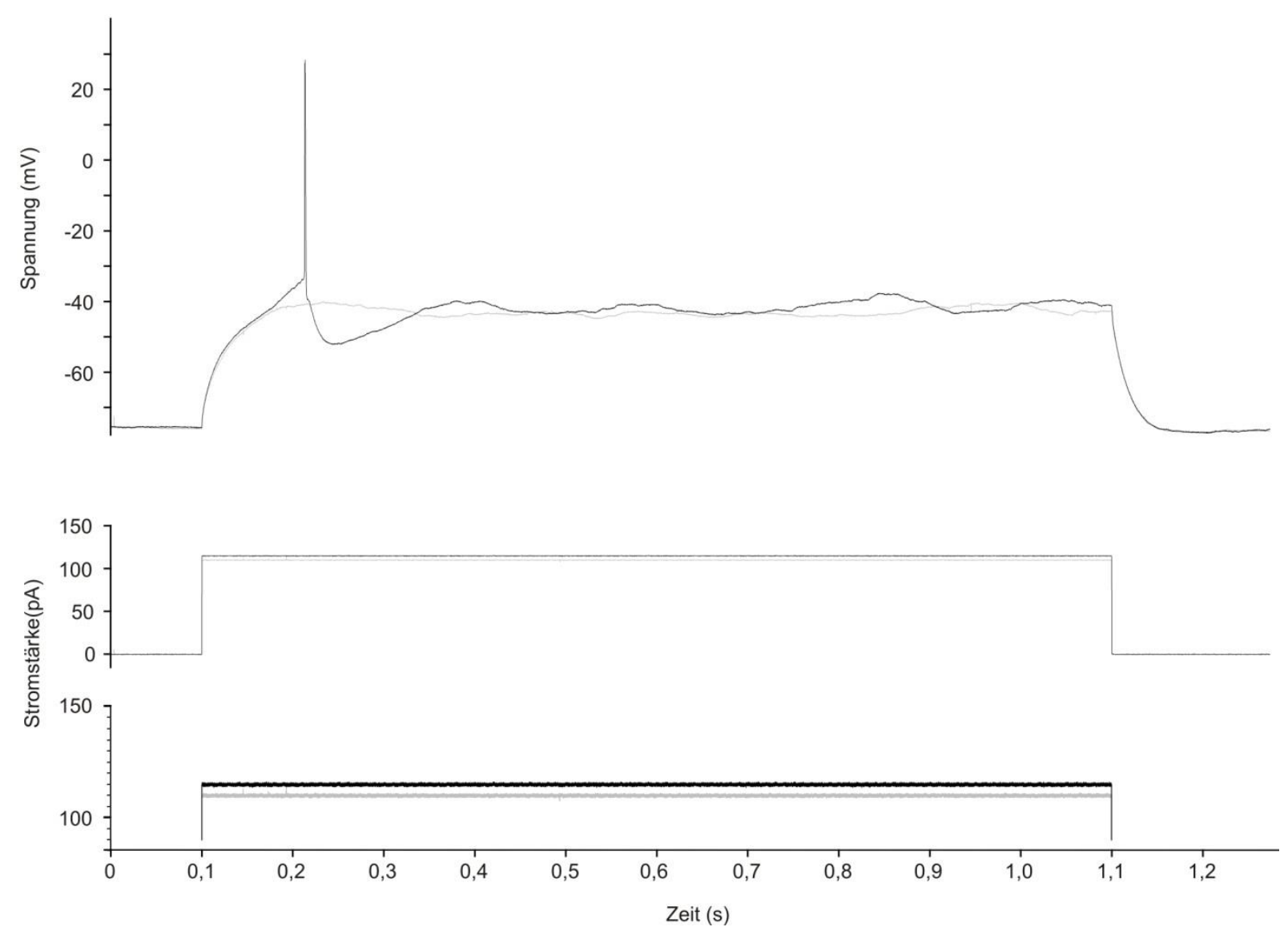

\section{Abbildung 2.5: Ermittlung der Rheobase}

Bei der Rheobase handelt es sich um die Schwelleninjektions-Stromstärke, ab welcher ein Neuron ein einzelnes Aktionspotential generiert. Die Abbildung zeigt Membranpotentialverläufe (oben) während Strominjektionen von 110pA und 115pA über je 1s (mitte/unten in verschiedener Achsskalierung). Das Neuron generiert bei einer Injektionsstromstärke von $115 \mathrm{pA}$ ein einzelnes AP - die Rheobase beträgt $115 \mathrm{pA}$. 
Nach Erreichen der Rheobase wurde mit konstanter Stromstärke repetitiv stimuliert (5-8 Wiederholungen) und aus den Membranpotentialverläufen die oben genannten aktiven Zelleigenschaften bestimmt und gemittelt (Abb. 2.6). Den Parametern AP- und AHP-Amplitude [mV] liegt dabei als Referenz das Niveau der Feuerschwelle [mV] zu Grunde. Die Zeit bis zum AP-Maximum [ms] wurde vom Erreichen der Feuerschwelle bis zur AP-Spitze gemessen, die AP-Weite [ms] als Zeit zwischen jeweils 50\% der AP-Amplitude. Die AHP-Weite [ms] wurde als Zeit zwischen zweitem rekurrenten Übertritt der Feuerschwelle und Erreichen von 63\% der AHP-Amplitude (nach erreichtem Maximum) bestimmt.
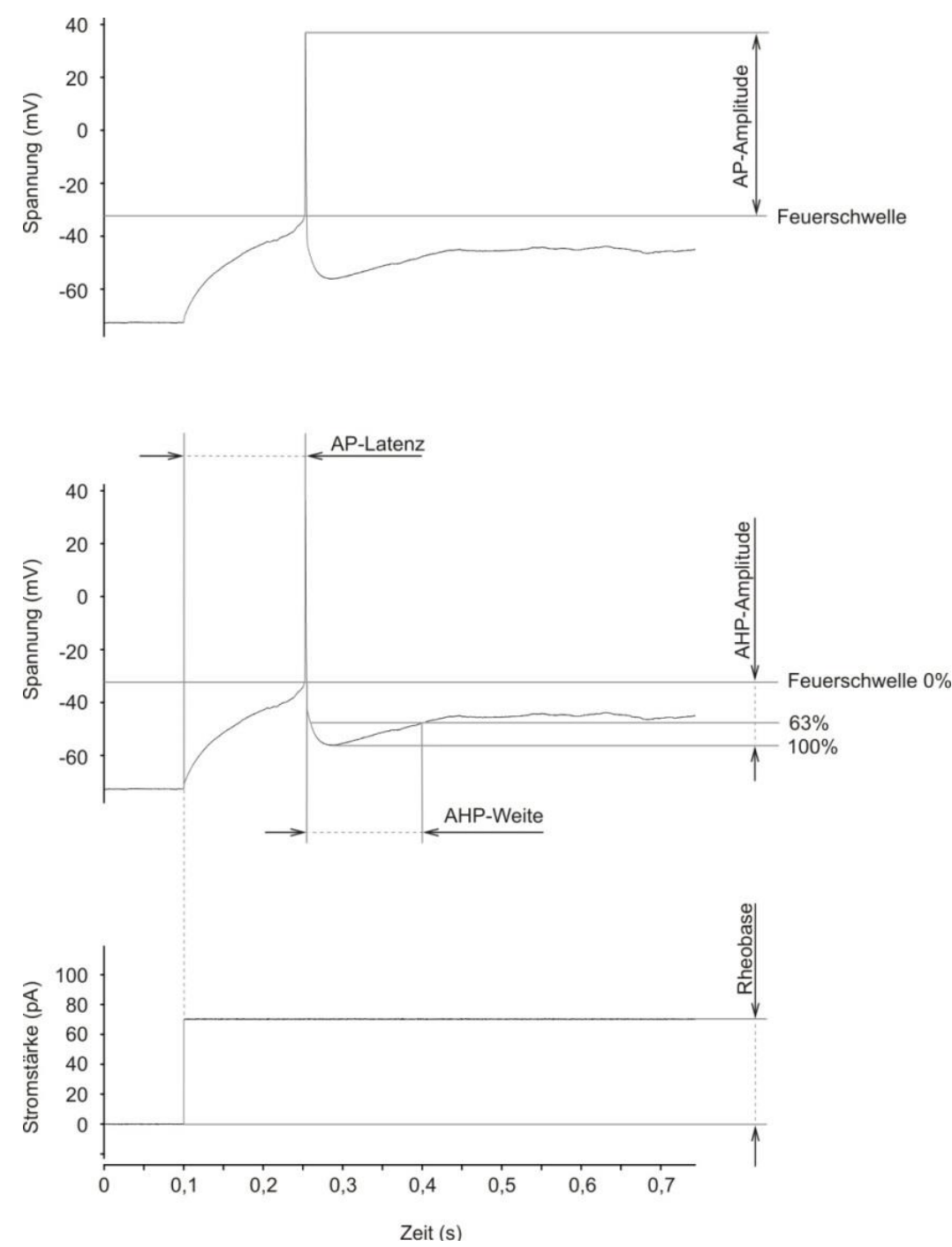

\section{Abbildung 2.6: Ermittlung aktiver Zelleigenschaften}

An der Rheobase (untere Spur) wurden die aktiven Zelleigenschaften wie AP-Amplitude und Feuerschwelle (obere Spur), AP-Latenz, AHP-Weite und AHP-Amplitude (mittlere Spur) sowie die Zeit bis zum Amplitudenmaximum, maximale AP-Steigung und AP-Weite bestimmt. Aus Gründen der Übersichtlichkeit wurde auf die grafische Darstellung der Parameter Zeit bis zum Amplitudenmaximum, AP-Weite und maximale AP-Steigung verzichtet. 


\subsection{Morphologie}

Zur Beurteilung der Morphologie der abgeleiteten exzitatorischen Neuronen wurden die Hirnschnitte mit 4\% Paraformaldehyd fixiert. Anschließend konnten die bereits während der elektrophysiologischen Experimente mit biocytinhaltiger Pipettenlösung gefüllten Neurone unter Zuhilfenahme der Avidin-Biotin-Komplex-Methode (avidin-biotin-complex-method; ABCMethode) mit 3,3'-Diamino-benzidin-tetrahydrochlorid (DAB) gefärbt werden.

Biocytin dient dabei als neuronaler Marker, der sich aufgrund seiner guten intrazellulären Transporteigenschaften auch in feinen zellulären Strukturen wie axonalen und dendritischen Zellausläufern absetzt (Kobbert et al. 2000). Die ABC-Methode nutzt die Affinität zwischen Biocytin und Avidin, um einen Avidin-Peroxidase-Komplex in den Biocytin-markierten Strukturen zu fixieren. Die katalytische Aktivität dieser Peroxidase setzt nach Zugabe von Wasserstoffperoxid Protonen frei, die durch die Oxidation von DAB zur lokalen dunkelbraunen Färbung der Biocytin-markierten Strukturen führen (Mulisch 2010).

Initial wurden die Schnitte mehrfach mit Phosphat-Puffer (phosphate buffer; PB) gespült und anschließend gefrierschutzbehandelt. Hierfür inkubierten die Schnitte über 1,5 Stunden in PB mit $25 \%$ Saccharose und $10 \%$ Glycerin. Anschließend wurden die Schnitte dreimal über flüssigem Stickstoff gefriergetaut und erneut mit PB gespült. Um die physiologisch im Gewebe vorkommende Peroxidase zu hemmen und so möglichen störenden Hintergrundfärbungen vorzubeugen, wurden die Schnitte für 15 Minuten in PB mit $1 \% \mathrm{H}_{2} \mathrm{O}_{2}$ inkubiert. Nach dieser Vorbehandlung wurden die Präparate dreimal für je 15 Minuten in PB, einmal für 15 Minuten in TRIS-Puffer (tris buffer; TB) und zweimal für je 15 Minuten in TRIS-gepufferter Saline (tris buffered saline; TBS) gespült. Das ABC-Reagenz wurde mit Hilfe des Vectastain ABC KIT (Vector Laboraties Inc, Burlingame, CA, USA) 30 Minuten vor Gebrauch angesetzt. Zur Herstellung des Avidin-Peroxidase-Komplexes wurden die im KIT bereitgestellten Reagenzien A und B jeweils im Verhältnis 1:400 mit TBS verdünnt. Die Schnitte inkubierten über Nacht bei $8^{\circ} \mathrm{C}$ in dieser Lösung. Zur Färbung wurde 0,5mg DAB pro 1ml TB gelöst und auf die Schnitte gegeben. Nach Vorinkubation von einer Minute wurde $1 \% \mathrm{H}_{2} \mathrm{O}_{2}$ zugegeben und so die Farbreaktion gestartet. Der Färbegrad konnte unter dem Mikroskop überprüft und die Farbreaktion nach Erreichen des gewünschten Ergebnisses durch wiederholtes Spülen mit TB gestoppt werden. Abschließend wurden die Schnitte mehrfach in PB gewaschen. 
Zur Darstellung neokortikaler Strukturen wurden die Schnitte anschließend Cytochrom-COxidase (CO) gefärbt. Die CO-Färbung weist die im Gewebe vorhandene Enzymaktivität der CO über die Oxidation und Färbung von DAB nach. Ihr Färbegrad richtet sich dabei nach der lokalen CO-Enzymaktivität (Welsch 2010). Da diese in mitochondrienreichen Regionen, wie z.B. Synapsen, besonders hoch ist, eignet sich die CO-Färbung sowohl zur Darstellung der verschiedenen Kortex-Schichten als auch der Barrels, bei denen es sich um Regionen intensiver thalamo-kortikaler Verschaltungen handelt (Fox 2008).

Für die Färbung wurden 6mg Cytochrom-C, 5mg DAB, 444mg Saccharose und 0,3\% Katalase in $10 \mathrm{ml}$ PB gelöst. Die Schnitte inkubierten bei $39^{\circ} \mathrm{C}$ (Wasserbad) in jeweils $1 \mathrm{ml}$ dieser Lösung. Nach Erreichen des gewünschten Färbegrades wurde die Farbreaktion durch wiederholtes Spülen mit PB gestoppt.

Zur Intensivierung der Färbung wurden die Schnitte anschließend versilbert. Nach initialer Spülung mit destilliertem Wasser wurden sie dafür über eine Stunde in $5 \%$ Thioglycolsäure und anschließend für 30 Minuten in 1,42\% Silbernitratlösung in einem auf $56^{\circ} \mathrm{C}$ temperierten Wasserbad inkubiert. Nach einem Spülschritt mit destilliertem Wasser inkubierten sie für 10 Minuten in 0,2\% Goldchloridlösung und anschließend für weitere 10 Minuten in 5\% Natrium-Thiosulfatlösung. Anschließend wurden die Schnitte mehrfach mit destilliertem Wasser sowie PB gespült und über Nacht bei $4^{\circ} \mathrm{C}$ in $\mathrm{PB}$ geschwenkt. Die Schnitte wurden abschließend mit Aqua Poly Mount (Polysciences GmbH, Eppelheim, Deutschland) eingedeckelt.

Die Morphologie der Präparate wurde mit Hilfe eines videogestützten Lichtmikroskops (Zeiss Axio Imager, Carl Zeiss Micro-Imaging $\mathrm{GmbH}$, Jena, Deutschland) beurteilt und dokumentiert. Die Ansteuerung des Mikroskops sowie die digitale Bildakquirierung erfolgten computergestützt mit Hilfe der Software Neurolucida (MicroBrightField Bioscience, Williston, VT, USA). Um den durch die Vergrößerung eingeschränkten sichtbaren Bildausschnitt zu erweitern, wurden sogenannte virtual-tissue-Aufnahmen angefertigt. Es wurden mehrere sich überlappende Bildausschnitte aufgenommen und anschließend übergangsfrei zu einem größeren Bild zusammengefügt. Parallel zu den vitual-tissue-Aufnahmen wurden sogenannte z-stack-Bildstapel aufgenommen. Hierfür wurden innerhalb eines Bildausschnitts verschiedene Fokusebenen im Abstand von $2 \mu \mathrm{m}$ schrittweise durchlaufen und dabei Bildserien angefertigt. 
Die entstandenen Aufnahmen wurden anschließend übereinandergelegt und mit Hilfe des (in der Software Neurolucida enthaltenen) Unschärfealgorithmus deep-focus (Tiefenfokus) auf eine Ebene projiziert. Gegenüber konventionellen Aufnahmen in Einzelebenen konnte auf diese Weise die Bildinformation aus unterschiedlichen Fokusebenen scharf abgebildet werden, was die zweidimensionale Projektion eines dreidimensionalen Objekts ermöglicht. Darüber hinaus wurden einzelne Neurone ausgewählt und mit Hilfe der Software Neurolucida dreidimensional rekonstruiert.

Die in dieser Arbeit abgebildeten lichtmikroskopischen Aufnahmen wurden mit dem Bildbearbeitungsprogramm Adobe Photoshop CS 4 (Version 11.0, Adobe, San Jose, CA, USA) nachbearbeitet. Dabei wurde die Bildqualität durch Anpassung von Kontrast, Helligkeit sowie Farbton und Sättigung optimiert und ein durch den Unschärfealgorithmus deep-focus entstandenes Artefakt, bei dem das Soma zentral ungefärbt erscheint, korrigiert.

\subsection{Datenanalyse}

\subsubsection{Detektion und Analyse von sEPSC und mEPSC}

Die Detektion der EPSC erfolgte, wie auch die anschließende Analyse, blind, d.h. weder Genotyp (NL-4-WT oder NL-4-KO) noch Art des exzitatorischen Neurons waren dem Autor zum Zeitpunkt der Detektion und Analyse bekannt.

Die Detektion der exzitatorischen postsynaptischen Ströme erfolgte im Programm Clampfit (Version 10.2.0.14, Molecular Devices Corporation, Sunnyvale, CA, USA) mit Hilfe der Schwellenanalyse. Durch diese Methode wurden Schwellen überschreitende Spitzen im Membranstromverlauf detektiert. Dafür wurde zunächst das mittlere Hintergrundrauschen verschiedener Zellableitungen analysiert und basierend darauf, ein einheitlicher Schwellenstrom in Höhe von -3pA - orientierend an der dreifachen Standardabweichung des Grundrauschens - als Detektionstrigger definiert. Im Verlauf der automatischen Schwellenanalyse wurde manuell eine Nullinie vorgegeben und regelmäßig an den Membranstromverlauf angepasst. Überschritt die Signalspur den als Trigger eingestellten Schwellenwert, war also der Abstand zwischen Membranstrom und manuell festgelegter Nulllinie größer als 3pA, wurde dies als EPSC detektiert. Zusätzlich wurde durch die 
sogenannte noise-rejection (Rauschunterdrückung) festgelegt, dass ein Stromsignal den Schwellenwert länger als 1,5ms überschreiten muss, um als EPSC detektiert zu werden. Durch Einstellen der sogenannten pretrigger-length (Länge vor dem Trigger) mit $5 \mathrm{~ms}$ und der sogenannten posttrigger-length (Länge nach dem Trigger) mit 35ms wurde der Zeitraum definiert, welcher vor und nach Erreichen des Triggers je EPSC für die weitere Analyse berücksichtigt wurde. Jeder auf diese Weise detektierte EPSC wurden im Hinblick auf seine Amplitude, Fläche, Frequenz und die erweiterten Kinetik-Parameter wie Anstiegszeit, maximale Steigung, Abfallszeit, maximales Gefälle sowie Halbwertszeit ausgewertet. Die Anstiegszeit wurde in der ansteigenden (zur maximalen Amplitude weisenden) Flanke im Bereich von 10-90\% der maximalen Amplitude gemessen. Die Abfallszeit wurde in der abfallenden (zur Nulllinie weisenden) Flanke im Bereich von 90-10\% der maximalen Amplitude gemessen. Die Halbwertszeit wurde als Zeit zwischen Anstiegs- und Abfallflanke bei je 50\% der Amplitude gemessen.

Die Beträge aller ausgewerteten Parameter hängen direkt oder indirekt von der Definition des Nulllinienniveaus ab. Die zur EPSC-Detektion manuell vorgegebene Nullinie beschreibt, obwohl sie in regelmäßigen Abständen an Fluktuationen im Signalverlauf angepasst wurde, nur eine Näherung des tatsächlichen Nullinienverlaufes, weshalb sie sich nur eingeschränkt als Bezugsgröße eignet. Sie wurde deshalb für die weitere Auswertung redefiniert. Hierfür wurde ein Bereich innerhalb der einheitlichen pretrigger-length markiert und der auf diese Weise eingegrenzte, gemittelte Stromsignalverlauf als neues, EPSC-individuelles Nullinien-Niveau definiert (Abb. 2.7). Dadurch konnten Amplitude, Fläche und Kinetik-Parameter der einzelnen EPSC auf Basis einer individuellen Nulllinie bestimmt werden.

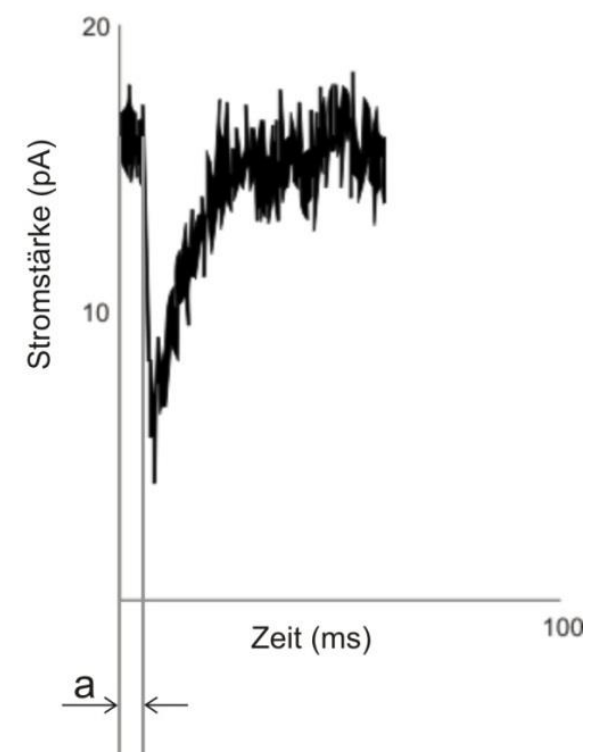

\section{Abbildung 2.7: Redefinition der Nulllinie}

Dargestellt ist ein einzelnes EPSC und die zur Redefinition einer EPSCindividuellen Nulllinie verwendeten Cursormarkierungen innerhalb der pretrigger-length (a). 
Die Prüfung der auf diese Weise ermittelten Daten zeigte, dass trotz verwendeter Rauschunterdrückung unspezifische Stromspitzen als EPSC detektiert wurden (Abb. 2.8). Diese wurden anhand der Parameter Amplitude, Anstiegszeit sowie Abfallszeit identifiziert. Alle EPSC mit einer Amplitude im Betrag kleiner als 3pA (von korrigierter Nulllinie gemessen) oder einer kürzeren Anstiegs- oder Abfallszeit als $0,8 \mathrm{~ms}$ wurden als Hintergrundrauschen definiert und in der Auswertung nicht berücksichtigt. Aus den verbleibenden Daten wurde im Zuge einer parameterdifferenzierten Auswertung die EPSCFrequenz als Anzahl an EPSC pro Zeiteinheit berechnet. Außerdem zeigte sich, dass mehrere, zeitlich eng aufeinander folgende und ineinander überlagerte EPSC durch die Auswertungssoftware zu einem einzelnen EPSC mit nicht korrekt bestimmten Parametern zusammengefasst wurden. Lag eine Überlagerung in der ansteigenden Flanke vor (zur maximalen Amplitude weisend), wies also das zeitlich später registrierte EPSC die größere Gesamtamplitude auf, war dies anhand einer überproportional langen Anstiegszeit erkennbar (Abb. 2.9). Nach visueller Abschätzung wurden EPSC mit längeren Anstiegszeiten als $5 \mathrm{~ms}$ bei falsch bestimmten Parametern Amplitude, Anstiegszeit, maximale Steigung, Abfallszeit, maximales Gefälle, Halbwertszeit sowie Fläche in der Auswertung nicht berücksichtigt.

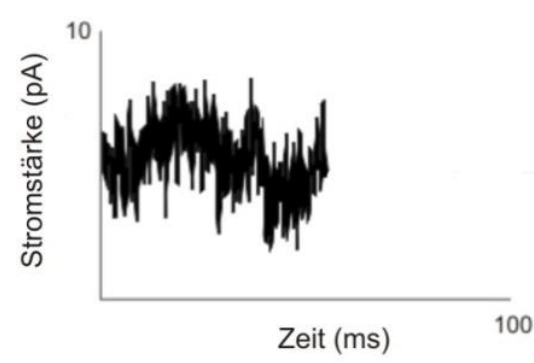

Abbildung 2.8:

Hintergrundrauschen

Als EPSC detektierte unspezifische Stromspitzen wurden anhand der Parameter Amplitude (im Betrag $<3 p A)$, Anstiegszeit $(<0,8 \mathrm{~ms})$ und Abfallszeit $(<0,8 \mathrm{~ms})$ identifiziert und in der weiteren Auswertung nicht berücksichtigt.

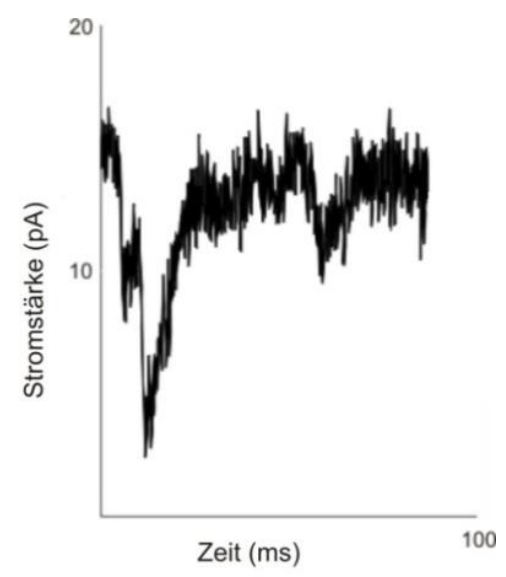

Abbildung 2.9: In ansteigender Flanke überlagertes EPSC

In der zur maximalen Amplitude weisenden Flanke überlagerte EPSC wurden anhand überproportional langer Anstiegszeiten (>5ms) identifiziert.

Die Parameter Amplitude, Anstiegszeit, maximale Steigung, Abfallszeit, maximales Gefälle, Halbwertszeit sowie Fläche dieser EPSC wurden in der Auswertung nicht berücksichtigt. 
Überlagerungen in der abfallenden Flanke (zur Nulllinie weisend), bei denen das zeitlich später registrierte EPSC die geringere Gesamtamplitude aufwies, wurden anhand der überproportional langen Abfallszeit identifiziert (Abb. 2.10). Ab einer Abfallszeit von $15 \mathrm{~ms}$ wurden die EPSC Parameter Abfallszeit, maximales Gefälle, Halbwertszeit und Fläche in der Auswertung nicht berücksichtigt. Da Überlagerungen in der abfallenden Flanke weder Auswirkungen auf Amplitude noch Anstiegszeit oder maximale Steigung haben, flossen diese Parameter in die Auswertung ein.

Bei EPSC kleiner Amplitude war zu beobachten, dass ein in der abfallenden Flanke rauschendes Signal durch eine vorzeitige Rückkehr auf das Nulllinienniveau zu inkorrekt bestimmten Parametern Abfallszeit, maximales Gefälle, Halbwertszeit und Fläche führte (Abb. 2.11). Diese Parameter wurden deshalb von EPSC mit einer Abfallszeit zwischen $0,8 \mathrm{~ms}$ und $2,0 \mathrm{~ms}$ in der Auswertung nicht berücksichtigt.

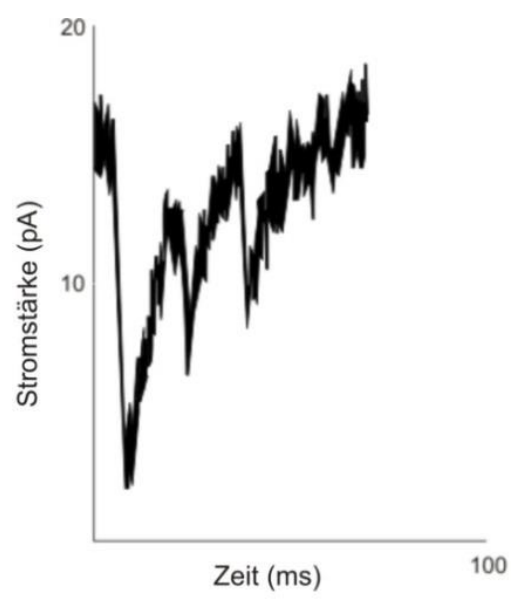

Abbildung 2.10: In abfallender Flanke überlagertes EPSC

In der zur Nullinie weisenden Flanke überlagerte EPSC wurden anhand überproportional langer Abfallszeiten ( $>15 \mathrm{~ms}$ ) identifiziert.

Die Parameter Abfallszeit, maximales Gefälle, Halbwertszeit sowie Fläche dieser EPSC wurden in der Auswertung nicht berücksichtigt. Die Parameter Amplitude, Anstiegszeit und maximale Steigung flossen hingegen in die Auswertung ein.

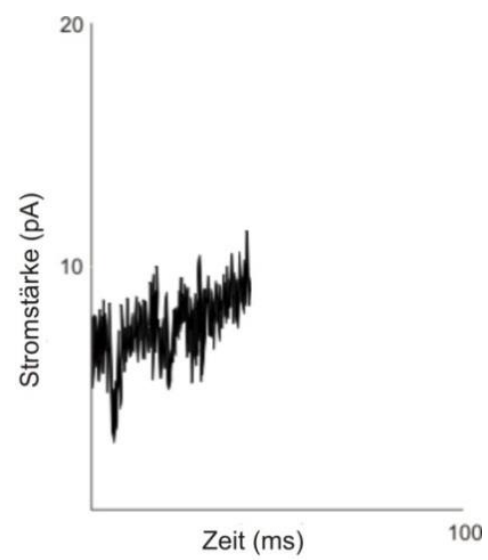

Abbildung 2.11: Rauschendes Signal in abfallender Flanke erreicht vorzeitig Nullinie

Vorzeitig auf das Niveau der Nulllinie zurückkehrende EPSC wurden anhand Abfallszeiten zwischen $0,8 \mathrm{~ms}$ und $2,0 \mathrm{~ms}$ identifiziert. Die Parameter Abfallszeit, maximales Gefälle, Halbwertszeit sowie Fläche dieser EPSC wurden in der Auswertung nicht berücksichtigt. Die Parameter Amplitude, Anstiegszeit und maximale Steigung flossen hingegen in die Auswertung ein. 
Die Abbildungen 2.12 und 2.13 illustrieren als Streudiagramme die detektierten sEPSC in Abhängigkeit der Parameter Anstiegszeit und Abfallszeit: Die aus 21 untersuchten exzitatorischen NL-4-WT-Neuronen im ersten Analyseschritt detektierten 40538 (100\%) sEPSC wurden unter Maßgabe der zuvor beschriebenen Grenzwerte zur Berechnung der EPSCFrequenz auf 33655 sEPSC (83\%), zur Auswertung der Parameter Amplitude, Anstiegszeit und maximale Steigung auf 28988 sEPSC (72\%) und zur Auswertung der Parameter Abfallszeit, maximales Gefälle, Fläche und Halbwertszeit auf 25040 sEPSC (62\%) reduziert.

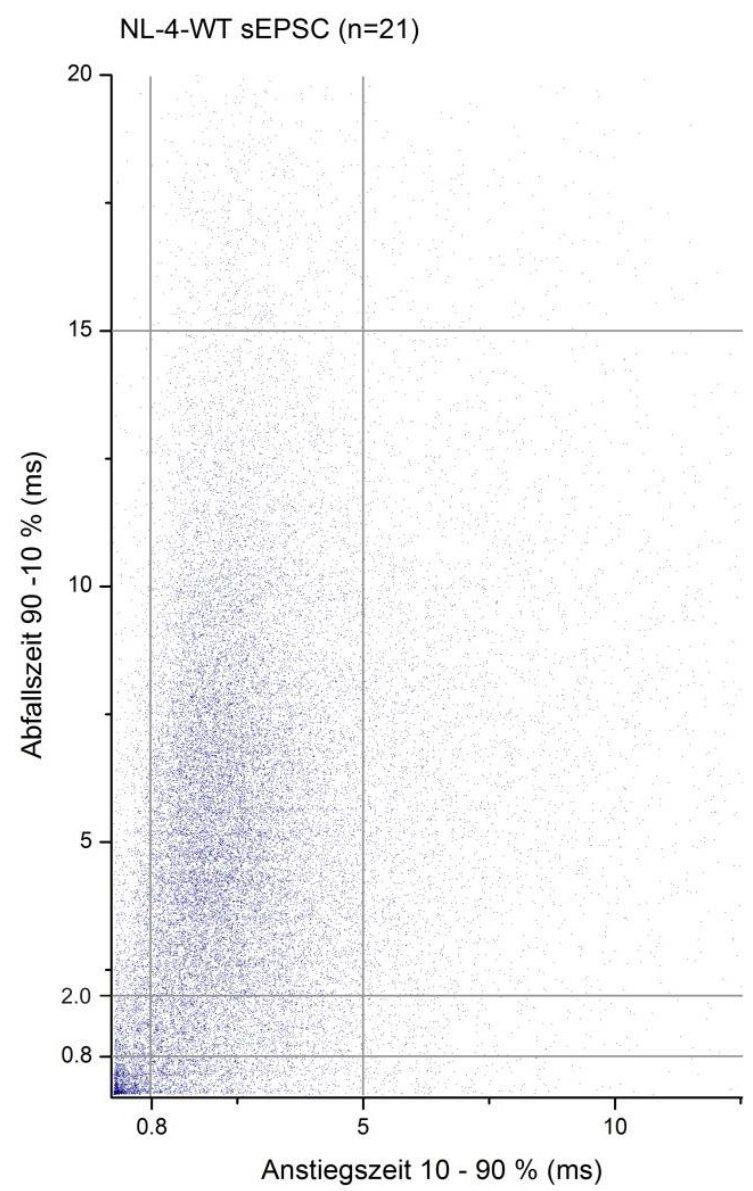

Abbildung 2.12: Streudiagramm detektierter sEPSC in Abhängigkeit von Anstiegs- und Abfallszeit

Die Punkte repräsentieren 40538 sEPSC von 21 NL-4-WT-Neuronen, abhängig von Anstiegszeit (Abszisse) und Abfallszeit (Ordinate). Die Grenzwerte der parameterdifferenzierten Auswertung sind als Linien (in grau) eingezeichnet.

EPSC mit einer Anstiegs- oder Abfallszeit<0,8ms wurden in der Auswertung nicht berücksichtigt.

EPSC mit einer Anstiegszeit>5ms wurden in der Auswertung der Parameter Amplitude, Anstiegszeit, maximale Steigung, Abfallszeit, maximales Gefälle, Halbwertszeit sowie Fläche nicht berücksichtigt.

EPSC mit einer Abfallszeit>15ms wurden in der Auswertung der Parameter Abfallszeit, maximales Gefälle, Halbwertszeit sowie Fläche nicht berücksichtigt.

EPSC mit einer Abfallszeit zwischen $0,8 \mathrm{~ms}$ und 2,0ms wurden in der Auswertung der Parameter Abfallszeit, maximales Gefälle, Halbwertszeit sowie Fläche nicht berücksichtigt. 
In ähnlichem Umfang wurden die initial detektierten 33574 sEPSC (100\%) der 17 ausgewerteten exzitatorischen NL-4-KO-Neurone, zur Berechnung der EPSC-Frequenz auf 28998 sEPSC (86\%), zur Auswertung der EPSC-Parameter Amplitude, Anstiegszeit und maximale Steigung auf 25563 sEPSC (76\%) und zur Auswertung der EPSC-Parameter Abfallszeit, maximales Gefälle, Fläche und Halbwertszeit auf 22906 sEPSC (68\%) reduziert.

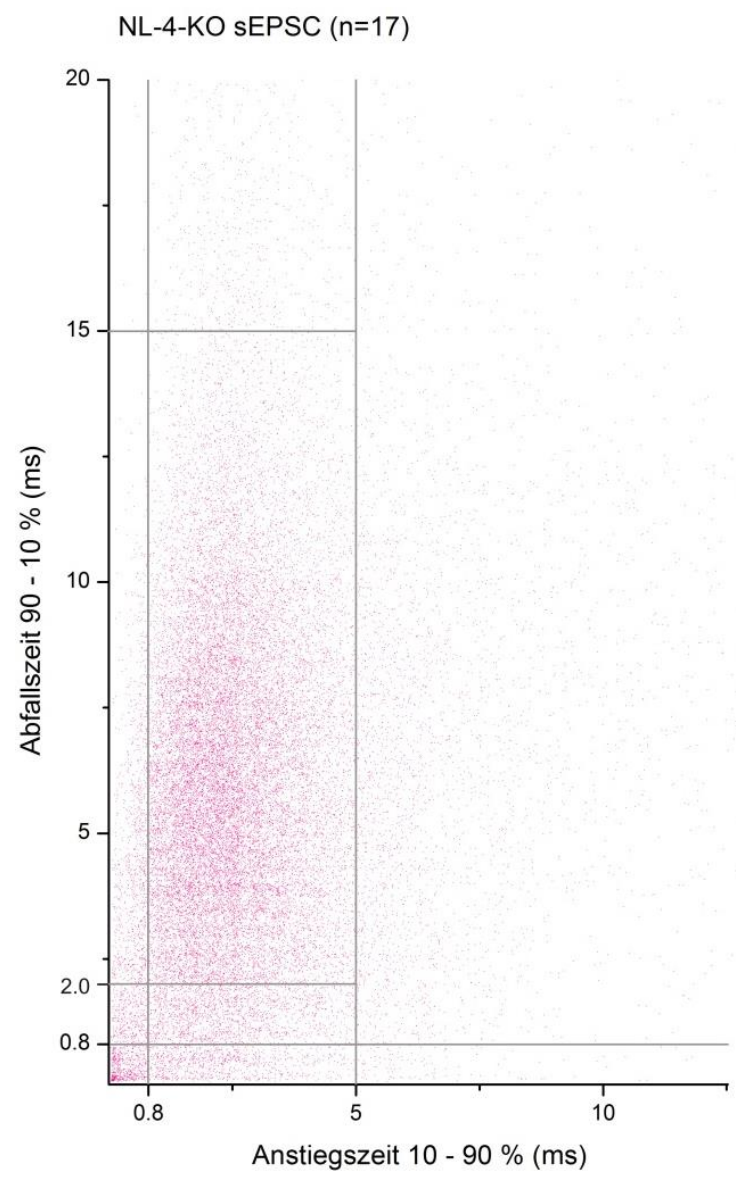

Abbildung 2.13: Streudiagramm detektierter SEPSC in Abhängigkeit von Anstiegs- und Abfallszeit

Die Punkte repräsentieren 33574 sEPSC von 17 NL-4-KO-Neuronen, abhängig von Anstiegszeit (Abszisse) und Abfallszeit (Ordinate). Die Grenzwerte der parameterdifferenzierten Auswertung sind als Linien (in grau) eingezeichnet.

EPSC mit einer Anstiegs- oder Abfallszeit<0,8ms wurden in der Auswertung nicht berücksichtigt.

EPSC mit einer Anstiegszeit $>5 \mathrm{~ms}$ wurden in der Auswertung der Parameter Amplitude, Anstiegszeit, maximale Steigung, Abfallszeit, maximales Gefälle, Halbwertszeit sowie Fläche nicht berücksichtigt.

EPSC mit einer Abfallszeit $>15 \mathrm{~ms}$ wurden in der Auswertung der Parameter Abfallszeit, maximales Gefälle, Halbwertszeit sowie Fläche nicht berücksichtigt.

EPSC mit einer Abfallszeit zwischen $0,8 \mathrm{~ms}$ und 2,0ms wurden in der Auswertung der Parameter Abfallszeit, maximales Gefälle, Halbwertszeit sowie Fläche nicht berücksichtigt. 
Die Auswertung bzw. Korrektur der registrierten mEPSC von NL-4-WT- und NL-4-KO-Neuronen wurde analog zu den sEPSC durchgeführt. Von den ursprünglich 19100 (100\%) detektierten mEPSC, von 11 NL-4-WT-Neuronen, wurden 15213 mEPSC (80\%) zur Berechnung der Frequenz, 13152 mEPSC (69\%) zur Auswertung der Amplitude, Anstiegszeit und maximalen Steigung und 11295 mEPSC (59\%) zur Auswertung der Abfallszeit, des maximalen Gefälles, der Fläche und der Halbwertszeit verwendet.

Die 26578 mEPSC (100\%) von 14 NL-4-KO-Neuronen wurden zur Berechnung der Frequenz auf 21897 mEPSC (82\%), zur Auswertung der Amplitude, der Anstiegszeit und der maximalen Steigung auf 19020 mEPSC (72\%) und zur Auswertung der Abfallszeit, des maximalen Gefälles, der Fläche und der Halbwertszeit auf 16859 mEPSC (63\%) reduziert.

Die Tabelle $7.1 \mathrm{im}$ Anhang gibt einen Überblick über die Anzahl der ausgewerteten EPSC abhängig von Ableitungsmodus (sEPSC/mEPSC), Genotyp (NL-4-WT/NL-4-KO) und EPSCParameter.

\subsubsection{Analyse der Netzwerkaktivität - Detektion und Analyse TTX-sensitiver EPSC}

Zur Beurteilung der präsynaptischen Netzwerkaktivität wurde der durch TTX unterdrückbare, AP-abhängige Anteil der synaptischen Übertragung mit Hilfe vergleichender Analysen der Amplitudenverteilungen zwischen mEPSC und zellzugehöriger sEPSC untersucht. Dafür wurde pro Zelle die größte mEPSC-Amplitude bestimmt und als zellindividuelle Referenz für den maximalen durch AP-unabhängige Transmitterfreisetzung erreichbaren postsynaptischen Summenstrom definiert (Abb. 2.14).

Zur Analyse der Amplitudenverteilungen wurde diese zellindividuelle Referenz zur Definition eines zellunabhängigen Amplitudenmaßstabs verwendet, auf dessen Basis die Verteilungen der mEPSC- und zugehöriger sEPSC-Amplituden standardisiert darstell- und auswertbar waren. Dafür wurde jede mEPSC- und zugehörige sEPSC-Amplitude durch ihre zelleigene Referenzamplitude dividiert.

Zur direkten Detektion TTX-sensitiver EPSC wurde die zellindividuelle Referenzamplitude als Kriterium einer neuen, separaten SEPSC-Schwellenanalyse eingestellt. Dabei wurden SEPSC in den Originalableitungen als TTX-sensitiv detektiert, sofern sie, ausgehend von einer EPSC- 
individuellen Nulllinie, die Referenzamplitude überschritten und dabei nicht in der ansteigenden Flanke überlagert waren. Die auf diese Weise detektierten TTX-sensitiven EPSC wurden auf ihre Frequenz (Anzahl EPSC pro Zeiteinheit) und ihr Intervall (Zeit zwischen zwei aufeinanderfolgenden Amplitudenmaxima) ausgewertet.
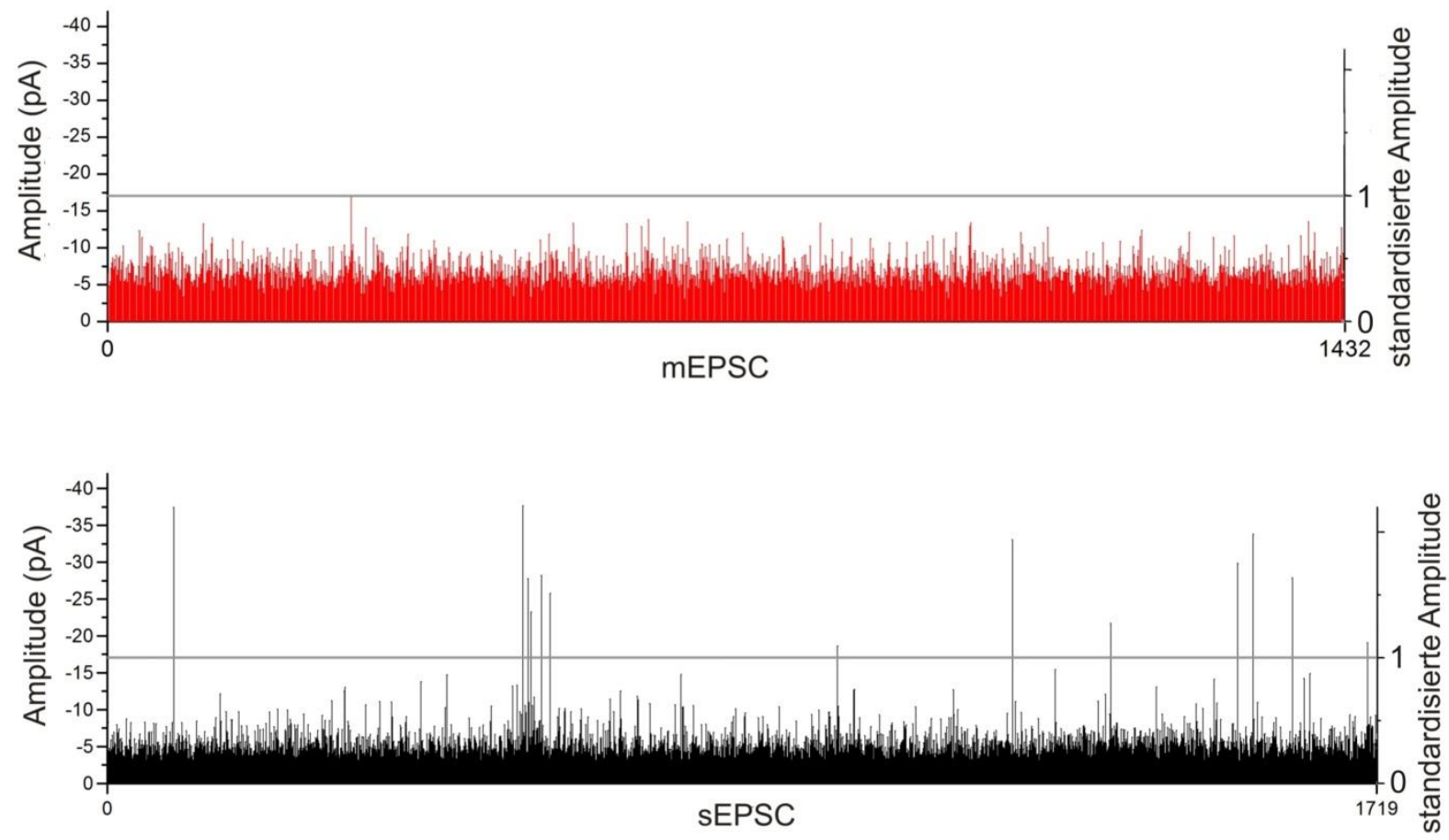

Schwelle TTX-sensitiver EPSC

Abbildung 2.14: Exemplarische Darstellung der ausgewerteten mEPSC- und sEPSC-Amplituden einer Zelle

Das maximale mEPSC (obere Spur, rot) definiert den maximalen, durch AP-unabhängige Transmitterfreisetzung erreichbaren postsynaptischen Summenstrom, zu dessen Basis alle EPSC einer Zelle standardisiert und neu skaliert wurden (Achse rechts: standardisierte Amplitude). Diese Referenz überschreitende SEPSC (untere Spur, schwarz) wurden anschließend in einer separaten Schwellenanalyse als TTX-sensitive EPSC detektiert. 


\subsubsection{Datenverarbeitung}

Die in der Software Clampfit generierten Datensätze wurden mit Hilfe des Programms MS Excel 2010 (Version 14.0, Microsoft Corporation, Redmond, WA, USA) verwaltet, weiterverarbeitet und ausgewertet. Je Ableitung wurde der Median, das arithmetische Mittel, die Standardabweichung und der Standardfehler der untersuchten EPSC-Parameter berechnet. Im Rahmen der statistischen Analysen wurden die Mediane der untersuchten EPSC-Parameter, abhängig vom Ableitungsmodus (sEPSC/mEPSC) und Genotyp (NL-4-WT/NL-4-KO), mit Hilfe der Software SigmaPlot (Version 12.0, Systat Software, San Jose, CA, USA) durch den nichtparametrischen Wilcoxon-Mann-Whitney-Rangsummentest, welcher keine Normalverteilung vorrausetzt, auf signifikante Unterschiede geprüft. Das Signifikanzniveau wurde dabei mit $p \leq 0,05$ festgelegt. Die Ergebnisse der statistischen Analysen wurden im Text als Median \pm Standardabweichung (SD) bzw. arithmetischem Mittel \pm Standardfehler (SE) mit zugehörigem p-Wert beschrieben. Zusätzlich wurden die Ergebnisse der statistischen Analyse mit Hilfe der Software MicroCal Origin (Version 8.5, Microcal Software, Northhampton, MA, USA) in Form von Boxplot-Diagrammen (Abb. 2.15) graphisch dargestellt. Dabei wurden signifikante Unterschiede durch einen Stern $(*)$ und nicht signifikante Unterschiede durch die Abkürzung n.s. gekennzeichnet.

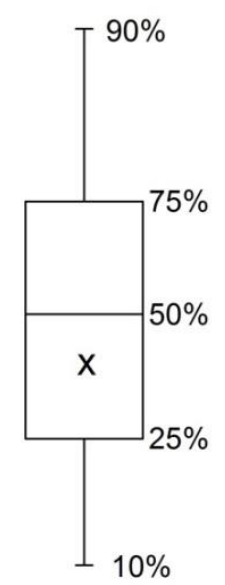

\section{Abbildung 2.15: Boxplot-Darstellung}

Die Länge der Box entspricht per Definition dem Interquartilsabstand (mittlere 50\% der Daten), die Länge der Antennen dem Bereich, in dem 10-90\% der gemessenen Daten liegen. Die horizontale Gerade innerhalb der Box markiert den Median, das Kreuz $(x)$ das arithmetische Mittel. 


\subsection{Lösungen und Puffer}

\section{- Präparationslösung:}

$87 \mathrm{mM} \mathrm{NaCl} ; 1,25 \mathrm{mM} \mathrm{NaH}_{2} \mathrm{PO}_{4} ; 2,5 \mathrm{mM} \mathrm{KCl} ; 10 \mathrm{mM}$ Glukose; 75mM Saccharose;

$0,5 \mathrm{mM} \mathrm{CaCl}_{2} ; 7 \mathrm{mM} \mathrm{MgCl}_{2} ; 26 \mathrm{mM} \mathrm{NaHCO}_{3}$

\section{- ACSF-Lösung (extrazelluläre Badlösung):}

$125 \mathrm{mM} \mathrm{NaCl} ; 1,25 \mathrm{mM} \mathrm{NaH}_{2} \mathrm{PO}_{4} ; 2,5 \mathrm{mM} \mathrm{KCl} ; 25 \mathrm{mM}$ Glukose; $2 \mathrm{mM} \mathrm{CaCl} 2 ; 1 \mathrm{mM} \mathrm{MgCl}_{2}$; $26 \mathrm{mM} \mathrm{NaHCO}_{3}$

Experimentabhängige Zusätze:

- $\quad$ 0,5 $\mu \mathrm{M}$ TTX (Sigma Aldrich, St. Louis, MO, USA); Tetrodotoxin

- $\quad 10 \mu \mathrm{M}$ NBQX (Sigma Aldrich, St. Louis, MO, USA);

2,3-dihydroxy-6-nitro-7-sulfamoylbenzo(f)chinoxalin

- $20 \mu \mathrm{M}$ Gabazine (Sigma Aldrich, St. Louis, MO, USA);

4-[6-imino-3-(4-methoxyphenyl)pyridazin-1-yl]-Butansäure-Hydrobromid

\section{- $\quad$ Pipettenlösung (intrazelluläre Lösung):}

$135 \mathrm{mM}$ K-Gluconat; $5 \mathrm{mM} \mathrm{KCl} ; 2 \mathrm{mM} \mathrm{MgCl} 2 ; 0,5 \mathrm{mM}$ EGTA (Ethylenglycol-bis-( $\beta$ aminoethylether)-N,N,N',N'-tetraessigsäure); $10 \mathrm{mM}$ HEPES (N-(2-Hydroxyethyl)piperazin-N'-2-ethansulfonsäure); $2 \mathrm{mM} \mathrm{Na}_{2} \mathrm{ATP}$ (Adenosintriphosphat); 0,5mM NaGTP (Guanosintriphosphat); 10mM Na-Phospokreatinphosphat; 5mg/ml Biocytin (Sigma Aldrich, St. Louis, MO, USA)

\section{- Phosphat Puffer (phosphate buffer; PB):}

$0,1 \mathrm{M} ; \mathrm{pH}=7,4$

$14,42 \mathrm{~g} \mathrm{Na}_{2} \mathrm{HPO}_{4} * 2 \mathrm{H}_{2} \mathrm{O}$ und 2,62g NaH $\mathrm{PO}_{4} * \mathrm{H}_{2} \mathrm{O}$ pro I Aqua destilliert 
- $\quad$ TRIS-Puffer (tris buffer; TB):

$0,05 \mathrm{M} ; \mathrm{pH}=7,6$

6,06g TRIS HCl und 1,39g TRIS Base pro I Aqua destilliert; $\mathrm{pH}$ mit $\mathrm{HCl}$ eingestellt TRIS = Tris(hydroxymethyl)-aminomethan

- $\quad$ TRIS-gepufferte Saline (tris buffered saline; TBS):

$\mathrm{pH}=7,6$

$1 \mathrm{~TB}+9 \mathrm{~g} \mathrm{NaCl}$ 


\section{ERGEBNISSE}

Im Rahmen der vorliegenden Arbeit wurde untersucht, inwiefern NL-4 die exzitatorische synaptische Übertragung auf exzitatorische Neurone der Schicht IV im Barrel-Kortex beeinflusst. Hierfür wurden elektrophysiologische Aufnahmen netzwerkunabhängiger mEPSC und spontan gemessener sEPSC von 17 NL-4-KO-Neuronen (aus zehn Tieren) und 21 NL-4-WTNeuronen (aus elf Tieren) analysiert und statistisch ausgewertet (siehe Abschnitt 2.2.2)

\subsection{Morphologische Zelldifferenzierung}

Die Schnitte der abgeleiteten Neurone wurden mit Hilfe der ABC-Methode und der Cytochrom-C-Oxidase-Reaktion DAB gefärbt und anschließend versilbert (siehe Abschnitt 2.3). Dadurch konnten die elektrophysiologisch als exzitatorisch charakterisierten Zellen morphologisch einer der in Schicht IV des Barrel-Kortex vorkommenden exzitatorischen Neuronenklassen zugeordnet werden. Dabei wurden bedornte Sternzellen, Sternpyramidenund Pyramidenzellen anhand der Konfiguration und Ausdehnung ihrer dendritischen und axonalen Zellfortsätze voneinander unterschieden (siehe Abschnitt 1.4).

In beiden verwendeten Genotypen, NL-4-WT und NL-4-KO, konnten alle drei beschriebenen exzitatorischen Neuronentypen der Schicht IV des Barrel-Kortex identifiziert werden. Unter den 21 abgeleiteten NL-4-WT-Neuronen ließen sich neun bedornte Sternzellen von sechs Sternpyramiden- und zwei Pyramidenzellen unterscheiden (Abb. 3.1). Vier Neurone waren morphologisch nicht eindeutig zuzuordnen. Sie wurden aufgrund ihrer Lokalisation in Schicht IV und der elektrophysiologisch dokumentierten exzitatorischen Merkmale (siehe Abschnitte 2.2.3) dennoch in die Auswertung der synaptischen Übertragung eingeschlossen.

Unter den $17 \mathrm{NL}-4-K O-N e u r o n e n$ ließen sich zwölf bedornte Sternzellen von zwei Sternpyramidenzellen und einer Pyramidenzelle differenzieren (Abb. 3.1). Zwei Neurone wiesen keine eindeutige Morphologie auf, wurden jedoch aufgrund der Lokalisation ihrer Zellsomata und ihrer elektrophysiologischen Merkmale als exzitatorische Neurone der Schicht IV charakterisiert und für die weiteren Auswertungen verwendet.

Nach Registrierung der sEPSC und Applikation von TTX blieben die Ableitungsbedingungen zur Aufzeichnung der mEPSC nicht bei allen Zellen ausreichend stabil. Der Auswertung der mEPSC 
und TTX-sensitiven EPSC liegt deshalb eine abweichende Zellzahl und Zellverteilung zugrunde (Abb. 3.1).

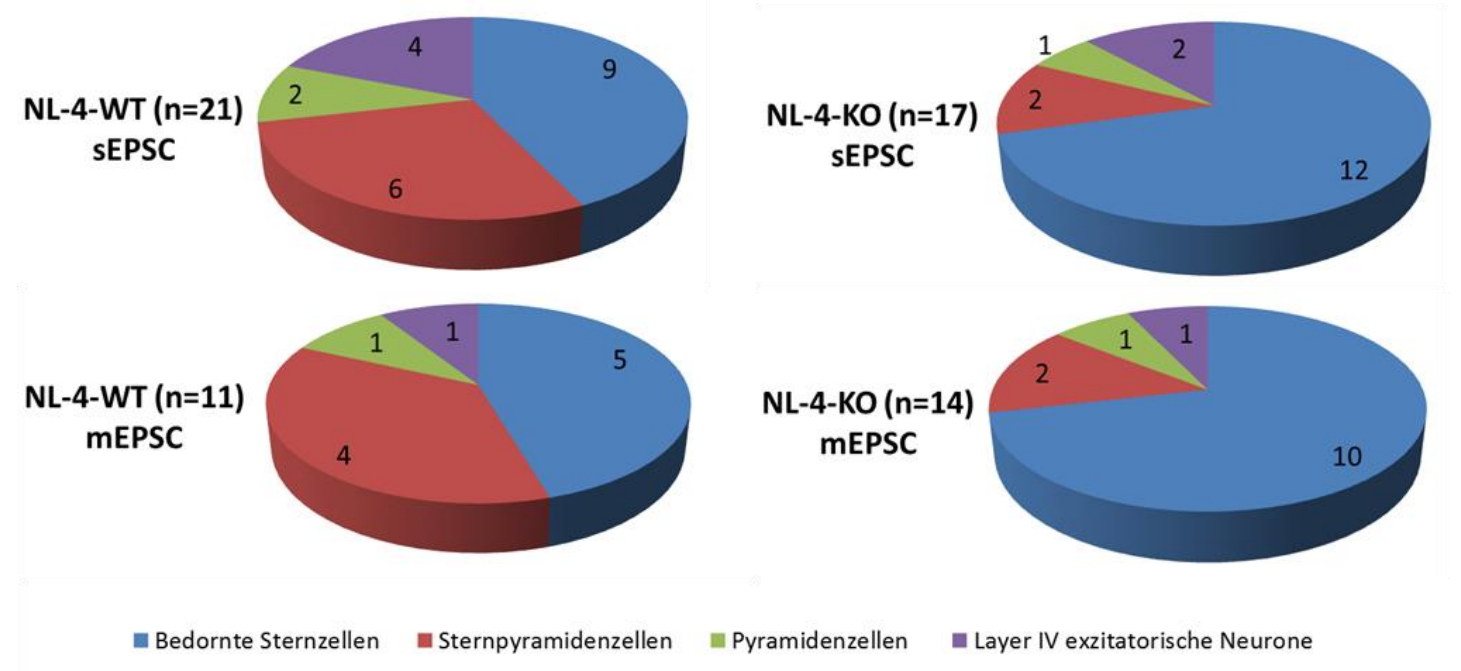

Abbildung 3.1: Verteilung der exzitatorischen Neurone in NL-4-WT und NL-4-KO für die Ableitbedingungen sEPSC und mEPSC

Zelldifferenzierung der abgeleiteten Zellen in bedornte Sternzellen, Sternpyramidenzellen und Pyramidenzellen. Die Unterscheidung erfolgte anhand spezifischer morphologischer Merkmale.

Zwei typische Vertreter der als bedornte Sternzellen charakterisierten Neurone wurden für die nachfolgende Rekonstruktion ausgewählt (Abb. 3.2 und 3.3). Bereits im lichtmikroskopischen Bild erkennt man die für bedornte Sternzellen (schwarz) typische Beschränkung des Dendritenbaumes auf die Lage des Ursprungs-Barrel und das Fehlen eines apikalen Dendriten. Die somatodendritische Rekonstruktion der Zelle (blau) und ihre Lage zu den Barrels (grau) bestätigen die lichtmikroskopisch getroffene Klassifizierung.

Zusätzlich wurden zwei Neurone, welche lichtmikroskopisch anhand ihrer apikalen Dendriten sowie der nicht polarisierten Ausrichtung der übrigen primären Dendriten als Sternpyramiden identifiziert werden konnten, somatodendritisch (blau) und axonal (rot) rekonstruiert (Abb. 3.4 und 3.5).

Auf weiterführende morphologische Analysen wurde aufgrund fehlender offensichtlicher Unterschiede in der Morphologie der Neurone im Vergleich der beiden Genotypen verzichtet. Es ist anzunehmen, dass das Ausschalten von NL-4 zu keinen die Neuronenmorphologie grob veränderten Effekten führt. 

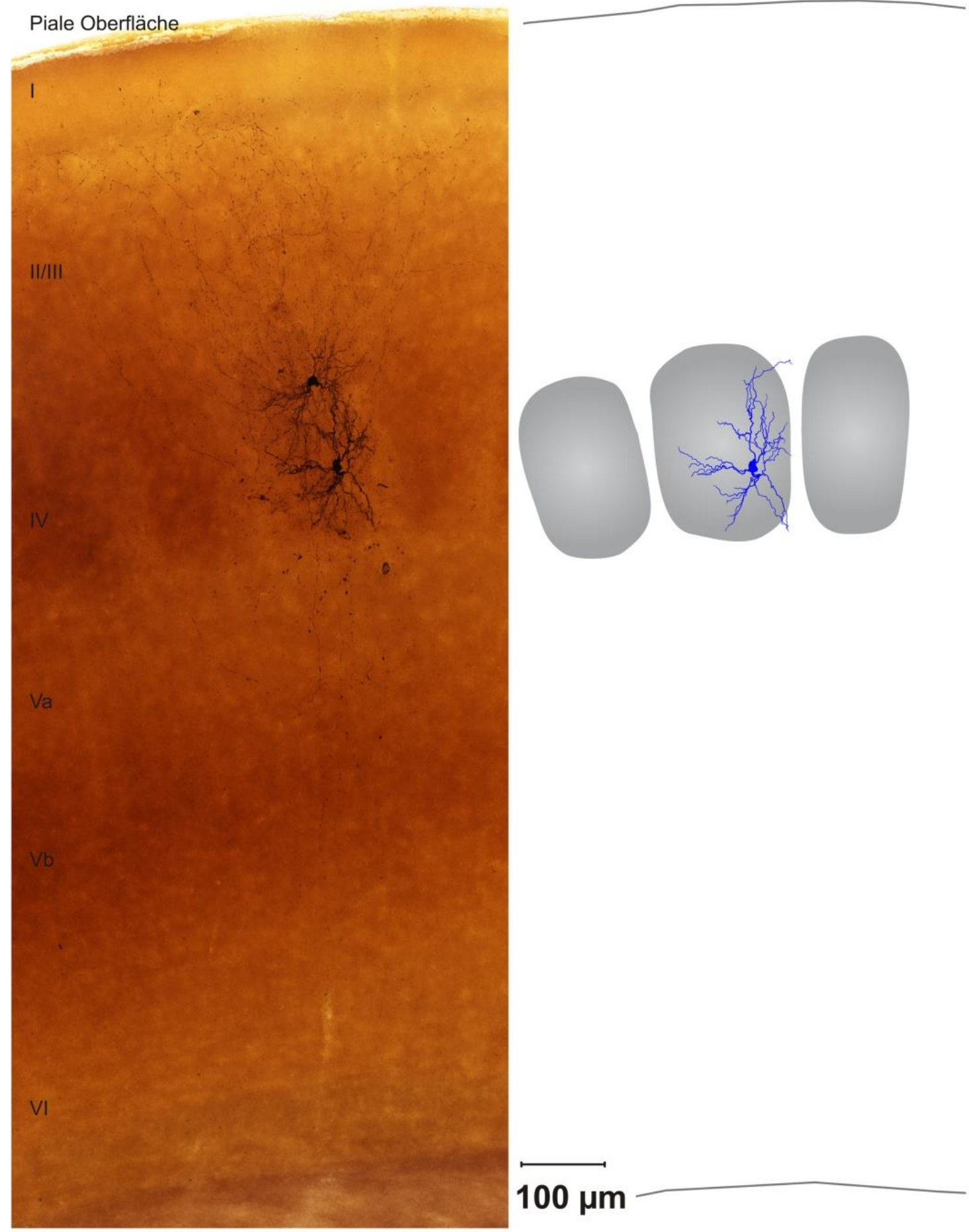

Abbildung 3.2: Lichtmikroskopisches Bild und Rekonstruktion bedornter Sternzellen im WT

Das lichtmikroskopische Bild zweier, sukzessive abgeleiteter bedornter Sternzellen im NL-4-WT-BarrelKortex. Die Neurone (schwarz) wurden mittels DAB-Färbung und Silberintensivierung gefärbt. Die schichtenspezifische Lage der Zellen konnte durch die CO-Reaktion (dunkelbraun) sichtbar gemacht werden. Römische Zahlen (I-VI) in dieser und den folgenden Abbildungen markieren die kortikalen Schichten. Die Rekonstruktion der somatodendritischen Verzweigung (blau) und ihre räumliche Orientierung zu den Barrels in Schicht IV (grau) ist im rechten Bildausschnitt in identischem Maßstab abgebildet. Die im lichtmikroskopischen Bild erkennbaren axonalen Verzweigungen konzentrieren sich, typisch für bedornte Sternzellen, vor allem in der Schicht II/III. 

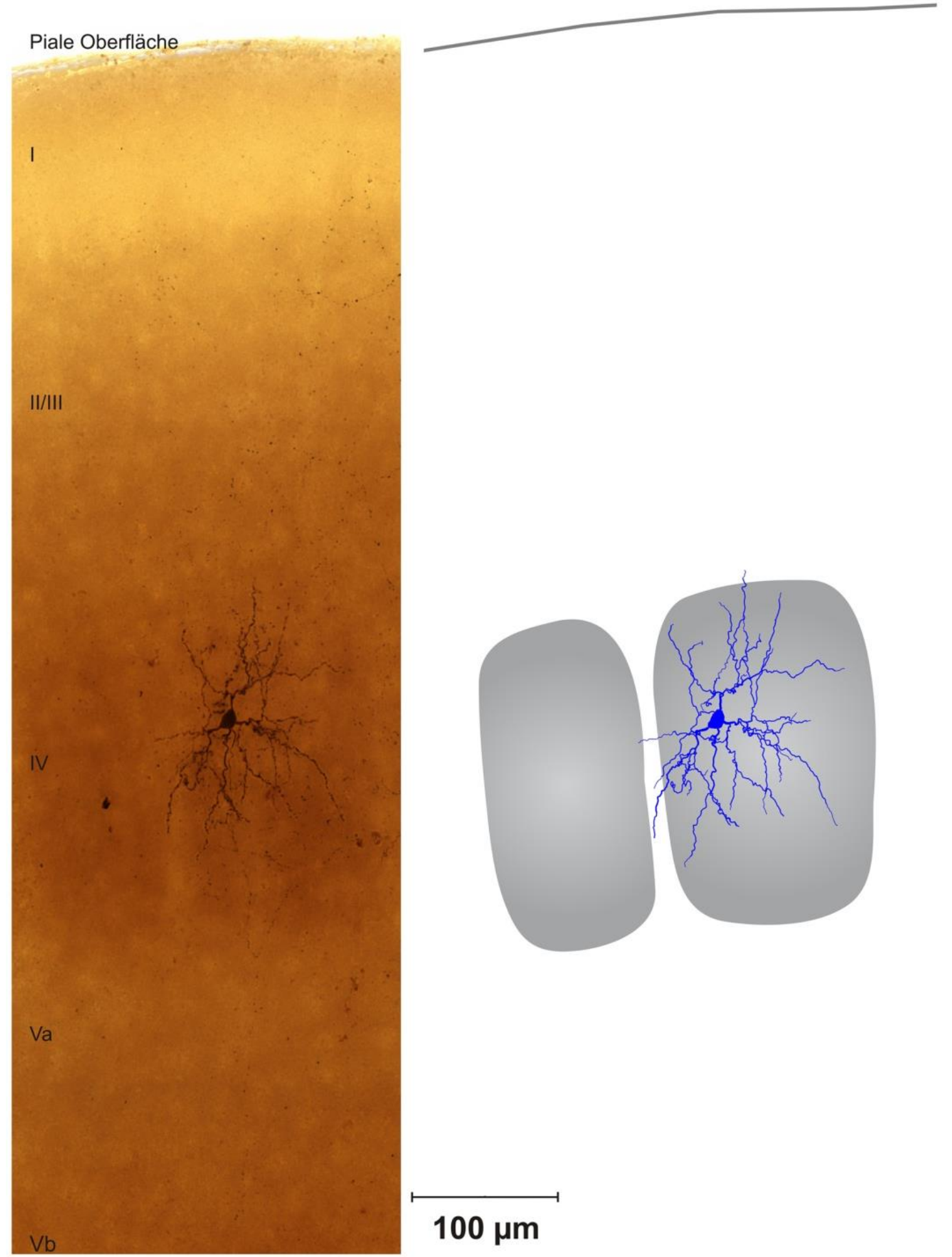

\section{$100 \mu \mathrm{m}$}

Abbildung 3.3: Lichtmikroskopisches Bild und Rekonstruktion einer bedornten Sternzelle im KO

Das lichtmikroskopische Bild einer abgeleiteten bedornten Sternzelle im NL-4-KO-Barrel-Kortex. Das Neuron (schwarz) wurde mittels DAB-Färbung und Silberintensivierung gefärbt. Die schichtenspezifische Lage der Zelle konnte durch die CO-Reaktion (dunkelbraun) sichtbar gemacht werden. Die Rekonstruktion der somatodendritischen Verzweigung (blau) und ihre räumliche Orientierung zu den Barrels in Schicht IV (grau) ist im rechten Bildausschnitt in identischem Maßstab abgebildet. 
Piale Oberfläche

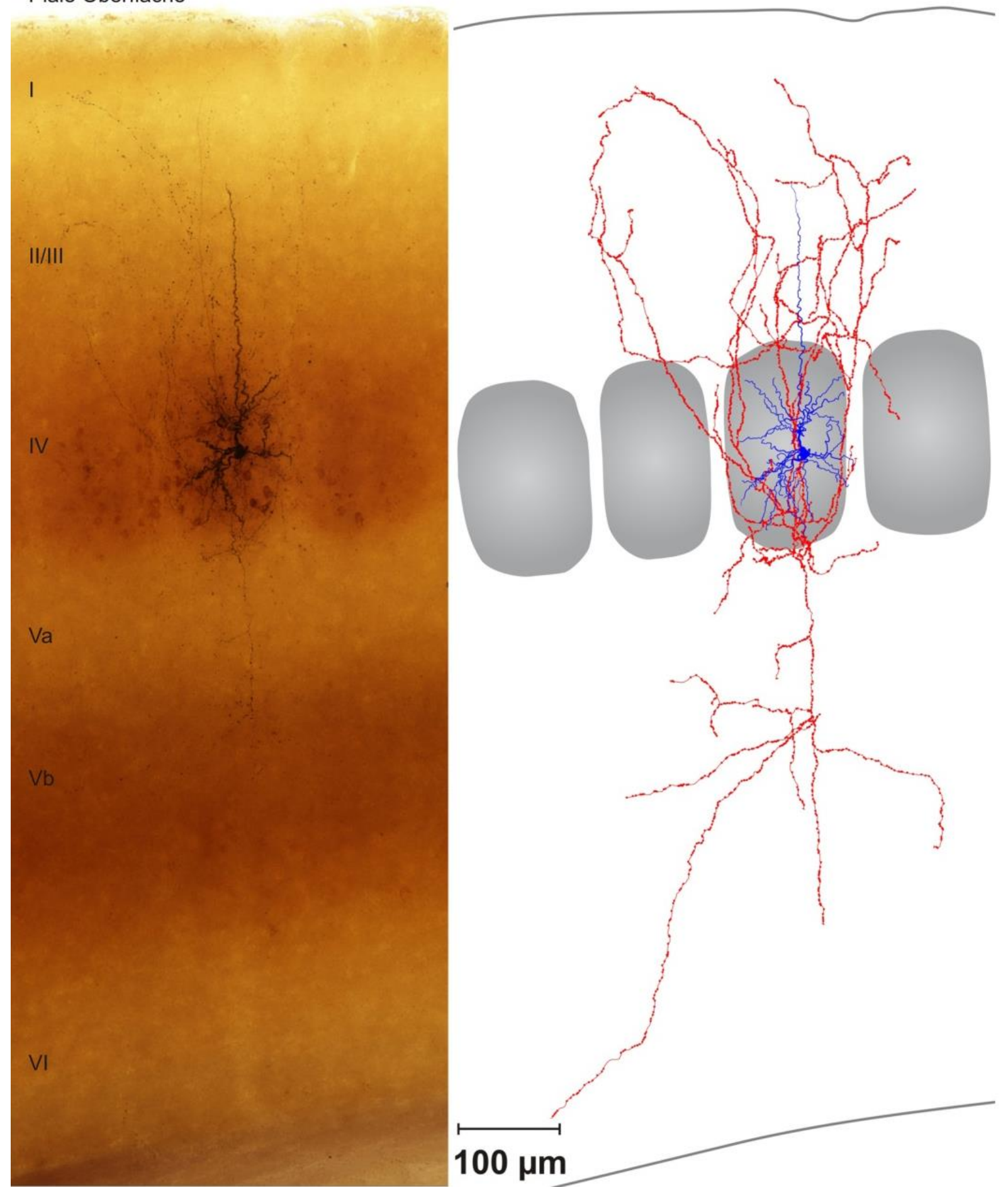

Abbildung 3.4: Lichtmikroskopisches Bild und Rekonstruktion einer Sternpyramidenzelle im WT

Das lichtmikroskopische Bild einer abgeleiteten Sternpyramidenzelle im NL-4-WT-Barrel-Kortex. Das Neuron (schwarz) wurde mittels DAB-Färbung und Silberintensivierung gefärbt. Die schichtenspezifische Lage der Zellen konnte durch die CO-Reaktion (dunkelbraun) sichtbar gemacht werden. Die Rekonstruktion der somatodendritischen Verzweigung (blau), des Axons (rot) und ihre räumliche Orientierung zu den Barrels in Schicht IV (grau) ist im rechten Bildausschnitt in identischem Maßstab abgebildet. 


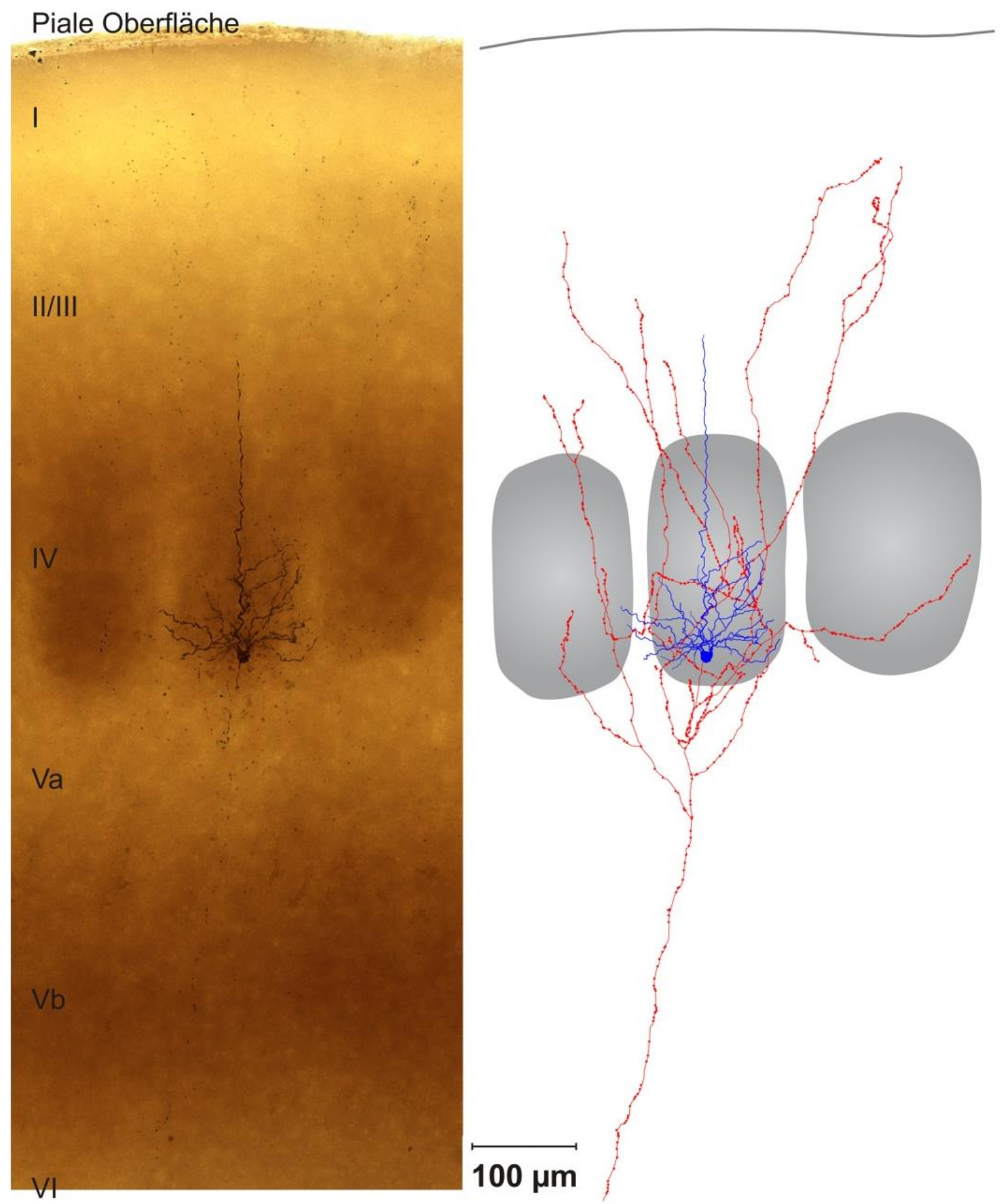

Abbildung 3.5: Lichtmikroskopisches Bild und Rekonstruktion einer Sternpyramidenzelle im KO

Das lichtmikroskopische Bild einer abgeleiteten Sternpyramidenzelle im NL-4-KO-Barrel-Kortex. Das Neuron (schwarz) wurde mittels DAB-Färbung und Silberintensivierung gefärbt. Die schichtenspezifische Lage der Zellen konnte durch die CO-Reaktion (dunkelbraun) sichtbar gemacht werden. Die Rekonstruktion der somatodendritischen Verzweigung (blau), des Axons (rot) und ihre räumliche Orientierung zu den Barrels in Schicht IV (grau) ist im rechten Bildausschnitt in identischem Maßstab abgebildet. 


\subsection{Analyse der synaptischen Übertragung - Auswertung der sEPSC und MEPSC}

Zur Beurteilung der synaptischen Übertragung an exzitatorischen Neuronen der Schicht IV des Barrel-Kortex wurden exzitatorische postsynaptische Ströme untersucht. Die aus den Originalableitungen extrahierten sEPSC und die nach Einwaschen von TTX registrierten mEPSC (siehe Abschnitt 2.4) konnten anschließend hinsichtlich der Parameter Amplitude, Anstiegszeit (10-90\%), maximale Steigung, Abfallszeit (90-10\%), maximales Gefälle, Halbwertszeit und Fläche sowie EPSC-Frequenz ausgewertet und statistisch auf signifikante Unterschiede zwischen Wild- und Knockout-Genotyp geprüft werden.

In einer ersten Auswertung wurden alle abgeleiteten exzitatorischen Neurone unabhängig von ihrer Morphologie zusammengefasst. In einer zweiten Analyse wurden die bedornten Sternzellen isoliert betrachtet.

\subsubsection{Auswertung exzitatorischer Neurone}

Die Auswertung der synaptischen Übertragung erfolgte einerseits für die netzwerkabhängigen sEPSC und andererseits für die netzwerkunabhängigen mEPSC. Diese wurden in den Originalableitungen über die in Abschnitt 2.4.1 beschriebene Methode detektiert und ausgewertet. Im Zuge einer parameterdifferenzierten Auswertung wurden dabei abhängig von Genotyp (NL-4-WT/NL-4-KO) und Ableitungsmodus (sEPSC/mEPSC) 59-86\% der initial detektierten EPSC zur Berechnung der einzelnen EPSC-Parameter herangezogen (Tab. 7.1).

\section{sEPSC-Auswertung:}

In der Analyse der sEPSC wurden alle 21 abgeleiteten NL-4-WT-Neurone bzw. 17 NL-4-KONeurone zusammengefasst und die Ergebnisse zwischen den Genotypen verglichen.

Für die NL-4-KO-Neurone kann eine signifikant verlängerte Abfallszeit ( $\mathrm{KO}_{(\mathrm{n}=17)}: 6,21 \pm 0,62 \mathrm{~ms}$ $\left.\mathrm{WT}_{(\mathrm{n}=21)}: 5,62 \pm 0,79 \mathrm{~ms} ; \mathrm{p}=0,040\right)^{1}$ der sEPSC festgestellt werden (Abb. 3.6 / Tab. 7.2).

\footnotetext{
${ }^{1}$ Schreibweise dieses und folgender Ergebnisse als Median \pm Standardabweichung; $\mathrm{n}=$ Anzahl der ausgewerteten Zellen
} 
Des Weiteren weisen die sEPSC der KO Neurone eine flachere maximale Steigung sowohl im Gefälle als auch im Anstieg der postsynaptischen Ströme auf. Die Werte für das maximale Gefälle betragen $27,81 \pm 5,21 \mathrm{pA} / \mathrm{ms}$ im $\mathrm{KO}_{(\mathrm{n}=17)}$ und $34,57 \pm 5,44 \mathrm{pA} / \mathrm{ms}$ im $\mathrm{WT}_{(\mathrm{n}=21)}$ (Abb. 3.6 / Tab. 7.3) bzw. für die maximale Steigung $-25,55 \pm 5,04 \mathrm{pA} / \mathrm{ms}$ im $\mathrm{KO}_{(\mathrm{n}=17)}$ und $-30,81$ $\pm 4,68 \mathrm{pA} / \mathrm{ms}$ im $\mathrm{WT}_{(\mathrm{n}=21)}$ (Abb. 3.7 / Tab. 7.4). Die Unterschiede zwischen WT und KO waren hinsichtlich beider Parameter signifikant ( $p_{\text {maximales Geälle }}=0,047$ bzw. $p_{\text {maximale Steigung }}=0,016$ ).

Für die übrigen ausgewerteten Parameter lassen sich keine statistisch signifikanten Unterschiede aufzeigen:

Anstiegszeit: $\quad \mathrm{KO}_{(\mathrm{n}=17)}: 2,39 \pm 0,20 \mathrm{~ms} ; \mathrm{WT}_{(\mathrm{n}=21)}: 2,35 \pm 0,19 \mathrm{~ms} ; \mathrm{p}=0,229$ (Abb. 3.7 / Tab. 7.5)

Amplitude: $\quad \mathrm{KO}_{(\mathrm{n}=17)}:-5,88 \pm 0,85 \mathrm{pA} ; \mathrm{WT}_{(\mathrm{n}=21)}:-6,26 \pm 1,19 \mathrm{pA} ; \mathrm{p}=0,159$

(Abb. 3.8 / Tab. 7.6)

Frequenz: $\quad \mathrm{KO}_{(\mathrm{n}=17)}: 6,04 \pm 1,84 / \mathrm{s} ; \mathrm{WT}_{(\mathrm{n}=21)}: 5,24 \pm 4,08 / \mathrm{s} ; \mathrm{p}=0,428$ (Abb. 3.8 / Tab. 7.7)

Halbwertszeit: $\quad \mathrm{KO}_{(\mathrm{n}=17)}: 1,90 \pm 0,63 \mathrm{~ms} ; \mathrm{WT}_{(\mathrm{n}=21)}: 1,51 \pm 0,85 \mathrm{~ms} ; \mathrm{p}=0,252$ (Tab. 7.8)

Fläche: $\quad \mathrm{KO}_{(\mathrm{n}=17)}:-42,26 \pm 7,39 p A \cdot m s ; \mathrm{WT}_{(\mathrm{n}=21)}:-45,72 \pm 10,04 p A \cdot m s ; p=0,056$

(Tab. 7.9)

Die negativen Werte für den maximalen Anstieg und die Fläche bzw. die positiven Werte für das maximale Gefälle resultieren aus den durch die lonenstromrichtung (einwärtsgerichteter Kationenstrom) definierten negativen EPSC-Amplituden (Abb. 2.7). Die ansteigende Stromflanke weist in Richtung maximaler Amplitude, weshalb der sie charakterisierende EPSCParameter der maximalen Steigung negative Werte annimmt. Entgegengesetzt verhält es sich für den Parameter des maximalen Gefälles, welcher die vom Maximum abfallende in Richtung Nulllinie weisende Stromflanke beschreibt und entsprechend positive Werte annimmt. 


\section{mEPSC-Auswertung:}

Nach Registrierung der sEPSC und Einwaschen von TTX gelang es nicht von jedem gepatchten Neuron mEPSC abzuleiten. Entsprechend wurden in der Analyse der mEPSC eine reduzierte Zellzahl von 11 exzitatorischen NL-4-WT-Neuronen und 14 NL-4-KO-Neuronen ausgewertet und verglichen.

Analog zur Analyse der sEPSC zeigt sich in der Auswertung der mEPSC eine in NL-4-KONeuronen signifikant verlängerte $\underline{\text { Abfallszeit }}\left(\mathrm{KO}_{(\mathrm{n}=14)}: 6,15 \pm 0,71 \mathrm{~ms}^{\mathrm{W}} \mathrm{WT}_{(\mathrm{n}=11)}: 5,23 \pm 0,76 \mathrm{~ms}\right.$; $p=0,017)(A b b .3 .6 /$ Tab. 7.2).

Weiterhin ist, wie auch in der sEPSC-Analyse, sowohl das Gefälle als auch der Anstieg in NL-4-KO-Neuronen signifikant flacher. Das maximale Gefälle beträgt im $\mathrm{KO}_{(\mathrm{n}=14)} 27,05 \pm 4,94 \mathrm{pA} / \mathrm{ms}$ und $\mathrm{im} \mathrm{WT}_{(\mathrm{n}=11)} 36,07 \pm 6,91 \mathrm{pA} / \mathrm{ms}(\mathrm{p}=0,007)$ (Abb. $3.6 /$ Tab. 7.3), wobei die maximale Steigung im $\mathrm{KO}_{(\mathrm{n}=14)}-25,55 \pm 4,71 \mathrm{pA} / \mathrm{ms}$ und $\mathrm{im} \mathrm{WT}_{(\mathrm{n}=11)}-31,56$ $\pm 6,45 p A / m s(p=0,005)$ (Abb. $3.7 /$ Tab 7.4) beträgt.

Für die darüber hinaus ausgewerteten mEPSC-Parameter können keine signifikanten Unterschiede nachgewiesen werden:

Anstiegszeit: $\quad \mathrm{KO}_{(\mathrm{n}=14)}: 2,51 \pm 0,28 \mathrm{~ms} ; \mathrm{WT}_{(\mathrm{n}=11)}: 2,37 \pm 0,14 \mathrm{~ms} ; \mathrm{p}=0,163$ (Abb. 3.7 / Tab. 7.5)

Amplitude: $\quad \mathrm{KO}_{(\mathrm{n}=14)}:-5,77 \pm 0,98 \mathrm{pA} ; \mathrm{WT}_{(\mathrm{n}=11)}:-6,42 \pm 1,19 p A ; \mathrm{p}=0,163$

(Abb. 3.8 / Tab. 7.6)

Frequenz: $\quad \mathrm{KO}_{(\mathrm{n}=14)}: 5,00 \pm 2,05 / \mathrm{s} ; \mathrm{WT}_{(\mathrm{n}=11)}: 2,80 \pm 3,87 / \mathrm{s} ; \mathrm{p}=0,147$ (Abb. 3.8 / Tab. 7.7)

Halbwertszeit: $\quad \mathrm{KO}_{(\mathrm{n}=14)}: 1,66 \pm 0,68 \mathrm{~ms} ; \mathrm{WT}_{(\mathrm{n}=11)}: 1,08 \pm 0,81 \mathrm{~ms} ; \mathrm{p}=0,059$ (Tab. 7.8)

Fläche: $\quad \mathrm{KO}_{(\mathrm{n}=14)}:-43,00 \pm 4,57 p A^{*} m s ; \mathrm{WT}_{(\mathrm{n}=11)}:-45,43 \pm 9,69 p A^{*} \mathrm{~ms} ; \mathrm{p}=0,106$

(Tab. 7.9) 

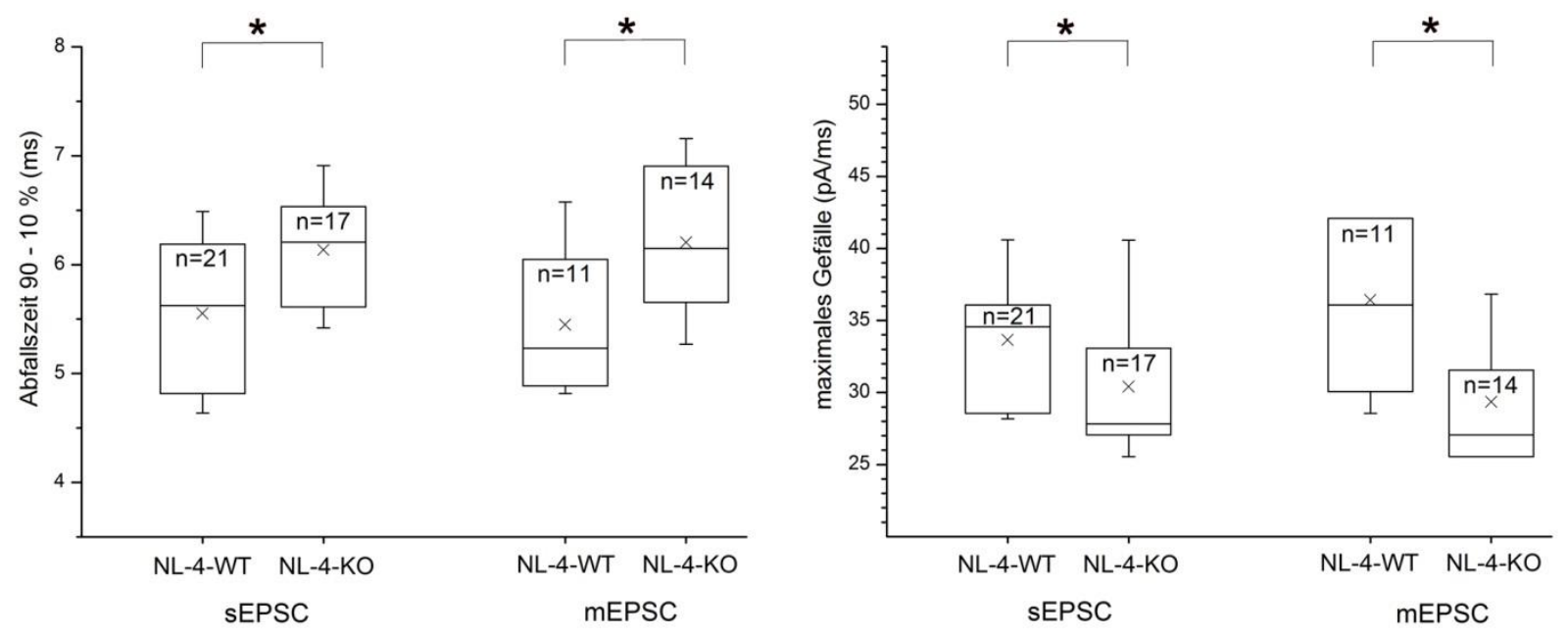

Abbildung 3.6: Abfallszeit und maximales Gefälle von sEPSC und mEPSC aller Klassen exzitatorischer Neurone

Die Boxplot-Darstellungen zeigen die ermittelten Abfallszeiten (90-10\%) sowie maximalen Gefälle für sEPSC und mEPSC der abgeleiteten NL-4-WT- und NL-4-KO-Neuronen ( $\mathrm{n}$ ). Es sind die Mediane (horizontale Linie), die 25-75\% Quartile (Box), die 10-90\% Perzentile (Antennen) und die arithmetischen Mittelwerte (Kreuz) dargestellt.

Die Abfallszeiten der sEPSC und mEPSC sind im NL-4-KO-Genotyp signifikant verlängert gegenüber der NL-4-WT-Kontrolle.

Median \pm SD für sEPSC: 5,62 $\pm 0,79$ ms für NL-4-WT und 6,21 $\pm 0,62$ ms für NL-4-KO;

Median \pm SD für mEPSC: 5,23 $\pm 0,76 \mathrm{~ms}$ für NL-4-WT und 6,15 $\pm 0,71 \mathrm{~ms}$ für NL-4-KO

Die maximalen Gefälle der sEPSC und mEPSC sind im NL-4-KO-Genotyp signifikant flacher gegenüber der NL-4-WT-Kontrolle.

Median \pm SD für sEPSC: $34,57 \pm 5,44 \mathrm{pA} / \mathrm{ms}$ für NL-4-WT und 27,81 $\pm 5,21 \mathrm{pA} / \mathrm{ms}$ für NL-4-KO;

Median \pm SD für mEPSC: $36,07 \pm 6,91 \mathrm{pA} / \mathrm{ms}$ NL-4-WT und 27,05 $\pm 4,94 \mathrm{pA} / \mathrm{ms}$ für NL-4-KO 

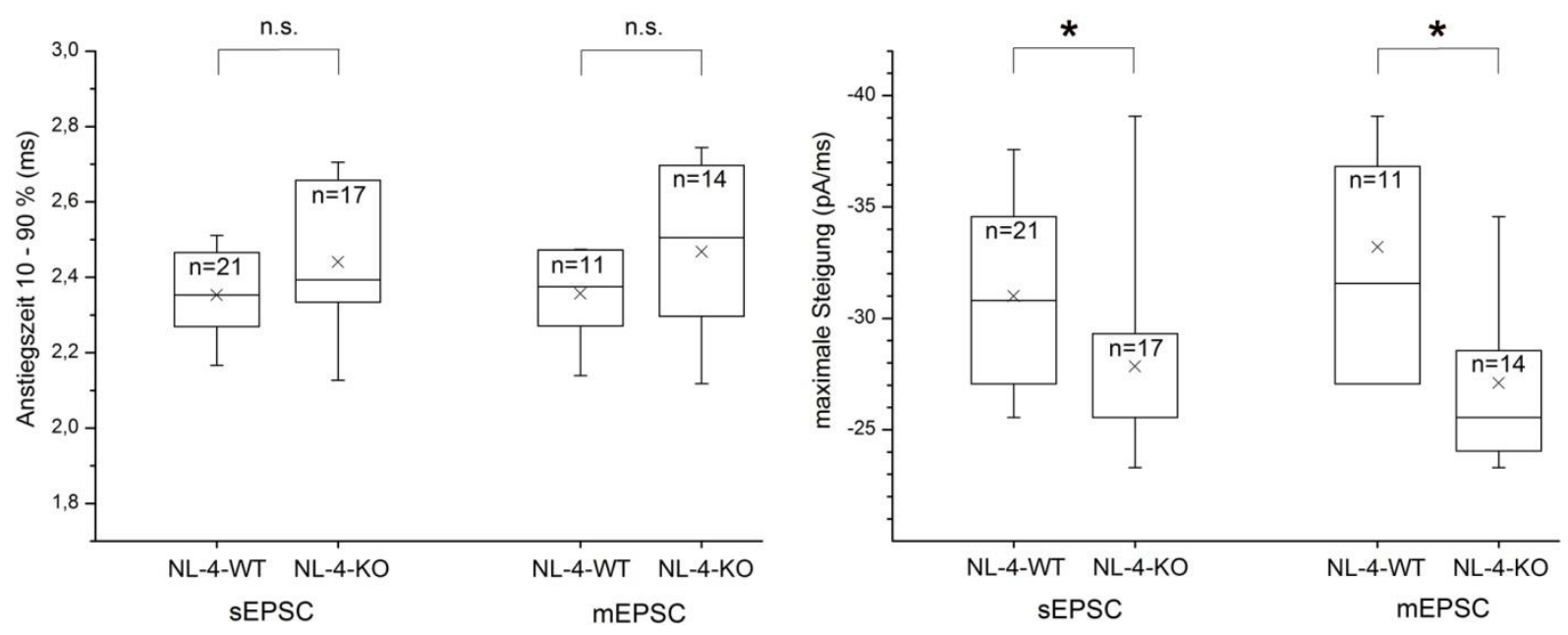
Abbildung 3.7: Anstiegszeit und maximale Steigung von sEPSC und mEPSC aller Klassen
exzitatorischer Neurone

Die Boxplot-Darstellungen zeigen die ermittelten Anstiegszeiten (10-90\%) sowie maximalen Steigungen für SEPSC und mEPSC der abgeleiteten NL-4-WT- und NL-4-KO-Neuronen (n). Es sind die Mediane (horizontale Linie), die 25-75\% Quartile (Box), die 10- 90\% Perzentile (Antennen) und die arithmetischen Mittelwerte (Kreuz) dargestellt.

Die Anstiegszeiten der sEPSC und mEPSC weisen zwischen NL-4-WT und NL-4-KO keine signifikanten Unterschiede auf.

Median \pm SD für sEPSC: $2,35 \pm 0,19$ ms für NL-4-WT und 2,39 $\pm 0,20$ ms für NL-4-KO;

Median \pm SD für mEPSC: $2,37 \pm 0,14 \mathrm{~ms}$ für NL-4-WT und 2,51 $\pm 0,28 \mathrm{~ms}$ für NL-4-KO

Die maximalen Steigungen der sEPSC und mEPSC sind im NL-4-KO-Genotyp signifikant flacher gegenüber der NL-4-WT-Kontrolle.

Median \pm SD für sEPSC: $-30,81 \pm 4,68 \mathrm{pA} / \mathrm{ms}$ für NL-4-WT und $-25,55 \pm 5,04 \mathrm{pA} / \mathrm{ms}$ für NL-4-KO;

Median \pm SD für mEPSC: $-31,56 \pm 6,45 \mathrm{pA} / \mathrm{ms}$ für NL-4-WT und $-25,55 \pm 4,71 \mathrm{pA} / \mathrm{ms}$ für NL-4-KO 

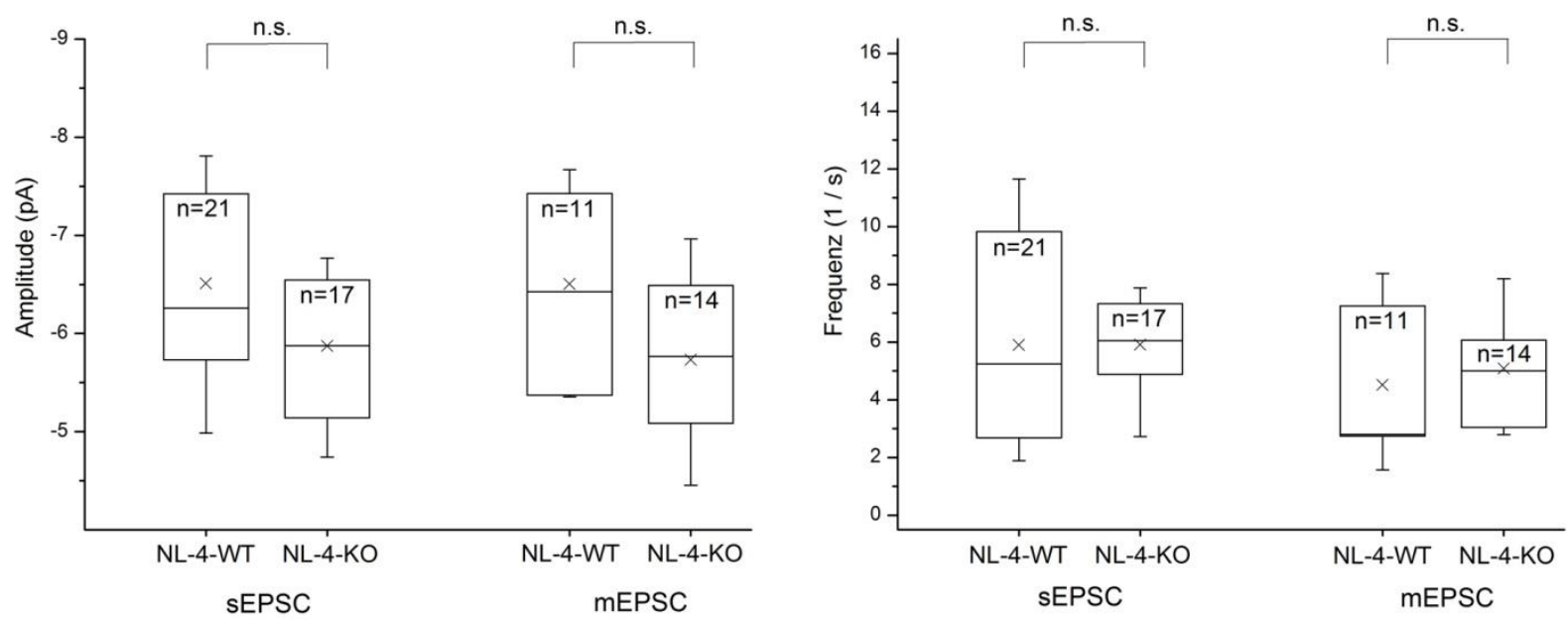

Abbildung 3.8: Amplitude und Frequenz von sEPSC und mEPSC aller Klassen exzitatorischer Neurone

Die Boxplot-Darstellungen zeigen die ermittelten Amplituden sowie Frequenzen für sEPSC und mEPSC der abgeleiteten NL-4-WT- und NL-4-KO-Neuronen (n). Es sind die Mediane (horizontale Linie), die 25-75\% Quartile (Box), die 10-90\% Perzentile (Antennen) und die arithmetischen Mittelwerte (Kreuz) dargestellt.

Die Amplituden der sEPSC und mEPSC weisen zwischen NL-4-WT und NL-4-KO keine signifikanten Unterschiede auf.

Median \pm SD für sEPSC: $-6,26 \pm 1,19 p A$ für NL-4-WT und $-5,88 \pm 0,85 p A$ für NL-4-KO;

Median \pm SD für mEPSC: $-6,42 \pm 1,19 p A$ für NL-4-WT und $-5,77 \pm 0,98 p A$ für NL-4-KO

Auch die Frequenzen der sEPSC und mEPSC weisen zwischen NL-4-WT und NL-4-KO keine signifikanten Unterschiede auf.

Median \pm SD für sEPSC: 5,24 $\pm 4,08 / \mathrm{s}$ für NL-4-WT und 6,04 $\pm 1,84 / \mathrm{s}$ für NL-4-KO;

Median \pm SD für mEPSC: $2,80 \pm 3,87 / \mathrm{s}$ für NL-4-WT und 5,00 $\pm 2,05 / \mathrm{s}$ für NL-4-KO

\subsubsection{Isolierte Auswertung bedornter Sternzellen}

Neben der zusammengefassten Analyse aller exzitatorischer Neurone wurden in einer Subanalyse ausschließlich die abgeleiteten bedornten Sternzellen, welche die größte Population der morphologisch identifizierten Zellen darstellten, ausgewertet und zwischen den Genotypen NL-4-WT und NL-4-KO verglichen. Damit sollte sichergestellt werden, dass durch das Zusammenfassen aller exzitatorischen Neurone (bedornte Sternzellen + Sternpyramidenzellen + Pyramidenzellen) keine signifikanten Unterschiede maskiert wurden.

Die Analyse zeigt in bedornten Sternzellen des NL-4-KO-Genotyps signifikant verlängerte Abfallszeiten, sowohl in der Auswertung der sEPSC $\left(\mathrm{KO}_{(\mathrm{n}=12)}: 6,25 \pm 0,55 \mathrm{~ms} \mathrm{WT}_{(\mathrm{n}=9)}: 5,07\right.$ $\pm 0,57 m s ; p=0,006)$, als auch in der Auswertung der mEPSC $\left(\mathrm{KO}_{(\mathrm{n}=10)}: 5,94 \pm 0,70 \mathrm{~ms} \mathrm{WT}_{(\mathrm{n}=5)}: 4,89\right.$ $\pm 0,31 \mathrm{~ms} ; \mathrm{p}=0,008$ ) (Abb. 3.9 / Tab. 7.10). 
Weiterhin lässt sich im KO-Genotyp eine signifikant verlängerte Halbwertszeit der sEPSC mit $1,81 \pm 0,66 \mathrm{~ms}$ im $\mathrm{KO}_{(\mathrm{n}=12)}$ gegenüber $1,37 \pm 0,48 \mathrm{~ms}$ im $\mathrm{WT}_{(\mathrm{n}=9)}(\mathrm{p}=0,030)$ bzw. der mEPSC mit $1,54 \pm 0,77 \mathrm{~ms}$ im $\mathrm{KO}_{(\mathrm{n}=10)}$ gegenüber 0,88 $\pm 0,21 \mathrm{~ms}$ im $\mathrm{WT}_{(\mathrm{n}=5)}(p=0,006)$ (Abb. 3.9 / Tab. 7.11) zeigen.

Der Parameter maximales Gefälle zeigt in der Auswertung der sEPSC mit 29,68 $\pm 5,03 p A / m s ~ i m$ $\mathrm{KO}_{(\mathrm{n}=12)}$ und $35,32 \pm 5,59 \mathrm{pA} / \mathrm{ms}$ im $\mathrm{WT}_{(\mathrm{n}=9)}$ bei einem $\mathrm{p}$-Wert von 0,055 keinen signifikanten Unterschied, jedoch einen gleichgerichteten Trend zu dem in der mEPSC-Auswertung in $\mathrm{NL}-4-\mathrm{KO}$ mit $\mathrm{p}=0,043$ signifikant flacheren Gefälle mit 30,06 $\pm 5,54 \mathrm{pA} / \mathrm{ms}$ im KO $\mathrm{K}_{(\mathrm{n}=10)}$ und 36,07 $\pm 8,22 \mathrm{pA} / \mathrm{ms}$ im $\mathrm{WT}_{(\mathrm{n}=5)}$ (Abb. 3.9 / Tab. 7.12).

Vergleichbar dazu zeigt sich in der Auswertung der sEPSC in NL-4-KO eine signifikant flachere maximale Steigung mit $-26,30 \pm 4,71 \mathrm{pA} / \mathrm{ms}$ im $\mathrm{KO}_{(\mathrm{n}=12)}$ und $-30,81 \pm 4,53 \mathrm{pA} / \mathrm{ms}$ im $\mathrm{WT}_{(\mathrm{n}=9)}$ $(p=0,030)$, während sich in der Auswertung der mEPSC lediglich ein gleichgerichteter Trend nachweisen lässt $\left(\mathrm{KO}_{(\mathrm{n}=10)}:-26,68 \pm 5,44 \mathrm{pA} / \mathrm{ms} \mathrm{WT}_{(\mathrm{n}=5)}:-31,56 \pm 8,17 \mathrm{pA} / \mathrm{ms} ; \mathrm{p}=0,058\right)$

(Abb. 3.9 / Tab. 7.13).

Für die darüber hinaus ausgewerteten EPSC-Parameter können keine signifikanten Unterschiede nachgewiesen werden:

Anstiegszeit: $\quad \operatorname{sEPSC~KO} \mathrm{O}_{(\mathrm{n}=12)}: 2,39 \pm 0,21 \mathrm{~ms} ; \mathrm{WT}_{(\mathrm{n}=9)}: 2,35 \pm 0,16 \mathrm{~ms} ; \mathrm{p}=0,500$ mEPSC KO $(n=10): 2,39 \pm 0,31 m s ; \mathrm{WT}_{(n=5)}: 2,33 \pm 0,12 \mathrm{~ms} ; \mathrm{p}=0,582$ (Tab. 7.14)

Amplitude: $\quad$ sEPSC KO ${ }_{(n=12)}:-6,29 \pm 0,86 p A ; W_{(n=9)}:-6,54 \pm 1,26 p A ; p=0,456$ $\operatorname{mEPSC} \mathrm{KO}_{(\mathrm{n}=10)}:-6,40 \pm 0,95 p A ; \mathrm{WT}_{(\mathrm{n}=5)}:-6,82 \pm 1,08 p A ; p=0,159$ (Tab. 7.15)

Frequenz: $\quad \quad \quad \quad \operatorname{SEPSC~KO}_{(\mathrm{n}=12)}: 5,13 \pm 2,03 / \mathrm{s} ; \mathrm{WT}_{(\mathrm{n}=9)}: 2,80 \pm 2,80 / \mathrm{s} ; \mathrm{p}=0,110$ mEPSC KO $\mathrm{K}_{(\mathrm{n}=10)}: 5,00 \pm 1,93 / \mathrm{s} ; \mathrm{WT}_{(\mathrm{n}=5)}: 2,77 \pm 2,38 / \mathrm{s} ; \mathrm{p}=0,159$ (Tab. 7.16)

Fläche: $\operatorname{sEPSC~KO}_{(n=12)}:-43,87 \pm 8,08 p A^{*} m s ; \mathrm{WT}_{(n=9)}:-45,59 \pm 9,59 p A^{*} m s ; p=0,337$ mEPSC KO $(n=10):-43,81 \pm 4,71 p{ }^{*} m s ; \mathrm{WT}_{(\mathrm{n}=5)}$ : $-45,43 \pm 10,05 p{ }^{*} \mathrm{~ms} ; \mathrm{p}=0,358$ (Tab. 7.17) 

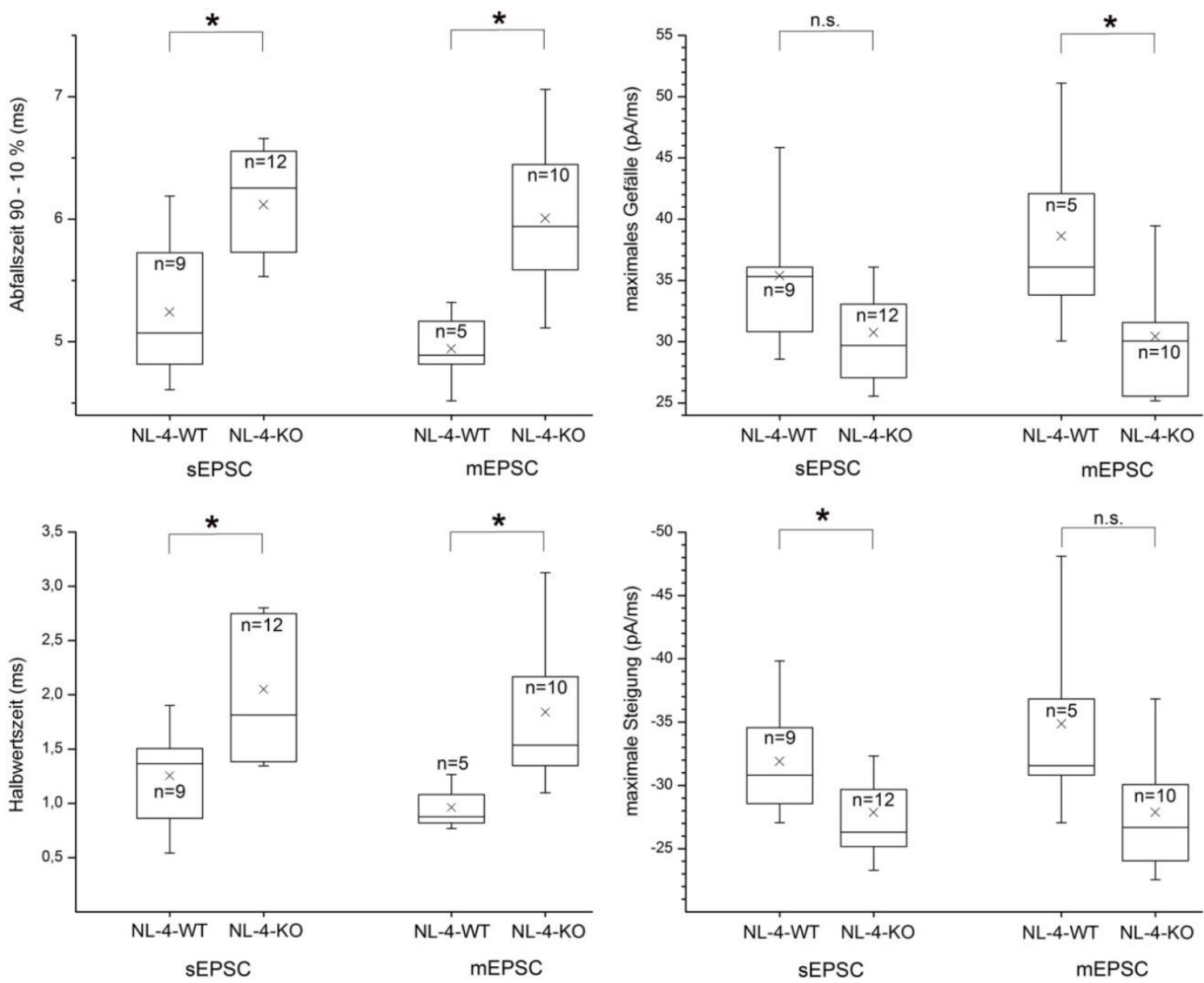

Abbildung 3.9: Abfallszeit, maximales Gefälle, Halbwertszeit und maximale Steigung von sEPSC und mEPSC der bedornten Sternzellen

Die Boxplot-Darstellungen zeigen die ermittelten Abfallszeiten (90-10\%), maximalen Gefälle, Halbwertszeiten sowie maximalen Steigungen für sEPSC und mEPSC von bedornten NL-4-WT- und NL4-KO-Sternzellen (n). Es sind die Mediane (horizontale Linie), die 25-75\% Quartile (Box), die 10-90\% Perzentile (Antennen) und das arithmetische Mittel (Kreuz) dargestellt.

Die Abfallszeiten der sEPSC und mEPSC sind im NL-4-KO-Genotyp signifikant verlängert gegenüber der NL-4-WT-Kontrolle.

Median \pm SD für sEPSC: $5,07 \pm 0,57 \mathrm{~ms}$ für NL-4-WT und 6,25 $\pm 0,55 \mathrm{~ms}$ für NL-4-KO;

Median \pm SD für mEPSC: 4,89 $\pm 0,31 \mathrm{~ms}$ für NL-4-WT und 5,94 $\pm 0,70 \mathrm{~ms}$ für NL-4-KO

Die Halbwertszeiten der sEPSC und mEPSC sind im NL-4-KO-Genotyp signifikant verlängert gegenüber der NL-4-WT-Kontrolle.

Median \pm SD für sEPSC: $1,37 \pm 0,48$ ms für NL-4-WT und $1,81 \pm 0,66$ ms für NL-4-KO;

Median \pm SD für mEPSC: $0,88 \pm 0,21 \mathrm{~ms}$ für NL-4-WT und 1,54 $\pm 0,77 \mathrm{~ms}$ für NL-4-KO

Die maximalen Gefälle der sEPSC weisen einen gleichgerichteten Trend zu dem in der mEPSCAuswertung signifikanten Unterschied zwischen NL-4-WT und NL-4-KO auf.

Median \pm SD für sEPSC: $35,32 \pm 5,59 \mathrm{pA} / \mathrm{ms}$ für NL-4-WT und 29,68 $\pm 5,03 \mathrm{pA} / \mathrm{ms}$ für NL-4-KO;

Median \pm SD für mEPSC: $36,07 \pm 8,22 \mathrm{pA} / \mathrm{ms}$ für NL-4-WT und 30,06 $\pm 5,54 \mathrm{pA} / \mathrm{ms}$ für NL-4-KO

Die maximalen Steigungen der sEPSC sind im NL-4-KO-Genotyp signifikant flacher gegenüber der NL-4WT-Kontrolle, während die mEPSC-Auswertung nur einen gleichgerichteten Trend zeigt.

Median \pm SD für sEPSC: $-30,81 \pm 4,53 \mathrm{pA} / \mathrm{ms}$ für NL-4-WT und -26,30 $\pm 4,71 \mathrm{pA} / \mathrm{ms}$ für NL-4-KO;

Median \pm SD für mEPSC: $-31,56 \pm 8,17 \mathrm{pA} / \mathrm{ms}$ für NL-4-WT und $-26,68 \pm 5,44 \mathrm{pA} / \mathrm{ms}$ für NL-4-KO 
Die Tabelle 3.1 stellt die oben aufgeführten durch statistische Vergleiche zwischen NL-4-WTund NL-4-KO-Neuronen bestimmten p-Werte, abhängig vom ausgewerteten Neuronenkollektiv (alle exzitatorischen Neurone der Schicht IV/Subanalyse der bedornten Sternzellen) und den Ableitbedingungen (sEPSC/ mEPSC), nochmals zusammengefasst dar.

\section{Tabelle 3.1: Statistik: p-Werte}

Tabellarische Darstellung der durch statistische Vergleiche zwischen NL-4-WT- und NL-4-KO-Neuronen bestimmten $p$-Werte, abhängig vom ausgewerteten Neuronenkollektiv (exzitatorische Neurone / bedornten Sternzellen) und den Ableitungsbedingungen (sEPSC / mEPSC). Signifikante p-Werte sind hervorgehoben.

\begin{tabular}{|c|c|c|c|c|}
\hline & \multicolumn{2}{|c|}{$\begin{array}{c}\text { Exzitatorische Schicht IV } \\
\text { Neurone }\end{array}$} & \multicolumn{2}{|c|}{ Bedornte Sternzellen } \\
\hline & sEPSC & mEPSC & sEPSC & mEPSC \\
\hline Amplitude & 0,159 & 0,163 & 0,456 & 0,159 \\
\hline Anstiegszeit & 0,229 & 0,163 & 0,500 & 0,582 \\
\hline Abfallszeit & 0,040 & 0,017 & 0,006 & 0,008 \\
\hline Halbwertszeit & 0,252 & 0,059 & 0,030 & 0,006 \\
\hline Maximale Steigung & 0,016 & 0,005 & 0,030 & 0,058 \\
\hline Maximales Gefälle & 0,047 & 0,007 & 0,055 & 0,043 \\
\hline Fläche & 0,056 & 0,106 & 0,337 & 0,358 \\
\hline Frequenz & 0,428 & 0,147 & 0,110 & 0,159 \\
\hline
\end{tabular}




\subsection{Elektrophysiologische Charakteristika}

Alle abgeleiteten Zellen wurden als exzitatorische Neurone charakterisiert. Die morphologisch als bedornte Sternzellen identifizierten Neurone wurden zusätzlich hinsichtlich dezidierter elektrophysiologischer Zelleigenschaften ausgewertet. Dabei wurden passive Zelleigenschaften (Ruhemembranpotential, Membranzeitkonstante, Eingangswiderstand, Membrankapazität) sowie ihre AP- (Latenzzeit, Feuerschwelle, Amplitude, Zeit bis Amplitudenmaximum, maximale Steigung, Spikeweite) und NachhyperpolarisationCharakteristik (AHP-Amplitude, AHP-Weite) analysiert und zwischen NL-4-WT- und NL-4-KONeuronen verglichen (siehe Abschnitt 2.2.3). Es zeigten sich in keinem der analysierten Parameter signifikante Unterschiede der intrinsischen elektrophysiologischen Merkmale zwischen bedornten Sternzellen des Genotyps NL-4-WT und NL-4-KO (Tab. 3.2).

Tabelle 3.2: Statistische Gegenüberstellung aktiver und passiver elektrophysiologischer Eigenschaften zwischen bedornten Sternzellen des Genotyps NL-4-WT und NL-4-KO

\begin{tabular}{|c|c|c|c|c|c|c|c|c|c|}
\hline \multirow[b]{2}{*}{$\begin{array}{l}\text { Bedornte } \\
\text { Sternzellen }\end{array}$} & \multicolumn{4}{|c|}{ NL-4-WT $(n=9)$} & \multicolumn{4}{|c|}{ NL-4-KO $(n=12)$} & \multirow[b]{2}{*}{$\begin{array}{c}p- \\
\text { Werte }\end{array}$} \\
\hline & $\begin{array}{l}\text { Arithme- } \\
\text { tisches } \\
\text { Mittel }\end{array}$ & Median & $\begin{array}{l}\text { Standard- } \\
\text { abweich- } \\
\text { ung }\end{array}$ & $\begin{array}{l}\text { Stan- } \\
\text { dard- } \\
\text { fehler }\end{array}$ & $\begin{array}{c}\text { Arithme- } \\
\text { tisches } \\
\text { Mittel }\end{array}$ & Median & $\begin{array}{l}\text { Standard- } \\
\text { abweich- } \\
\text { ung }\end{array}$ & $\begin{array}{l}\text { Stan- } \\
\text { dard- } \\
\text { fehler }\end{array}$ & \\
\hline $\begin{array}{l}\text { Ruhemembran- } \\
\text { potential (mV) }\end{array}$ & $-72,86$ & $-73,15$ & 3,04 & 1,01 & $-69,82$ & $-70,39$ & 2,96 & 0,85 & 0,06 \\
\hline $\begin{array}{l}\text { Membranzeit- } \\
\text { konstante (ms) }\end{array}$ & 14,97 & 16,78 & 3,44 & 1,15 & 20,17 & 18,98 & 7,05 & 2,04 & 0,07 \\
\hline $\begin{array}{l}\text { Eingangswider- } \\
\text { stand }(\mathrm{M} \Omega)\end{array}$ & 223,91 & 203,84 & 70,85 & 23,62 & 288,96 & 290,35 & 69,93 & 20,19 & 0,06 \\
\hline $\begin{array}{l}\text { Membrankapa- } \\
\text { zität (pF) }\end{array}$ & 70,52 & 67,06 & 19,56 & 6,52 & 69,66 & 70,41 & 16,66 & 4,81 & 0,97 \\
\hline $\begin{array}{l}\text { Rheobase } \\
(\mathrm{pA})\end{array}$ & 86,01 & 80,52 & 38,20 & 12,73 & 63,93 & 70,49 & 25,23 & 7,28 & 0,21 \\
\hline AP-Latenz (ms) & 260,74 & 121,33 & 284,21 & 94,74 & 213,39 & 135,94 & 208,47 & 60,18 & 0,97 \\
\hline $\begin{array}{l}\text { Feuerschwelle } \\
(\mathrm{mV})\end{array}$ & $-32,97$ & $-31,14$ & 5,18 & 1,73 & $-31,90$ & $-32,38$ & 1,97 & 0,57 & 0,97 \\
\hline $\begin{array}{l}\text { AP-Amplitude } \\
(\mathrm{mV})\end{array}$ & 62,66 & 60,42 & 10,72 & 3,57 & 65,73 & 65,85 & 3,95 & 1,14 & 0,55 \\
\hline $\begin{array}{l}\text { Zeit bis } \\
\text { Amplituden- } \\
\text { maximum (ms) }\end{array}$ & 0,79 & 0,74 & 0,19 & 0,06 & 0,73 & 0,71 & 0,08 & 0,02 & 0,64 \\
\hline $\begin{array}{l}\text { Maximale } \\
\text { Steigung (V/s) }\end{array}$ & 199,42 & 183,56 & 66,65 & 22,22 & 209,66 & 206,81 & 19,81 & 5,72 & 0,55 \\
\hline AP-Weite (ms) & 1,00 & 0,99 & 0,11 & 0,04 & 0,94 & 0,95 & 0,06 & 0,02 & 0,10 \\
\hline $\begin{array}{l}\text { AHP Amplitude } \\
\text { (mV) }\end{array}$ & $-20,69$ & $-20,19$ & 3,16 & 1,05 & $-20,79$ & $-20,72$ & 2,93 & 0,84 & 0,86 \\
\hline AHP Weite (ms) & 121,96 & 109,56 & 52,96 & 17,65 & 137,41 & 124,60 & 63,36 & 18,29 & 0,55 \\
\hline
\end{tabular}




\subsection{AMPA-Rezeptor-vermittelte EPSC}

Alle elektrophysiologischen Experimente wurden bei einem Haltepotential von $-70 \mathrm{mV}$, nahe dem Gleichgewichtspotential für Chlorid durchgeführt. Das Gleichgewichtspotential eines spezifischen lons kann mit Hilfe der Nernst-Gleichung bei bekannten intrazellulären und extrazellulären lonenkonzentrationen berechnet werden.

Nernst-Gleichung: $\quad E=\frac{R^{*} T}{z^{*} F} * \ln \frac{C_{i}}{C_{e}}$

(E-ionenspezifisches Gleichgewichtspotential [V], R-universelle Gaskonstante $\left[\mathrm{J}^{*} \mathrm{~mol}^{-1} * \mathrm{~K}^{-1}\right], \mathrm{T}$ - Temperatur $[\mathrm{K}], \mathrm{z}$ - Ionenvalenz, $\mathrm{F}$ - Faradaykonstante $\left[\mathrm{C}^{*} \mathrm{~mol}^{-1}\right]$, $\mathrm{c}_{\mathrm{i}}$ - intrazelluläre lonenkonzentration $[\mathrm{M}], \mathrm{c}_{\mathrm{e}}$ - extrazelluläre lonenkonzentration [M]).

Für die verwendete Pipettenlösung mit einer Chloridkonzentration von $9 \mathrm{mM}\left(\mathrm{c}_{\mathrm{i}}\right)$ und der verwendeten ACSF-Lösung mit einer Chloridkonzentration von 133,5mM ( $c_{e}$ ) (siehe Abschnitt 2.5) ergibt die Nernst-Gleichung ein Chlorid-Gleichgewichtspotential $\left(E_{C l}{ }^{-}\right)$von $-70,93 m V$ (für $\mathrm{T}=32^{\circ} \mathrm{C}=305,15 \mathrm{~K}$ ).

Durch das Angleichen des Haltepotentials $(-70 \mathrm{mV})$ an das ionenspezifische Gleichgewichtspotential ( $\mathrm{E}_{\mathrm{Cl}}$; siehe Abschnitt 2.2.2) wurde die auf $\mathrm{Cl}^{-}$-lonen wirkende, zelleinwärtsgerichtete chemische Triebkraft elektrisch kompensiert und damit inhibitorischen $\mathrm{Cl}^{-}-$Membranströmen vorgebeugt.

Abbildung 3.10 zeigt exemplarisch Spuren eines NL-4-WT- und eines NL-4-KO-Neurons unter Kontrollbedingungen und nach Einwaschen des AMPA-Rezeptorantagonisten NBQX. Die unter Kontrollbedingungen detektierbaren, durch kurzzeitiges Öffnen von Rezeptorkanälen verursachten SEPSC, waren infolge des Einwaschens von NBQX nicht mehr gegenüber dem Grundrauschen abgrenzbar. Es handelt sich demzufolge bei den unter Kontrollbedingungen aufgezeichneten und ausgewerteten SEPSC um AMPA-Rezeptor-vermittelte glutamaterge Membranströme. IPSC, welche sich entgegengesetzt zu EPSC durch eine positive Amplitude auszeichnen, waren weder unter Kontrollbedingungen noch nach Einwaschen von 10 $\mu \mathrm{M}$ NBQX detektierbar. Die ausgewerteten EPSC können demzufolge keiner Subtraktion mit interferierenden, gleichzeitig auftretenden, entgegengesetzten IPSC unterliegen. Sie sind rein exzitatorischen Ursprungs. 
myindy

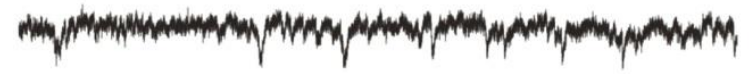

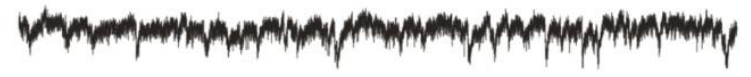

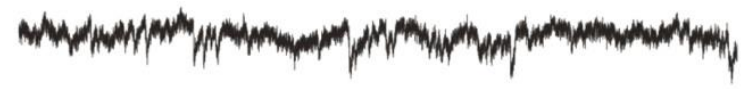

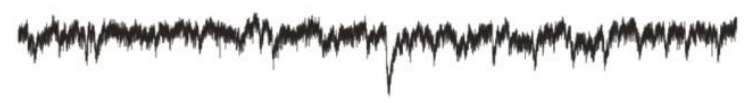

Kontrolle

$\mathrm{NL}-4-\mathrm{KO}$

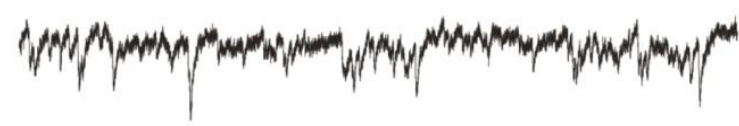

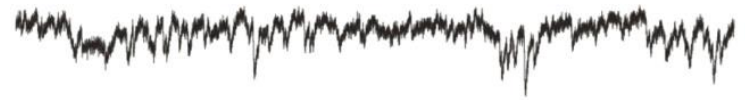

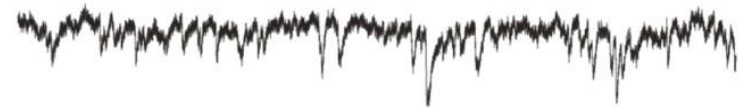

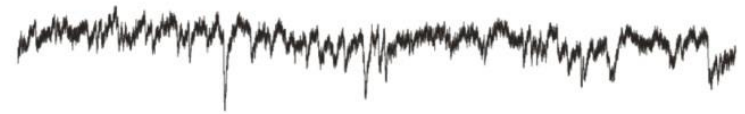

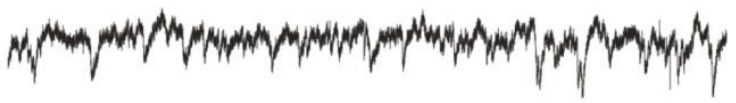

$\bigsqcup^{10 \mathrm{pA}} 0.2 \mathrm{~s}$

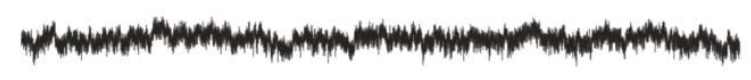

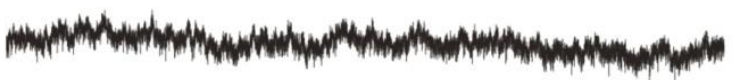

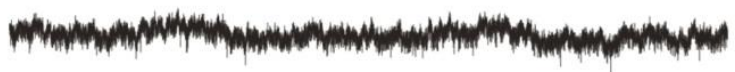

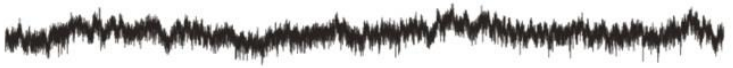

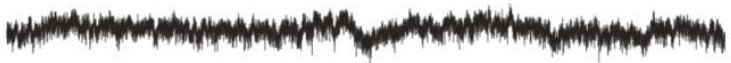

NBQX

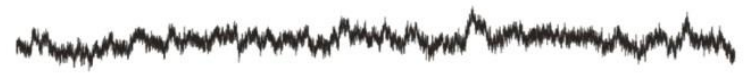

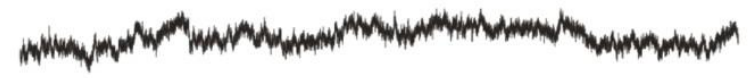

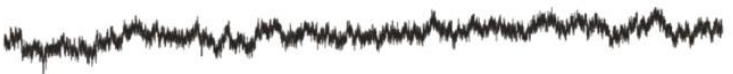

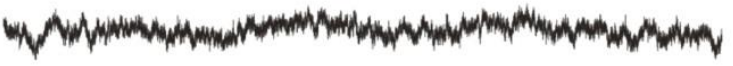

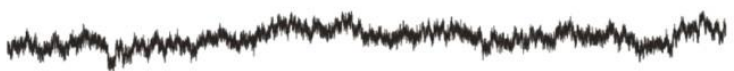

NBQX

Abbildung 3.10: Originalspuren eines NL-4-WT- und NL-4-KO-Neurons unter Kontrollbedingungen und nach Einwaschen von NBQX

Je Genotyp sind fünf zufällig ausgewählte Spuren einer Länge von $2 s$ unter Kontrollbedingungen und nach Einwaschen von NBQX dargestellt.

Unter Kontrollbedingungen registrierte sEPSC sind durch Zusatz von NBQX vollständig unterdrückbar. Inhibitorische IPSC, gekennzeichnet durch positive Amplituden, sind weder unter Kontrollbedingungen noch nach Einwaschen von 10 $\mathrm{MM}$ NBQX nachweisbar. Bei den ausgewerteten sEPSC handelt es sich entsprechend um AMPA-Rezeptor-vermittelte, von IPSC unabhängige, glutamaterge Membranströme. 
Um den exzitatorischen Ursprung der ausgewerteten EPSC zu bestätigen, wurden zusätzliche Untersuchungen mit Hilfe von Gabazine, einem $G_{A B A}$-Rezeptorantagonisten, der inhibitorische GABAerge $\mathrm{Cl}^{-}$-Ströme unterdrückt, durchgeführt. Dabei wurden die Membranströme jeweils eines NL-4-WT- und eines NL-4-KO-Neurons unter Kontrollbedingungen und nach Einwaschen von $20 \mu \mathrm{M}$ Gabazine abgeleitet (siehe Abschnitt 2.2.2) und die detektierten EPSC im Hinblick auf die Parameter Amplitude, Anstiegszeit (10-90\%), Abfallszeit (90-10\%), maximale Steigung und maximales Gefälle differenziert ausgewertet (siehe Abschnitt 2.4.1). Die Auswertung umfasste die Berechnung des arithmetischen Mittels, des Medians, der Standardabweichung und des Standardfehlers der einzelnen EPSC-Parameter innerhalb jedes Genotyps und den Vergleich zwischen Kontrollbedingungen und dem Zustand nach Einwaschen von Gabazine.

Im NL-4-WT-Neuron sind die Amplituden unter Kontrollbedingungen mit $-5,61 \pm 1,50 p A$ bzw. $-5,77 \pm 0,05 p A^{2}$ vergleichbar mit den unter Gabazine erhobenen Werten mit -5,65 $\pm 1,78$ pA bzw. $-5,91 \pm 0,08$ pA (Abb. 3.11 / Tab. 7.18).

Analog dazu sind im NL-4-WT-Neuron die Mittelwerte und Verteilungen der restlich untersuchten Parameter nach Applikation von Gabazine vergleichbar zu den Kontrollbedingungen:

Anstiegszeit

$\underline{\text { maximale Steigung }}$

$\underline{\text { Abfallszeit }}$

$\underline{\text { maximales Gefälle }}$
Kontrolle: $2,58 \pm 1,08 \mathrm{~ms} ; 2,73 \pm 0,03 \mathrm{~ms}$

Gabazine: 2,53 $\pm 1,07 \mathrm{~ms} ; 2,71 \pm 0,05 \mathrm{~ms}$ (Abb. 3.12 /Tab. 7.19),

Kontrolle: $-24,80 \pm 6,93 \mathrm{pA} / \mathrm{ms} ;-25,15 \pm 0,21 \mathrm{pA} / \mathrm{ms}$

Gabazine: $-26,30 \pm 7,70 \mathrm{pA} / \mathrm{ms} ;-25,93 \pm 0,34 \mathrm{pA} / \mathrm{ms}$

(Abb. 3.12 / Tab. 7.20),

Kontrolle: $6,31 \pm 3,07 \mathrm{~ms} ; 6,73 \pm 0,10 \mathrm{~ms}$

Gabazine: 6,03 $\pm 3,14 \mathrm{~ms} ; 6,47 \pm 0,15 \mathrm{~ms}$ (Abb. 3.13 / Tab. 7.21)

Kontrolle: $27,80 \pm 7,21 \mathrm{pA} / \mathrm{ms} ; 27,91 \pm 0,23 \mathrm{pA} / \mathrm{ms}$

Gabazine: $28,56 \pm 8,38 \mathrm{pA} / \mathrm{ms} ; 28,50 \pm 0,40 \mathrm{pA} / \mathrm{ms}$

(Abb. 3.13 / Tab. 7.22)

\footnotetext{
${ }^{2}$ Schreibweise dieses und folgender Ergebnisse Median \pm Standardabweichung; arithmetisches Mittel \pm Standardfehler
} 
In den untersuchten Parametern des NL-4-KO-Neurons zeigen sich gleichermaßen keine relevanten Unterschiede in den Mittelwerten und Verteilungen nach Gabazine-Applikation gegenüber den Kontrollmessungen:

$\underline{\text { Amplitude }}$

$\underline{\text { Anstiegszeit }}$

$\underline{\text { maximale Steigung }}$

Abfallszeit

maximales Gefälle
Kontrolle: $-5,86 \pm 1,89 p A ;-6,32 \pm 0,05 p A$

Gabazine: $-5,83 \pm 2,69 p A ;-6,24 \pm 0,08 p A$ (Abb. 3.11 / Tab. 7.18)

Kontrolle: $2,33 \pm 0,97 \mathrm{~ms} ; 2,41 \pm 0,02 \mathrm{~ms}$

Gabazine: 2,40 $\pm 1,02 \mathrm{~ms} ; 2,54 \pm 0,03 \mathrm{~ms}$ (Abb. 3.12 / Tab. 7.19)

Kontrolle: $-23,30 \pm 5,26 \mathrm{pA} / \mathrm{ms} ;-23,92 \pm 0,13 \mathrm{pA} / \mathrm{ms}$

Gabazine: $-23,30 \pm 5,11 \mathrm{pA} / \mathrm{ms} ;-24,10 \pm 0,15 \mathrm{pA} / \mathrm{ms}$

(Abb. 3.12 / Tab. 7.20)

Kontrolle: $5,42 \pm 2,59 \mathrm{~ms} ; 5,87 \pm 0,07 \mathrm{~ms}$

Gabazine: 5,47 $\pm 2,76 \mathrm{~ms} ; 5,97 \pm 0,09 \mathrm{~ms}$ (Abb. 3.13 / Tab. 7.21)

Kontrolle: $26,30 \pm 5,39 \mathrm{pA} / \mathrm{ms} ; 26,37 \pm 0,14 \mathrm{pA} / \mathrm{ms}$

Gabazine: $26,30 \pm 4,72 \mathrm{pA} / \mathrm{ms} ; 26,90 \pm 0,15 \mathrm{pA} / \mathrm{ms}$

(Abb. 3.13 / Tab. 7.22)

Diese Ergebnisse belegen eine Unabhängigkeit der ausgewerteten EPSC-Parameter von einem $\mathrm{GABA}_{\mathrm{A}}$-Rezeptor vermittelten inhibitorischen Einfluss. Sie bestätigen damit den rein exzitatorischen Ursprung der ausgewerteten sEPSC. 


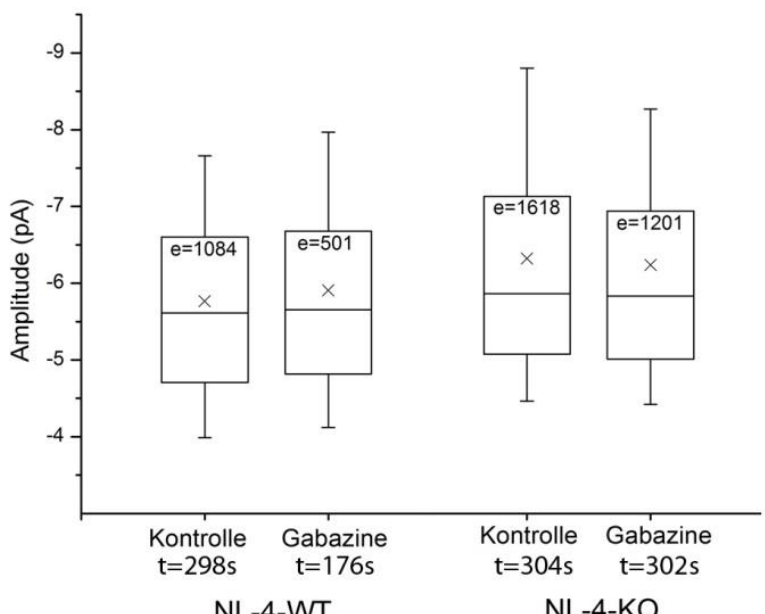

\section{Abbildung 3.11: EPSC-Amplitude eines NL-4-WT- und eines NL-4-KO-Neurons unter Kontrollbedingungen und nach Einwaschen von Gabazine}

Die Boxplot-Darstellungen zeigen die über die Ableitzeiten ( $t$ ) ermittelten Amplituden (e) eines NL-4-WT- und eines NL-4-KO-Neurons unter Kontrollbedingungen und nach Einwaschen von Gabazine. Die Mittelwerte sind als Mediane (horizontale Linie) und arithmetische Mittel (Kreuz), die Verteilungen als 25-75\% Quartile (Box) bzw. 10-90\% Perzentile (Antennen) dargestellt.

Die Amplitude zeigt weder im NL-4-WT- noch im NL-4-KO-Neuron relevante Unterschiede im Mittelwert oder in der Verteilung zwischen den Kontroll- und Gabazine-Messungen.

Median \pm SD für WT: $-5,61 \pm 1,50 p A$ in Kontrolle und $-5,65 \pm 1,78 p A$ unter Gabazine

Arithmetisches Mittel \pm SE für WT: $-5,77 \pm 0,05 p A$ in Kontrolle und $-5,91 \pm 0,08 p A$ unter Gabazine Median \pm SD für KO: $-5,86 \pm 1,89 \mathrm{pA}$ in Kontrolle und $-5,83 \pm 2,69 \mathrm{pA}$ unter Gabazine

Arithmetisches Mittel \pm SE für KO: $-6,32 \pm 0,05 p A$ in Kontrolle und $-6,24 \pm 0,08 p A$ unter Gabazine 

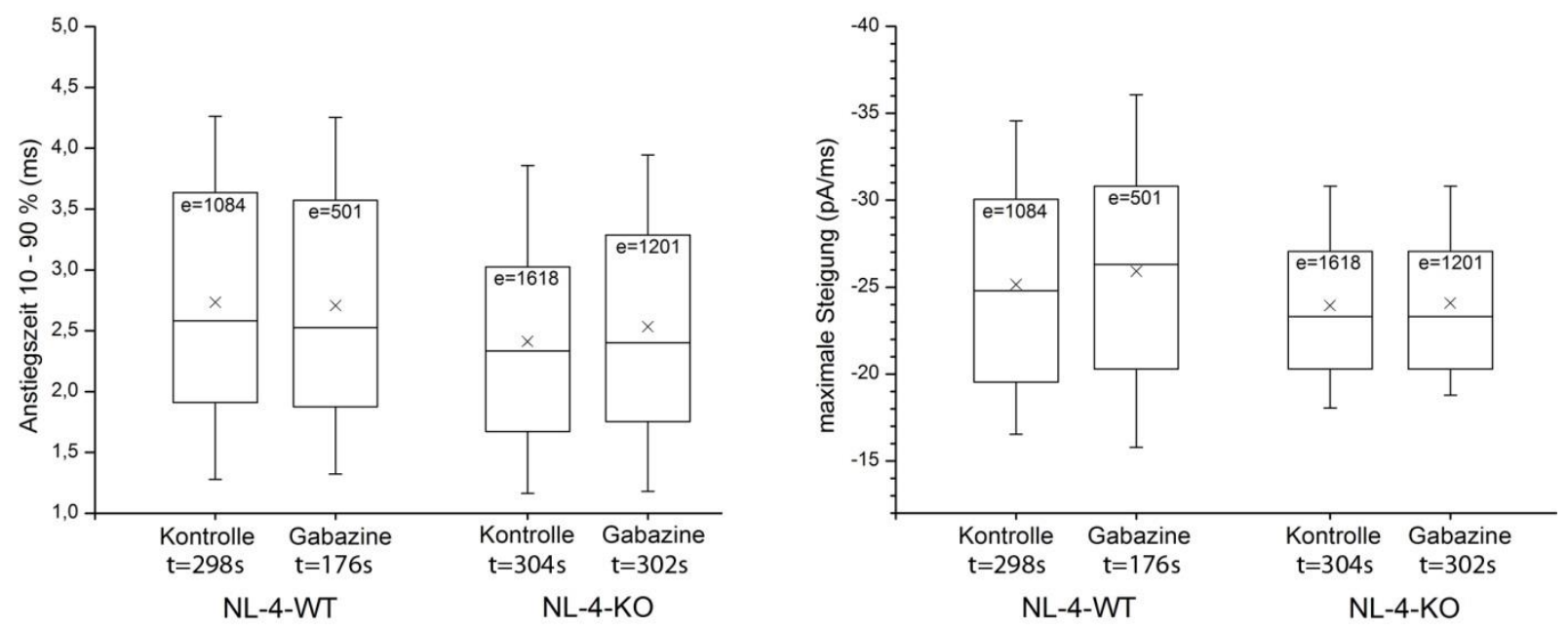

\section{Abbildung 3.12: EPSC-Anstiegszeit und maximale Steigung eines NL-4-WT- und eines NL-4-KO- Neurons unter Kontrollbedingungen und nach Einwaschen von Gabazine}

Die Boxplot-Darstellungen zeigen die über die Ableitzeiten ( $t$ ) ermittelten Anstiegszeiten bzw. maximale Steigungen (e) eines NL-4-WT- und eines NL-4-KO-Neurons unter Kontrollbedingungen und nach Einwaschen von Gabazine. Die Mittelwerte sind als Mediane (horizontale Linie) und arithmetische Mittel (Kreuz), die Verteilungen als 25-75\% Quartile (Box) bzw. 10-90\% Perzentile (Antennen) dargestellt.

Die Anstiegszeit zeigt weder im NL-4-WT- noch im NL-4-KO-Neuron relevante Unterschiede im Mittelwert oder der Verteilung zwischen den Kontroll- und Gabazine-Messungen.

Median \pm SD für WT: $2,58 \pm 1,08 \mathrm{~ms}$ in Kontrolle und 2,53 $\pm 1,07 \mathrm{~ms}$ unter Gabazine

Arithmetisches Mittel \pm SE für WT: 2,73 $\pm 0,03 \mathrm{~ms}$ in Kontrolle und 2,71 $\pm 0,05 \mathrm{~ms}$ unter Gabazine

Median \pm SD für KO: 2,33 $\pm 0,97 \mathrm{~ms}$ in Kontrolle und 2,40 $\pm 1,02 \mathrm{~ms}$ unter Gabazine

Arithmetisches Mittel \pm SE für KO: 2,41 $\pm 0,02 \mathrm{~ms}$ in Kontrolle und 2,54 $\pm 0,03 \mathrm{~ms}$ unter Gabazine

Auch die maximale Steigung zeigt weder im NL-4-WT- noch im NL-4-KO-Neuron relevante Unterschiede im Mittelwert oder der Verteilung zwischen den Kontroll- und Gabazine-Messungen.

Median \pm SD für WT: $-24,80 \pm 6,93 \mathrm{pA} / \mathrm{ms}$ in Kontrolle und $-26,30 \pm 7,70 \mathrm{pA} / \mathrm{ms}$ unter Gabazine

Arithmetisches Mittel \pm SE für WT: $-25,15 \pm 0,21 \mathrm{pA} / \mathrm{ms}$ in Kontrolle und $-25,93 \pm 0,34 \mathrm{pA} / \mathrm{ms}$ unter Gabazine

Median \pm SD für KO: $-23,30 \pm 5,26 \mathrm{pA} / \mathrm{ms}$ in Kontrolle und $-23,30 \pm 5,11 \mathrm{pA} / \mathrm{ms}$ unter Gabazine

Arithmetisches Mittel \pm SE für KO: $-23,92 \pm 0,13 p A / m s$ in Kontrolle und $-24,10 \pm 0,15 p A / m s$ unter Gabazine 

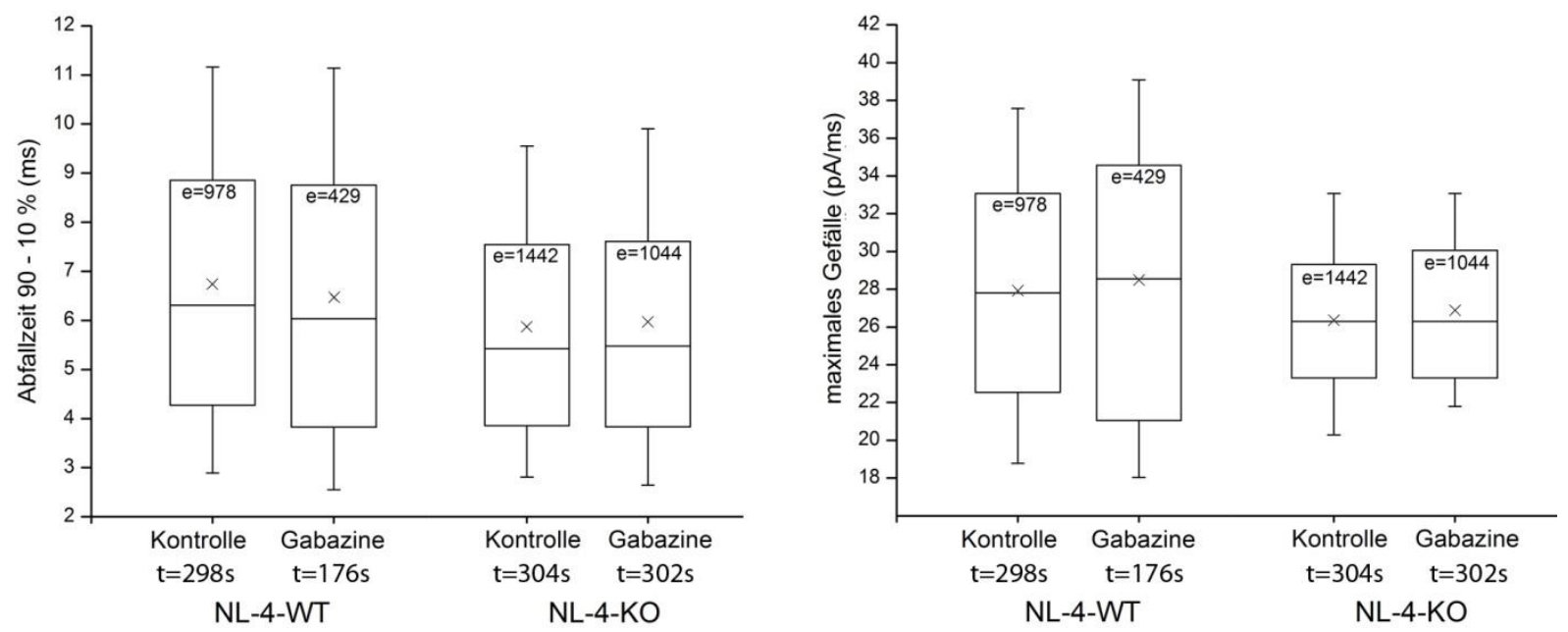

\section{Abbildung 3.13: EPSC-Abfallszeit und maximales Gefälle eines NL-4-WT- und eines NL-4-KO-Neurons unter Kontrollbedingungen und nach Einwaschen von Gabazine}

Die Boxplot-Darstellungen zeigen die über die Ableitzeiten ( $t$ ) ermittelten Abfallszeiten bzw. maximalen Gefälle (e) eines NL-4-WT- und eines NL-4-KO-Neurons unter Kontrollbedingungen und nach Einwaschen von Gabazine. Die Mittelwerte sind als Mediane (horizontale Linie) und arithmetische Mittel (Kreuz), die Verteilungen als 25-75\% Quartile (Box) bzw. 10-90\% Perzentile (Antennen) dargestellt.

Die Abfallszeit zeigt weder im NL-4-WT- noch im NL-4-KO-Neuron relevante Unterschiede im Mittelwert oder der Verteilung zwischen den Kontroll- und Gabazine-Messungen.

Median \pm SD für WT: 6,31 $\pm 3,07 \mathrm{~ms}$ in Kontrolle und 6,03 $\pm 3,14 \mathrm{~ms}$ unter Gabazine

Arithmetisches Mittel \pm SE für WT: 6,73 $\pm 0,10 \mathrm{~ms}$ in Kontrolle und 6,47 $\pm 0,15 \mathrm{~ms}$ unter Gabazine

Median \pm SD für KO: 5,42 $\pm 2,59 \mathrm{~ms}$ in Kontrolle und 5,47 $\pm 2,76 \mathrm{~ms}$ unter Gabazine

Arithmetisches Mittel \pm SE für KO: 5,87 $\pm 0,07 \mathrm{~ms}$ in Kontrolle und 5,97 $\pm 0,09 \mathrm{~ms}$ unter Gabazine

Auch das maximale Gefälle zeigt weder im NL-4-WT- noch im NL-4-KO-Neuron relevante Unterschiede im Mittelwert oder der Verteilung zwischen den Kontroll- und Gabazine-Messungen.

Median \pm SD für WT: $27,80 \pm 7,21 \mathrm{pA} / \mathrm{ms}$ in Kontrolle und 28,56 $\pm 8,38 \mathrm{pA} / \mathrm{ms}$ unter Gabazine

Arithmetisches Mittel \pm SE für WT: $27,91 \pm 0,23 \mathrm{pA} / \mathrm{ms}$ in Kontrolle und $28,50 \pm 0,40 \mathrm{pA} / \mathrm{ms}$ unter Gabazine

Median \pm SD für KO: $26,30 \pm 5,39 \mathrm{pA} / \mathrm{ms}$ in Kontrolle und 26,30 $\pm 4,72 \mathrm{pA} / \mathrm{ms}$ unter Gabazine

Arithmetisches Mittel \pm SE für KO: 26,37 $\pm 0,14 \mathrm{pA} / \mathrm{ms}$ in Kontrolle und 26,90 $\pm 0,15 \mathrm{pA} / \mathrm{ms}$ unter Gabazine 


\subsection{Analyse der Netzwerkaktivität - TTX-sensitive EPSC}

Neben den Auswertungen der sEPSC und mEPSC wurde zur Beurteilung der präsynaptischen Netzwerkaktivität der durch TTX unterdrückbare (AP-abhängige) Anteil der synaptischen Übertragung mit Hilfe vergleichender Analysen der Amplitudenverteilungen zwischen mEPSC und zellzugehöriger sEPSC untersucht (siehe Abschnitt 2.4.2).

Abbildung 3.14 stellt die kumulativen Verteilungen der zur zellindividuellen Referenz standardisierten mEPSC- und sEPSC-Amplituden von 10 exzitatorischen NL-4-WT- und 13 NL-4-KONeuronen dar. Die schwarze Kurve repräsentiert dabei die spontan gemessene synaptische Aktivität (sEPSC), welche sich aus einer AP-unabhängigen und AP-abhängigen Komponente zusammensetzt und gegenüber der roten Kurve, welche isoliert die AP-unabhängige Komponente der synaptischen Übertragung repräsentiert (mEPSC), nach rechts in Richtung höherer Amplituden verschoben ist (siehe Abschnitt 1.2). Diese Verschiebung lässt sich entsprechend den Entstehungsmechanismen von sEPSC und mEPSC durch die Gegenwart (sEPSC) bzw. die TTX-induzierte Abwesenheit (mEPSC) AP-abhängiger EPSC erklären und zur Beurteilung der präsynaptischen Netzwerkaktivität nutzen. Als Maß der Verschiebung wurden die von den Kurven eingeschlossenen, die Netzwerkaktivität-repräsentierenden Flächen (grün) berechnet. Im NL-4-KO-Genotyp ist die Fläche mit 2,90 Flächeneinheiten doppelt so groß als im NL-4-WT mit 1,45 Flächeneinheiten. 

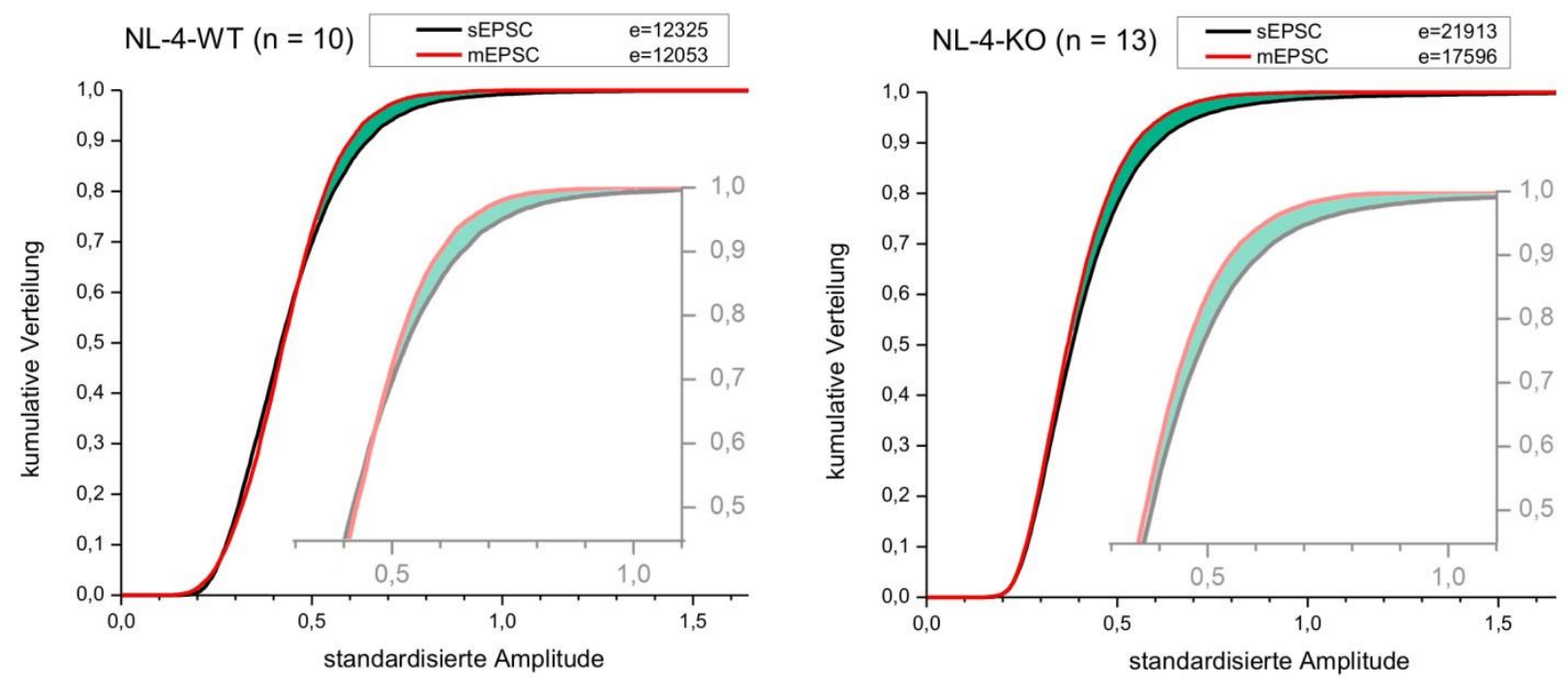

Netzwerkaktivität-repräsentierende Fläche

Abbildung 3.14: Kumulative Verteilung der standardisierten mEPSC- und SEPSC-Amplituden
exzitatorischer NL-4-WT- und NL-4-KO-Neurone

Zur Beurteilung der präsynaptischen Netzwerkaktivität wurden die kumulativen Verteilungen der standardisierten sEPSC-Amplituden (schwarz) sowie mEPSC-Amplituden (rot) in exzitatorischen NL-4-WT- (links) und NL-4-KO-Neuronen (rechts) untersucht. Entsprechend den Entstehungsmechanismen von sEPSC und mEPSC repräsentiert die Rechtsverschiebung der schwarzen Kurve (sEPSC) gegenüber der roten Kurve (mEPSC) die AP-abhängige synaptische Aktivität, also die Netzwerkaktivität. Als Maß für die Verschiebung wurden die Netzwerkaktivität-repräsentierenden Flächen (grün) berechnet. Im NL-4-KO-Genotyp ist die Fläche mit 2,90 Flächeneinheiten doppelt so groß als im NL-4-WT mit 1,45 Flächeneinheiten.

Das Verhältnis der Netzwerkaktivität-repräsentierenden Flächen deutet auf eine in NL-4-KONeuronen gesteigerte Netzwerkaktivität hin, was im Weiteren durch eine separate Schwellenanalyse zur Detektion und Auswertung TTX-sensitiver EPSC untersucht wurde (siehe Abschnitt 2.4.2). TTX-sensitive EPSC wurden dabei auf ihre Frequenz, als Anzahl EPSC pro Zeiteinheit sowie ihr Intervall, als Zeitraum zwischen zwei aufeinanderfolgenden Amplitudenmaxima, ausgewertet.

Dabei zeigt sich weder in der Frequenz mit 0,012 $\pm 0,025$ TTX-sensitiven EPSC pro Sekunde ${ }^{3}$ im $\mathrm{WT}_{(\mathrm{n}=10)}$ und 0,024 $\pm 0,092$ pro Sekunde im $\mathrm{KO}_{(\mathrm{n}=13)}$, noch im EPSC-Intervall mit 41,28 $\pm 37,92 \mathrm{~s}$ $\operatorname{im~} \mathrm{WT}_{(\mathrm{n}=9)}$ und $24,26 \pm 57,99 \mathrm{~s}$ im $\mathrm{KO}_{(\mathrm{n}=13)}$ ein signifikanter Unterschied zwischen NL-4-WT- und $N L-4-K O-N e u r o n e n\left(p_{\text {Frequenz }}=0,352 ; p_{\text {EPSC-Intervall }}=0,285\right.$ ) (Abb. 3.15 / Tab. 7.23).

\footnotetext{
${ }^{3}$ Schreibweise: Median \pm Standardabweichung; $\mathrm{n}=$ Anzahl der verglichenen Zellen
} 


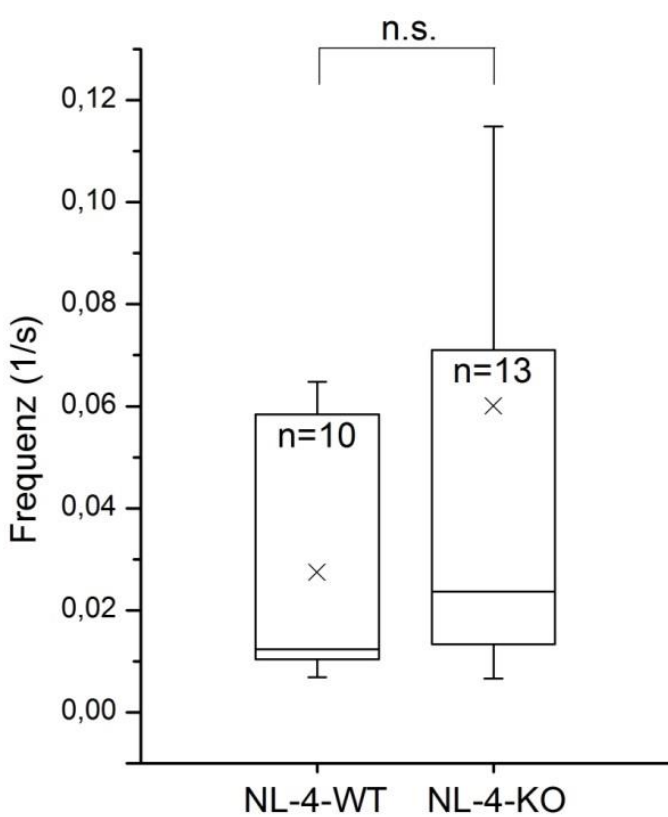

TTX-sensitive EPSC

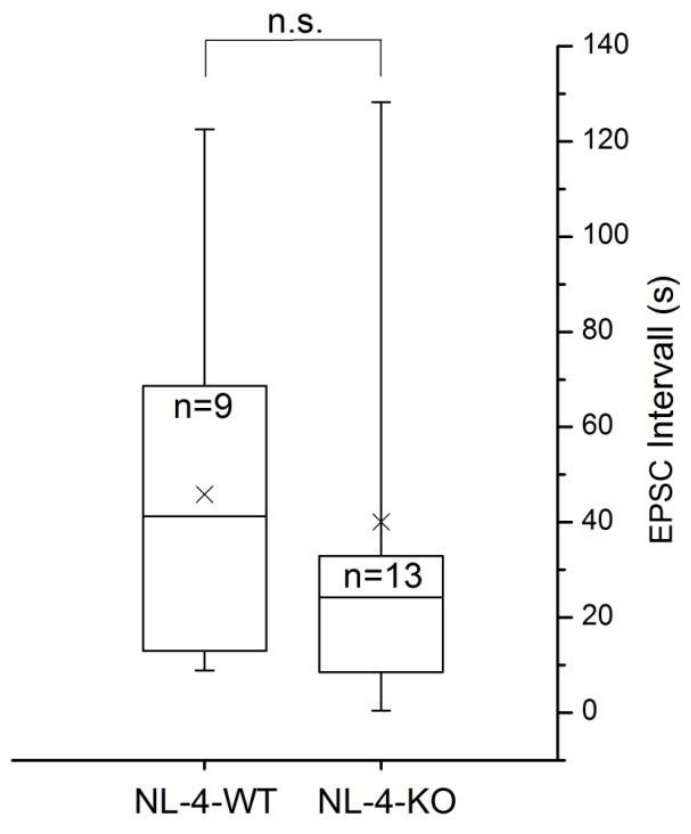

TTX-sensitive EPSC

\section{Abbildung 3.15: Frequenz und Intervall TTX-sensitiver EPSC}

Die Boxplot-Darstellungen zeigen alle ermittelten Frequenzen und Intervalle TTX-sensitiver EPSC von NL-4-WT- und NL-4-KO-Neuronen (n). Es sind die Mediane (horizontale Linie), die $25-75 \%$ Quartile (Box), die 10-90\% Perzentile (Antennen) und das arithmetische Mittel (Kreuz) dargestellt.

Die Frequenz der TTX-sensitiven EPSC weist zwischen NL-4-WT und NL-4-KO keinen signifikanten Unterschied auf. Median \pm SD: 0,012 $\pm 0,025$ /s für NL-4-WT und 0,024 $\pm 0,092 / s$ für NL-4-KO

Auch das Intervall der TTX-sensitiven EPSC weist zwischen NL-4-WT und NL-4-KO keinen signifikanten Unterschied auf. Median \pm SD: 41,28 $\pm 37,92$ s für NL-4-WT und 24,26 \pm 57 ,99s für NL-4-KO 


\section{DISKUSSION}

\subsection{Einfluss von NL-4 auf die AMPA-Rezeptor-vermittelte synaptische Übertragung auf exzitatorische Neurone der Schicht IV des Barrel- Kortex}

Im Rahmen dieser Arbeit wurde untersucht, inwiefern NL-4 die exzitatorische synaptische Übertragung auf bedornte Sternzellen, Sternpyramiden- und Pyramidenzellen der Schicht IV des Barrel-Kortex beeinflusst. In einigen Regionen des ZNS (wie z.B. der Retina) konnte bereits ein Einfluss von NL-4 auf die inhibitorische glycinerge synaptische Übertragung nachgewiesen werden. Inwiefern auch die immunhistochemisch beobachtete Lokalisation des Proteins NL-4 in der Schicht IV des Barrel-Kortex für die synaptische Übertragung relevant ist, ist gegenwärtig unbekannt. Die dominierenden exzitatorischen Verschaltungen von thalamischen Projektionen (Haupteingangsschicht somatosensorischer Information) und kolumnenassoziierten Rückverschaltungen innerhalb des Neokortex lassen eine Interaktion des NL-4-Proteins mit exzitatorischen Synapsen in Schicht IV vermuten.

Im Rahmen dieser Arbeit wurden deshalb mit Hilfe der Patch-Clamp-Technik abgeleitete spontan generierte, netzwerkabhängige sEPSC und netzwerkunabhängige mEPSC ausgewertet und zwischen NL-4-WT- und NL-4-KO-Neuronen verglichen. Die EPSC-Detektion erfolgte dabei softwareunterstützt mit Hilfe der Schwellendetektion, die EPSC-Auswertung differenziert für die Parameter Amplitude, Anstiegszeit, maximale Steigung, Abfallszeit, maximales Gefälle, Halbwertszeit, Fläche und Frequenz (siehe Abschnitt 2.4.1).

Nach morphologischer Identifizierung der abgeleiteten Zellen wurden neben zusammengefassten Analysen aller exzitatorischer Neurone in Subanalysen ausschließlich die abgeleiteten bedornten Sternzellen ausgewertet und statistisch zwischen den Genotypen NL4-WT und NL-4-KO verglichen. Dabei zeigte sowohl die Auswertung aller abgeleiteten exzitatorischen Neurone als auch die selektive Auswertung der bedornten Sternzellen signifikante Veränderungen in der Kinetik der abgeleiteten exzitatorischen postsynaptischen Membranströme. Je nach untersuchter Neuronenpopulation zeigten sich diese Veränderungen in den ausgewerteten EPSC-Parametern Abfallszeit, maximales Gefälle und maximale Steigung (Auswertung aller exzitatorischen Neurone; siehe Abschnitt 3.2.1) oder in den Parametern 
Abfallszeit, maximales Gefälle, maximale Steigung und Halbwertszeit (isolierte Auswertung der bedornten Sternzellen; siehe Abschnitt 3.2.2).

Durch die durchgeführte erweiterte elektrophysiologische Charakterisierung der bedornten Sternzellen, welche keine signifikanten Unterschiede zwischen NL-4-WT und NL-4-KO zeigte (siehe Abschnitt 3.3), konnten die registrierten Veränderungen auf einen synaptischen Ursprung zurückgeführt, durch pharmakologische Untersuchungen, mit Hilfe von NBQX und Gabazine, auf eine AMPA-Rezeptor-vermittelte Herkunft eingegrenzt werden (siehe Abschnitt 3.4). Die vorliegenden Ergebnisse weisen demzufolge auf eine in NL-4-KO-Neuronen veränderte, glutamaterge AMPA-Rezeptor-vermittelte synaptische Übertragung auf exzitatorische Neurone (im Allgemeinen) und bedornte Sternzellen (im Besonderen) der Schicht IV des Barrel-Kortex hin.

Grundsätzlich können Veränderungen in der synaptischen Übertragung, entsprechend dem anatomischen und funktionellen Aufbau einer Synapse, einerseits aus einer präsynaptisch veränderten Neurotransmitterausschüttung und/oder einer veränderten postsynaptischen rezeptorvermittelten Neurotransmitterwirkung resultieren (Conti und Weinberg 1999).

Aufgrund des Musters, der in NL-4-KO-Neuronen veränderten EPSC-Kinetik schlägt der Autor hier vor, vorrangig postsynaptische Modifikationen als Ursache der in NL-4-KO-Neuronen registrierten Veränderungen der synaptischen Übertragung zu diskutieren, welche letztlich für die Ausprägung der in NL-4-KO-Mäusen beobachteten Autismus-assoziierten Verhaltensauffälligkeiten relevant sein könnten. Dies soll im Folgenden erörtert werden.

\section{Postsynaptische Modifikation durch NL-4-KO:}

Auf postsynaptischer Seite könnten die in NL-4-KO-Neuronen registrierten Veränderungen der EPSC-Kinetik mit Veränderungen der biophysikalischen Eigenschaften des AMPA-Rezeptors in Zusammenhang stehen.

Es ist bekannt, dass verschiedene AMPA-Rezeptor-Subtypen existieren, welche sich, abhängig vom Aufbau ihrer Quartärstruktur aus Proteinuntereinheiten, in der Kinetik der durch sie vermittelten exzitatorischen Membranströme voneinander unterscheiden. Es existieren dabei vier, durch unterschiedliche Gene codierte Proteinuntereinheiten, GluR1 - GluR4, welche nach 
posttranslationalen Modifizierungen durch alternatives Spleißen in einer flip und flop Variante vorkommen und sich in variabler Kombination als Homo- oder Heteromer zu einem funktionellen AMPA-Rezeptor-Subtyp zusammenlagern (Hille 2001; Traynelis et al. 2010).

Neben dem eigentlichen Aufbau des AMPA-Rezeptors beeinflussen zusätzlich sogenannte Transmembrane-AMPA-Rezeptor-Regulator-Proteine (TARP) die biophysikalischen AMPARezeptoreigenschaften. Es existieren vier verschiedene TARP-Isoformen, $\gamma 2$ (auch als Stargazin bekannt), Y3, v4 und Y8 (Chen et al. 2000; Hashimoto et al. 1999; Tomita et al. 2003). Als zusätzlicher Bestandteil des AMPA-Rezeptors vermitteln sie die gezielte Insertion von AMPARezeptoren in die synaptische Zellmembran (Chen et al. 2000; Hashimoto et al. 1999; Tomita et al. 2003) und modulieren AMPA-Rezeptor-vermittelte Membranströme (Tomita et al. 2005; Turetsky et al. 2005; Yamazaki et al. 2004).

Abhängig vom kombinierten AMPA-Rezeptor-Subtyp (Komposition der Rezeptoruntereinheiten GluR1-GluR4 flip/flop) besitzen die verschiedenen TARP $\left(\nu 2, \nu_{3}, \nu 4, \gamma 8\right)$ einen unterschiedlich starken modulatorischen Effekt auf die biophysikalischen Rezeptoreigenschaften. Sie beeinflussen in unterschiedlicher Stärke insbesondere die Desensibilisierungs- und Deaktivierungsraten von AMPA-Rezeptoren sowie die Wirkpotenz von Glutamat auf AMPARezeptoren (Cho CH et al. 2007; Kott et al. 2007; Suzuki et al. 2008) (Abb. 4.1).

Grundsätzlich prägen die Desensibilisierungs- und Deaktivierungsraten des AMPA-Rezeptors insbesondere den Verlauf der abfallenden EPSC-Flanke, welche die Beendigung des glutamatinduzierten postsynaptischen Membranstroms repräsentiert (Jonas und Spruston 1994; Otis et al. 1996; Trussell et al. 1993). Eben dieser Verlauf der abfallenden EPSC-Flanke, beschrieben durch die Parameter Abfallszeit und maximales Gefälle, ist in NL-4-KO-Neuronen gegenüber NL-4-WT-Neuronen signifikant verändert (siehe Abschnitt 3.2). 


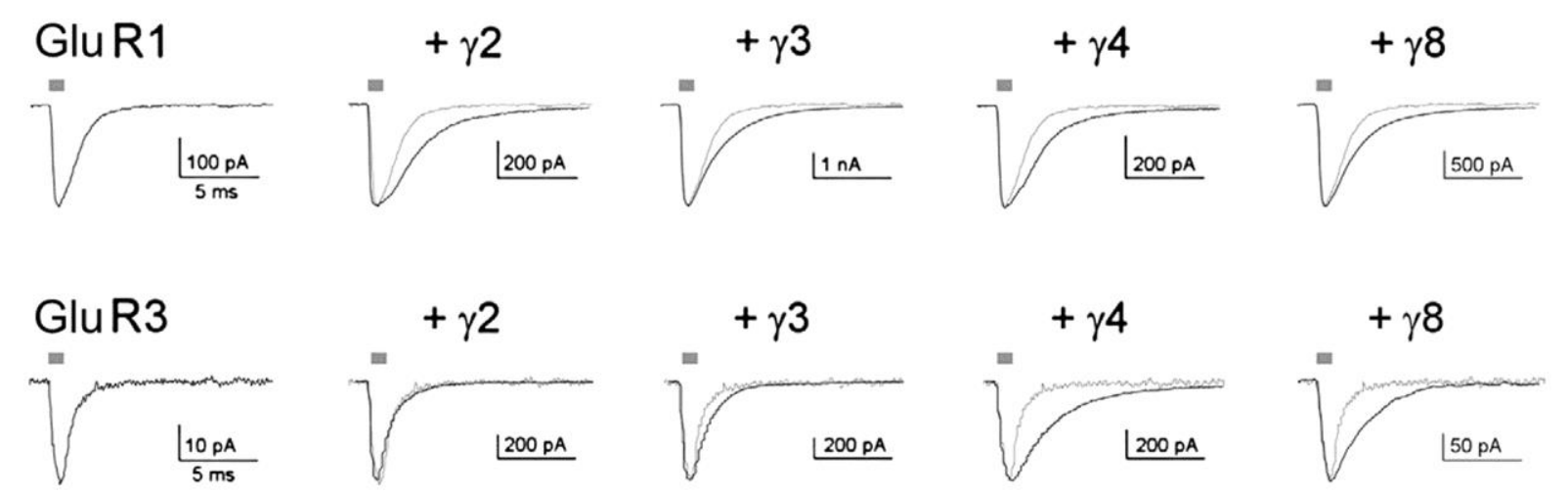

\section{Abbildung 4.1: AMPA-Rezeptor-vermittelte Membranströme unterliegen der Modulation durch TARP}

Die Abbildung zeigt durch Applikation von 10mM Glutamat (1ms Dauer) ausgelöste, in Outside-OutKonfiguration gemessene, Membranströme der AMPA-Rezeptor-Subtypen GluR1 und GluR3 alleine (Spuren der 1. Spalte in schwarz, Spuren der 2.-5. Spalte in grau) und in Kombination mit den TARPIsoformen $\gamma 2, \gamma 3, \gamma 4$ und $\gamma 8$ (Spuren der 2.-5. Spalte in schwarz).

Die einzelnen TARP-Isoformen beeinflussen in unterschiedlich starker Ausprägung den AMPA-Rezeptorvermittelten Membranstromverlauf. Sie verlangsamen die AMPA-Rezeptor-Deaktivierungs- und Desensibilisierungsraten und verlängern auf diese Weise den Verlauf der abfallenden Stromflanke. Abbildung modifiziert nach Suzuki et al. (2008); S.118.

Entsprechend könnten die in NL-4-KO-Neuronen registrierten Veränderungen der EPSC-Kinetik auf Veränderungen der synaptisch vorherrschenden AMPA-Rezeptor/TARP-Kombination zurückgeführt werden.

Diese Hypothese erscheint auch deshalb plausibel, weil über wechselseitige Interaktionen mit dem postsynaptischen Proteinnetzwerk PSD ein Zusammenhang zwischen AMPARezeptoren/TARP und Neuroligin zu bestehen scheint. Besondere Relevanz kommt hierbei den PSD-Proteinen Postsynaptische Dichte-95 (post synaptic density-95; PSD-95) und Synaptisches Gerüstprotein (synaptic scaffolding-molecule; S-SCAM) zu (Abb. 4.2). Sowohl PSD-95 als auch S-SCAM interagieren mit TARP über sogenannte PDZ-Domänen (PDZ = post synaptic density protein-95 (PSD-95) / Drosophila disc large tumor suppressor (DlgA) / zonula occludens-1 protein (ZO-1) (Chen et al. 2000; Deng et al. 2006; Tomita et al. 2003). Es handelt sich bei PDZDomänen um Proteinabschnitte, welche mit spezifischen Abschnitten anderer Proteine, den PDZ-Bindemustern, interagieren und auf diese Weise das Ausbilden von Proteinkomplexen ermöglichen (Saras und Heldin 1996). PSD-95 besitzt drei, S-SCAM fünf solcher PDZ Domänen (Cho KO et al. 1992; Hirao et al. 1998; Saras und Heldin 1996), über die sie mit dem C-terminalen PDZ-Bindemuster von TARP interagieren und auf diese Weise die gezielte 
synaptische Lokalisation von AMPA-Rezeptoren vermitteln (Chen et al. 2000; Deng et al. 2006; Tomita et al. 2003).

Parallel dazu interagiert sowohl PSD-95 als auch S-SCAM über PDZ-Domänen mit dem C-terminalen PDZ-Bindemuster von Neuroligin (Hirao et al. 1998; lida et al. 2004; Irie et al. 1997; Sumita et al. 2007), wobei diese Interaktion in einer Art Wechselspiel einerseits für die synaptische Lokalisation von Neuroligin (Gerrow et al. 2006; lida et al. 2004; Levinson et al. 2010) und andererseits für die Lokalisation und Strukturierung der PSD von Bedeutung zu sein scheint (Barrow et al. 2009; Graf et al. 2004; Heine et al. 2008; Mondin et al. 2011; Nam und Chen 2005).

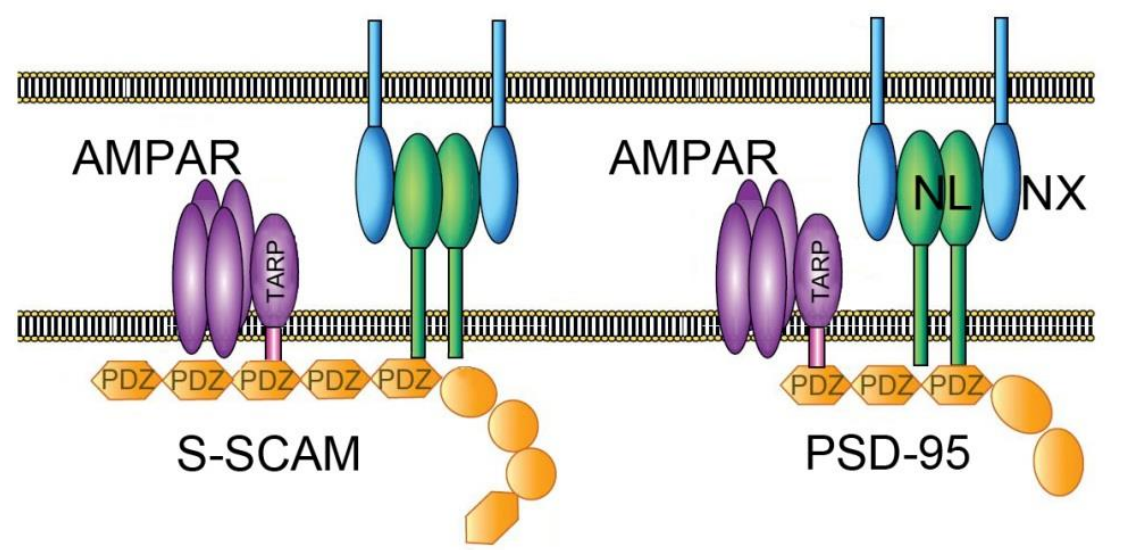

\author{
Präsynaptische \\ Endigung
}

Synaptischer

Spalt

Postsynaptische

Endigung

\title{
Abbildung 4.2: Interaktion zwischen Neuroligin und AMPA-Rezeptoren über Proteine der PSD
}

Das postsynaptisch lokalisierte Protein Neuroligin (NL) interagiert extrazellulär mit dem präsynaptisch lokalisierten Neurexin (NX) sowie durch sein C-terminales Ende mit den Proteinen PSD-95 und S-SCAM der postsynaptischen Dichte über deren PDZ-Domänen. Über diese PDZ-Domänen stehen die Proteine PSD-95 und S-SCAM darüber hinaus über Transmembrane-AMPA-Rezeptor-Regulator-Proteine (TARP) mit AMPA-Rezeptoren (AMPAR) in Verbindung. Abbildung modifiziert nach Krueger et al. (2012); S. 413. 
Bei einer genaueren Betrachtung der Interaktionen zwischen AMPA-Rezeptoren/TARP und Neuroligin über die Proteine der PSD (PSD-95/S-SCAM), lassen sich weiterführende Überlegungen anstellen, wie NL-4-KO eine veränderte AMPA-Rezeptor/TARP-Subtypexpression verursachen könnte:

Das Protein PSD-95 reguliert bevorzugt die Akkumulation des AMPA-Rezeptor-Subtyps GluR1 (Ehrlich und Malinow 2004; El-Husseini et al. 2000). Das Protein S-SCAM reguliert bevorzugt die Akkumulation des Subtyps GluR2 (Danielson et al. 2012). Es wäre also vorstellbar, dass eine durch NL-4-KO beeinflusste Komposition dieser PSD-Proteine zu einer subtypspezifisch veränderten AMPA-Rezeptor-Expression führen könnte. Tatsächlich zeigten Etherton et al. (2011) wie eine gezielte Mutation der zytoplasmatischen Sequenz von NL-3 (R704C; Austausch der Aminosäure Arginin durch Cystein an Position 704) zur Beeinträchtigung der synaptischen Übertragung auf hippocampale Pyramidenzellen führt, die mit einer subtypspezifisch gesteigerten Expression der AMPA-Rezeptoren GluR1 und GluR3 einhergeht.

Ferner könnten Veränderungen in der AMPA-Rezeptor/TARP-Expression mit einem konkurrierenden Bindeverhalten zwischen AMPA-Rezeptor/TARP und Neuroligin zu den PDZ-Domänen der PSD-Proteine PSD-95 und S-SCAM in Zusammenhang stehen. Für NL-1 konnte gezeigt werden, dass es selektiv mit der ersten PDZ-Domäne des Proteins S-SCAM interagiert (Hirao et al. 1998; lida et al. 2004). Überlappend damit konnte für das TARP $\gamma 2$ gezeigt werden, dass es mit der ersten, dritten und fünften PDZ-Domäne von S-SCAM interagiert, wobei die erste PDZ-Domäne die größte und die fünfte die geringste Affinität aufweist (Deng et al. 2006). Ob für NL-4 oder die übrigen TARP ein vergleichbares oder abweichendes Affinitätsmuster existiert, ist nicht bekannt. Es erscheint jedoch plausibel, dass durch NL-4-KO freigewordene PDZ-Bindungsstellen selektiv durch einzelne TARP-Isoformen besetzt werden könnten, was zu einer Modulation der synaptisch vorherrschenden AMPARezeptor/TARP-Kombination führen und dadurch die registrierten Veränderungen der EPSCKinetik hervorrufen könnte. 


\section{Modifikation der präsynaptischen Neurotransmitterausschüttung:}

NL-4-KO könnte nicht nur einen Effekt auf die postsynaptische Neurotransmitterwirkung, sondern auch auf die präsynaptische Neurotransmitterausschüttung haben.

Neuroligin interagiert durch Neurexin mit der präsynaptischen Endigung und ist auf diese Weise an der Regulation ihrer Differenzierung (Scheiffele et al. 2000) und Reifung (Wittenmayer et al. 2009) beteiligt. Dabei interagiert NL über Neurexin mit verschiedenen präsynaptischen Proteinen, die an der Struktur- und der Transmitterausschüttung beteiligt sind (Biederer und Südhof 2000; Hata et al. 1996; Lise und El-Husseini 2006).

Entgegen dieses Zusammenhangs liefern die erhobenen Daten jedoch keine Anhaltspunkte für eine in NL-4-KO-Neuronen veränderte präsynaptische Transmitterfreisetzung. Die Ergebnisse zeigen zwischen NL-4-WT- und NL-4-KO-Neuronen keinen signifikanten Unterschied der EPSCAmplitude (siehe Abschnitt 3.2), wie es sowohl bei einer Modulation der ausgeschütteten Transmittermenge als auch der Freisetzungskinetik, also der zeitlichen Synchronität der Transmitterfreisetzung, zu erwarten wäre (Diamond und Jahr 1995).

In Untersuchungen zum retrograden Einfluss von Neuroligin auf die präsynaptische Transmitterfreisetzung zeigte Futai et al. (2007) bereits, dass einzelnes Ausschalten von NL-1 keinen Effekt auf AMPA-Rezeptor-vermittelte EPSC-Amplituden hat, wohingegen gleichzeitiges Ausschalten aller Neuroligine, sowohl AMPA- als auch NMDA-Rezeptor vermittelte glutamaterge EPSC-Amplituden vermindert. Als Ursache dieser Beobachtung diskutieren Futai et al. (2007) die Redundanz der verschiedenen Neuroligin-Isoformen, welche die präsynaptische Transmitterfreisetzung trotz Ausschalten eines einzelnen Neuroligins konstant halten könnte. In Analogie dazu könnte eine in NL-4-KO-Neuronen potentiell beeinträchtigte präsynaptische Transmitterfreisetzung durch die exprimierten Neuroligin-Isoformen 1-3 kompensiert und auf diese Weise die EPSC-Amplituden konstant gehalten werden. 


\subsection{Funktionelle Konsequenz einer veränderten synaptischen Übertragung}

Neben Überlegungen zu den Ursachen der in NL-4-KO-Neuronen detektierten Veränderungen, lassen sich auch solche zu den Konsequenzen einer modifizierten EPSC-Kinetik anstellen.

Veränderungen in der synaptischen Übertragung können sich auf die postsynaptische Generierung von Aktionspotentialen auswirken und auf diese Weise die neuronale Informationsverarbeitung beeinflussen. Inwieweit dies auch auf Veränderungen der EPSCKinetik, wie sie in NL-4-KO-Neuronen registriert wurden zutrifft, untersuchten RodriguezMolina et al. (2007) in Pyramidenzellen der Schicht V des Kortex. Aus ihren Untersuchungen geht hervor, dass die zeitliche Präzision mit der EPSC Aktionspotentiale auslösen können, gemessen als sogenannte spike-time-precison (Aktionspotential-Präzision; STP), wesentlich von der EPSC-Kinetik abhängen. Dabei scheint ein sigmoidaler Zusammenhang zwischen EPSCAbfallszeit und STP zu bestehen, deren steilster Bereich zwischen einer EPSC-Abfallszeit von 4 und $8 \mathrm{~ms}$ liegt. In diesem Bereich führen bereits geringe Veränderungen der Abfallszeit zu relativ großen Veränderungen der STP. Kurze Abfallszeiten gehen dabei mit einer höheren, lange Abfallszeiten mit einer geringeren Präzision der AP-Generierung einher.

In NL-4-KO-Neuronen ist die Abfallszeit gegenüber der NL-4-WT-Kontrolle sowohl in der Auswertung der sEPSC als auch in der Auswertung der mEPSC signifikant verlängert (siehe Abschnitt 3.2). Trotz der eingeschränkten Vergleichbarkeit der aktuell erhobenen NL-4-Daten mit den von Rodriguez-Molina et al. (2007) erhobenen Ergebnissen - einerseits liegen beiden Untersuchungen verschiedene Neuronenkollektive zugrunde, andererseits kann nicht von einer identischen prozentualen Definition der Abfallszeit ausgegangen werden - fällt auf, dass die Verlängerung der Abfallszeiten in NL-4-KO-Neuronen (sEPSC: WT=5,62ms KO=6,21ms; mEPSC: WT=5,23ms KO=6,15ms; jeweils Mediane der Auswertung aller exzitatorischen Neurone) in dem von Rodriguez-Molina et al. (2007) beschriebenen sensiblen Bereich liegen, in dem bereits eine geringe Verlängerung der Abfallszeit zu einer relativ stark verminderten Präzision der AP-Generierung führt.

Es erscheint entsprechend plausibel, dass die in NL-4-KO-Neuronen gemessene verlängerte EPSC-Kinetik zu einer verringerten Präzision der AP-Generierung und auf diese Weise zur Beeinträchtigung der neuronalen Informationsverarbeitung führen könnte. Da die Schicht IV 
des Barrel-Kortex die Haupteingangsschicht thalamischer Projektionen darstellt (Bernardo und Woolsey 1987; Killackey 1973; Killackey und Leshin 1975; Lu und Lin 1993; Staiger et al. 1996), könnte sich eine solche Beeinträchtigung auf die gesamte weiterführende somatosensorische Informationsprozessierung auswirken und letztlich mit der Ausprägung der in NL-4-KO-Mäusen beobachteten Autismus-assoziierten Verhaltensauffälligkeiten ursächlich zusammenhängen.

\subsection{Einfluss von NL-4 auf die präsynaptische Netzwerkaktivität}

Mit Hilfe TTX-sensitiver EPSC wurde die präsynaptische Netzwerkaktivität und auf diese Weise indirekt das präsynaptische Verhältnis von Exzitation zu Inhibition der abgeleiteten NL-4-WTund NL-4-KO-Neuronen untersucht. Dafür wurde der durch TTX unterdrückbare (AP-abhängige) Anteil der synaptischen Übertragung mit Hilfe vergleichender Analysen der Amplitudenverteilungen zwischen mEPSC und zellzugehöriger sEPSC und einer wiederholten SEPSC-Schwellenanalyse zur direkten Detektion der TTX-sensitiven EPSC untersucht (siehe Abschnitt 2.4.2.).

Die Auswertung der kumulativen Analysen der Amplitudenverteilungen zeigt in NL-4-KONeuronen eine Verdopplung der, die Netzwerkaktivität-repräsentierenden Fläche. Die Auswertung der separat detektierten TTX-sensitiven EPSC zeigt hingegen keine signifikanten Unterschiede in Frequenz oder EPSC-Intervall zwischen NL-4-KO- und NL-4-WT-Neuronen (siehe Abschnitt 3.5). Die Divergenzen dieser Ergebnisse ergeben sich mutmaßlich aus den Definitionen der TTX-sensitiven EPSC und den Netzwerkaktivität-repräsentierenden Flächen:

Die konservative Definition der TTX-sensitiven EPSC, welche die Amplitude des größten mEPSC als zellindividuelle Referenzamplitude für den maximalen durch spontane Transmitterfreisetzung erreichbaren postsynaptischen Summenstrom definiert, ab welchem ein sEPSC als TTX-sensitiv gilt (Abb. 2.14), erfasst AP-vermittelte EPSC mit hoher Spezifität. Das heißt, ein auf diese Weise als TTX-sensitiv erfasstes EPSC ist mit hoher Wahrscheinlichkeit tatsächlich AP-vermittelt, also mit der präsynaptischen Netzwerkaktivität assoziiert.

Die Netzwerkaktivität-repräsentierende Fläche berechnet sich dagegen aus der in den kumulativen Darstellungen der standardisierten Amplituden ersichtlichen Rechtsverschiebung der sEPSC-repräsentierenden Kurve gegenüber der mEPSC-repräsentierenden Kurve und 
quantifiziert auf diese Weise die Menge der durch TTX-unterdrückbaren (also AP-vermittelten) EPSC (siehe Abschnitt 3.5 und Abb. 3.14). Bei genauem Betrachten der kumulativen Darstellungen fällt auf, dass die sEPSC- (schwarz) und mEPSC- (rot) repräsentierenden Kurven vorzeitig, bereits deutlich vor Erreichen der definierten TTX-sensitiven-Schwelle (Standard Amplitude $=1$ ), divergieren. Dies deutet darauf hin, dass die Menge EPSC mit einer Amplitude $_{\text {Standardisiert }}<1$ bereits AP-vermittelte EPSC beinhaltet. Diese Beobachtung weist darauf hin, dass die Sensitivität, also die Wahrscheinlichkeit mit der AP-vermittelte EPSC in der separaten Schwellenanalyse auch als TTX-sensitiv erkannt werden, reduziert ist. Entsprechend bilden die Netzwerkaktivität-repräsentierenden Flächen die präsynaptische Netzwerkaktivität wenig spezifisch, dafür aber hoch sensitiv ab, wohingegen die Auswertung der TTX-sensitiven EPSC die präsynaptische Netzwerkaktivität hoch spezifisch, gleichzeitig jedoch wenig sensitiv misst.

Die Frage ob NL-4-KO zu Veränderungen im präsynaptischen Verhältnis von Exzitation zu Inhibition führt, lässt sich demzufolge auf Basis der verwendeten Methode der Detektion TTXsensitiver EPSC nicht eindeutig beantworten. Obwohl im statistischen Vergleich der TTXsensitiven EPSC kein signifikanter Unterschied in der präsynaptischen Netzwerkaktivität zwischen NL-4-KO- und NL-4-WT-Neuronen nachgewiesen werden kann, lassen die Betrachtung der kumulativen Illustrationen und die oben angestellten Überlegungen Zweifel an der Validität dieses Ergebnisses aufkommen. 


\subsection{Ausblick}

Die vorliegende Arbeit weist auf eine in NL-4-KO-Neuronen veränderte, AMPA-Rezeptorvermittelte synaptische Übertragung auf exzitatorische Neuronen der Schicht IV des BarrelKortex hin. Inwiefern diese Veränderung tatsächlich mit Modulationen des AMPA-Rezeptors, den assoziierten TARP oder dem Aufbau bzw. der Funktion der Proteine der PSD durch NL-4-KO in Zusammenhang steht, kann durch die vorliegende Arbeit nicht beantwortet werden und bleibt weiteren molekulargenetischen und/oder immunhistochemischen Untersuchungen vorbehalten.

Neben der im Barrel-Kortex vermuteten Assoziation von NL-4 zu exzitatorischen Synapsen konnte in anderen Regionen des ZNS (wie der Retina) die Lokalisation und funktionelle Relevanz von NL-4 an glycinergen inhibitorischen Synapsen nachgewiesen werden (Hoon et al. 2011). Ob NL-4 dementsprechend auch im Barrel-Kortex für die inhibitorische synaptische Übertragung auf exzitatorische Neurone der Schicht IV relevant ist, wäre im Rahmen weiterer elektrophysiologischer Einzelzellableitungen (der inhibitorischen postsynaptischen Eingänge) zu untersuchen. Im Übrigen erscheint es sinnvoll, neben den bedornten Sternzellen, Sternpyramiden- und Pyramidenzellen, weitere Neuronenpopulationen der Schicht IV (inhibitorische Interneurone) hinsichtlich der auf sie projizierenden exzitatorischen und inhibitorischen synaptischen Eingänge im Zusammenhang mit NL-4 zu untersuchen.

Die Analyse der präsynaptischen Netzwerkaktivität erfolgte im Rahmen dieser Arbeit durch die Auswertung TTX-sensitiver EPSC und zeigte keine signifikanten Unterschiede zwischen NL-4-WT- und NL-4-KO-Neuronen. Da die Validität der durchgeführten Auswertung aufgrund der hohen Spezifität im Verhältnis zur geringen Sensitivität zweifelbehaftet bleibt, sind zur Beurteilung der auf die exzitatorischen Neurone der Schicht IV des Barrel-Kortex projizierenden Netzwerkaktivität weiterführende Untersuchungen erforderlich. Als geeignet erscheinen hierfür zum Beispiel in vivo Patch-Clamp-Messungen. Diese Methode würde, neben dem Erhalt neuronaler Schaltkreise, was die Untersuchung des kompletten Netzwerks des intakten somatosensorischen Systems erlaubt, den Vorteil bieten, zusätzlich zur spontanen (passiven) Netzwerkaktivität, die durch Vibrissenstimulation evozierbare (aktive) Netzwerkaktivität untersuchen zu können (Feldmeyer et al. 2012). 


\section{ZUSAMMENFASSUNG (DEUTSCH)}

Neuroligine (NL) sind vorwiegend postsynaptisch lokalisierte transmembrane Adhäsionsmoleküle, die in Wechselwirkung mit dem präsynaptisch lokalisierten Protein Neurexin eine wichtige Rolle in der Reifung und Funktion von Synapsen spielen. Es existieren verschiedene NL-Isoproteine (NL-1 - NL-4), die sich in ihrer Assoziation zu exzitatorischen und inhibitorischen Synapsen unterscheiden. Die funktionelle und klinische Relevanz der Neuroligine belegen beispielhaft Mutationen des Isotyps NL-4, welche mit neuropsychiatrischen Erkrankungen wie Autismus-Spektrum-Störungen assoziiert vorkommen.

Anhand eines durch Ausschalten des human-orthologen NL-4-Gens generierten Mausmodells (NL-4-Knockout, NL-4-KO) konnte in vorhergehenden Studien die Bedeutung einer immunhistochemisch beobachteten Lokalisation von NL-4 an glycinergen Synapsen der Retina für die inhibitorische synaptische Übertragung nachgewiesen werden. Im Unterschied dazu konnte kein Zusammenhang zwischen einer in Schicht IV des Barrel-Kortex nachweisbaren Lokalisation von NL-4 mit inhibitorischen Synapsen hergestellt werden. Deshalb, und aufgrund der in Schicht IV dominierenden exzitatorischen Verschaltung von thalamischen Projektionen und den kolumnenassoziierten Rückverschaltungen aus dem Neokortex, lässt sich eine Interaktion von NL-4 mit exzitatorischen Synapsen in diesem Areal vermuten. Im Rahmen der vorliegenden Arbeit wurde anhand der NL-4-KO-Modellmaus der Frage nachgegangen, inwiefern NL-4 die exzitatorische synaptische Übertragung im Barrel-Kortex beeinflusst. Dafür wurden mit Hilfe der Patch-Clamp-Technik abgeleitete AMPA-Rezeptor-vermittelte exzitatorische postsynaptische Ströme (EPSC) von bedornten Sternzellen, Sternpyramiden- und Pyramidenzellen der Schicht IV ausgewertet und zwischen NL-4Wildtyp- (NL-4-WT) und NL-4-KO-Neuronen verglichen. Dabei zeigten NL-4-KO-Neurone signifikant veränderte Parameter der EPSC-Kinetik. Die Abfallszeit war in NL-4-KO-Neuronen signifikant länger, das maximale Gefälle und die maximale Steigung signifikant flacher gegenüber NL-4-WT-Kontrollen. Diese Veränderungen sprechen für eine funktionelle Relevanz von NL-4 für die AMPA-Rezeptor-vermittelte synaptische Übertragung auf exzitatorische Neurone in Schicht IV des Barrel-Kortex. Das Muster der in NL-4-KO-Neuronen veränderten EPSC-Kinetik weist dabei auf eine Modulation der biophysikalischen AMPA-Rezeptoreigenschaften hin und könnte mit Veränderungen der synaptisch exprimierten AMPARezeptor-TARP-Subtypen in Zusammenhang stehen, die über Proteine der postsynaptischen Dichte (wie PSD-95 und S-SCAM) mit Neuroliginen interagieren. 


\section{ZUSAMMENFASSUNG (ENGLISCH)}

Neuroligins (NL) are predominant postsynaptically localized transmembrane adhesion molecules that interact with the presynaptically localized protein neurexin. There are different NL-isoproteins (NL-1 NL-4) that differ in their association to excitatory and inhibitory synapses. Neuroligins play an important role in maturation and function of synapses. Their functional and clinical relevance is demonstrated by the association between mutations of the NL isoprotein NL-4 and neuropsychiatric diseases like autism spectrum disorders.

Immunohistochemical experiments have shown that NL-4 is localized in the retina where it plays a role in inhibitory synaptic transmission. However no link between the immunohistochemical localization of NL-4 in layer IV of the barrel-cortex and inhibitory synapses was observed. These findings and the predominant excitatory synaptic connections by thalamocortical projections and column-associated neocortical circuitries in layer IV leads to the question of whether NL-4 interacts with excitatory synapses in this area.

To address this question this work observed the excitatory synaptic transmission to excitatory neurons in layer IV of barrel-cortex. Therefore AMPA-receptor mediated excitatory postsynaptic currents (EPSC) of layer IV spiny stellate cells, star pyramidal and pyramidal cells were recorded using the patch-clamp technique. The analysis of the recorded EPSC showed significant differences in the EPSC-kinetics between NL-4-WT and NL-4-KO neurons. The decay time of EPSC in NL-4-KO neurons was significantly longer, the maximum decay slope and maximum rise slope significantly lower than in NL-4-WT neurons. These findings suggest a functional relevance of NL-4 for the AMPA-receptor mediated synaptic transmission to excitatory neurons in Layer IV of barrel-cortex. The pattern of alterations indicates a change in biophysical AMPA-receptor characteristics in NL-4 neurons that might be caused by alterations of synaptically expressed AMPA-receptor/TARP subunits which are related to NL via postsynaptic scaffolding proteins of the postsynaptic density (like PSD-95 and S-SCAM). 


\section{ANHANG}

\subsection{Detektion und Analyse von sEPSC und mEPSC}

Tabelle 7.1: Überblick über die Anzahl der ausgewerteten EPSC, abhängig von Ableitungsmodus (sEPSC/mEPSC), Genotyp (NL-4-WT/NL-4-KO) und EPSC-Parameter

\begin{tabular}{|c|c|c|c|c|c|c|}
\hline SE & Identifikationskriterien & \multicolumn{2}{|c|}{$\begin{array}{l}\text { NL-4-WT } \\
(n=21)\end{array}$} & \multicolumn{2}{|c|}{$\begin{array}{l}N L-4-K O \\
(n=17)\end{array}$} & $\begin{array}{c}\text { Ausgewertete } \\
\text { Parameter }\end{array}$ \\
\hline $\begin{array}{l}\text { Initial detektierte } \\
\text { EPSC }\end{array}$ & & 40538 & $100 \%$ & 33574 & $100 \%$ & \\
\hline $\begin{array}{l}\text { Hintergrund- } \\
\text { rauschen }\end{array}$ & $\begin{array}{l}\text { Amplitude }<3 p A \\
\text { Anstiegszeit } 10-90 \%<0,8 \mathrm{~ms} \\
\text { Abfallszeit } 90-10 \%<0,8 \mathrm{~ms}\end{array}$ & 33655 & $83 \%$ & 28998 & $86 \%$ & Frequenz \\
\hline $\begin{array}{l}\text { Überlagerung } \\
\text { ansteigende } \\
\text { Flanke }\end{array}$ & Anstiegszeit $10-90 \% \geq 5 \mathrm{~ms}$ & 28988 & $72 \%$ & 25563 & $76 \%$ & $\begin{array}{l}\text { Amplitude } \\
\text { Anstiegszeit } \\
\text { Maximale Steigung }\end{array}$ \\
\hline \multirow[t]{2}{*}{$\begin{array}{l}\text { Überlagerung } \\
\text { abfallende Flanke } \\
\text { + rauschendes } \\
\text { Signal abfallende } \\
\text { Flanke }\end{array}$} & $\begin{array}{l}\text { Abfallszeit } 90-10 \% \geq 15 \mathrm{~ms} \\
\text { Abfallszeit } 90-10 \% \text { zwischen } \\
0,8 \mathrm{~ms} \text { und } 2,0 \mathrm{~ms}\end{array}$ & 25040 & $62 \%$ & 22906 & $68 \%$ & $\begin{array}{l}\text { Abfallszeit } \\
\text { Maximales Gefälle } \\
\text { Fläche } \\
\text { Halbwertszeit }\end{array}$ \\
\hline & Identifikationskriterien & \multicolumn{2}{|c|}{$\begin{array}{l}\text { NL-4-WT } \\
(n=11)\end{array}$} & \multicolumn{2}{|c|}{$\begin{array}{l}N L-4-K O \\
(n=14)\end{array}$} & $\begin{array}{c}\text { Ausgewertete } \\
\text { Parameter }\end{array}$ \\
\hline $\begin{array}{l}\text { Initial detektierte } \\
\text { EPSC }\end{array}$ & & 19100 & $100 \%$ & 26578 & $100 \%$ & \\
\hline $\begin{array}{l}\text { Hintergrund- } \\
\text { rauschen }\end{array}$ & $\begin{array}{l}\text { Amplitude }<3 p A \\
\text { Anstiegszeit } 10-90 \%<0,8 \mathrm{~ms} \\
\text { Abfallszeit } 90-10 \%<0,8 \mathrm{~ms}\end{array}$ & 15213 & $80 \%$ & 21897 & $82 \%$ & Frequenz \\
\hline $\begin{array}{l}\text { Überlagerung } \\
\text { ansteigende } \\
\text { Flanke }\end{array}$ & Anstiegszeit $10-90 \% \geq 5 \mathrm{~ms}$ & 13152 & $69 \%$ & 19020 & $72 \%$ & $\begin{array}{l}\text { Amplitude } \\
\text { Anstiegszeit } \\
\text { Maximale Steigung }\end{array}$ \\
\hline $\begin{array}{l}\text { Überlagerung } \\
\text { abfallende Flanke } \\
+ \text { rauschendes } \\
\text { Signal abfallende } \\
\text { Flanke }\end{array}$ & $\begin{array}{l}\text { Abfallszeit } 90-10 \% \geq 15 \mathrm{~ms} \\
\text { Abfallszeit } 90-10 \% \text { zwischen } \\
0,8 \mathrm{~ms} \text { und } 2,0 \mathrm{~ms}\end{array}$ & 11295 & $59 \%$ & 16859 & $63 \%$ & $\begin{array}{l}\text { Abfallszeit } \\
\text { Maximales Gefälle } \\
\text { Fläche } \\
\text { Halbwertszeit }\end{array}$ \\
\hline
\end{tabular}




\subsection{Auswertung exzitatorischer Neurone}

Tabelle 7.2:

Abfallszeit exzitatorischer Neurone

\begin{tabular}{|c|c|c|c|c|}
\hline \multirow[b]{2}{*}{$\begin{array}{l}\text { Abfallszeit } \\
\text { (ms) }\end{array}$} & \multicolumn{2}{|c|}{ sEPSC } & \multicolumn{2}{|c|}{ mEPSC } \\
\hline & $\begin{array}{c}\text { NL-4- } \\
\text { WT } \\
(n=21)\end{array}$ & $\begin{array}{c}\text { NL-4- } \\
\text { KO } \\
(n=17)\end{array}$ & $\begin{array}{c}\text { NL-4- } \\
\text { WT } \\
(n=11)\end{array}$ & $\begin{array}{c}\text { NL-4- } \\
\text { KO } \\
(n=14)\end{array}$ \\
\hline $\begin{array}{l}\text { Arithmetisches } \\
\text { Mittel }\end{array}$ & 5,55 & 6,14 & 5,45 & 6,20 \\
\hline Median & 5,62 & 6,21 & 5,23 & 6,15 \\
\hline $\begin{array}{l}\text { Standardab- } \\
\text { weichung }\end{array}$ & 0,79 & 0,62 & 0,76 & 0,71 \\
\hline Standardfehler & 0,17 & 0,15 & 0,23 & 0,19 \\
\hline $\mathrm{p}$-Wert & \multicolumn{2}{|c|}{0,040} & \multicolumn{2}{|c|}{0,017} \\
\hline
\end{tabular}

Tabelle 7.3:

Maximales Gefälle exzitatorischer Neurone

\begin{tabular}{|c|c|c|c|c|}
\hline \multirow[b]{2}{*}{$\begin{array}{l}\text { maximales } \\
\text { Gefälle }\left(\frac{\mathrm{pA}}{\mathrm{ms}}\right)\end{array}$} & \multicolumn{2}{|c|}{ sEPSC } & \multicolumn{2}{|c|}{ mEPSC } \\
\hline & $\begin{array}{c}\text { NL-4- } \\
\text { WT } \\
(n=21)\end{array}$ & $\begin{array}{c}\text { NL-4- } \\
\text { KO } \\
(n=17)\end{array}$ & $\begin{array}{c}\text { NL-4- } \\
\text { WT } \\
(n=11)\end{array}$ & $\begin{array}{c}\mathrm{NL}-4- \\
\mathrm{KO} \\
(n=14)\end{array}$ \\
\hline $\begin{array}{l}\text { Arithmetisches } \\
\text { Mittel }\end{array}$ & 33,66 & 30,41 & 36,41 & 29,36 \\
\hline Median & 34,57 & 27,81 & 36,07 & 27,05 \\
\hline $\begin{array}{l}\text { Standardab- } \\
\text { weichung }\end{array}$ & 5,44 & 5,21 & 6,91 & 4,94 \\
\hline Standardfehler & 1,19 & 1,26 & 2,08 & 1,32 \\
\hline $\mathrm{p}$-Wert & \multicolumn{2}{|c|}{0,047} & \multicolumn{2}{|c|}{0,007} \\
\hline
\end{tabular}

Tabelle 7.4:

Maximale Steigung exzitatorischer Neurone

\begin{tabular}{|c|c|c|c|c|}
\hline \multirow{2}{*}{$\begin{array}{c}\text { maximale } \\
\text { Steigung } \\
\left(\frac{\mathrm{pA}}{\mathrm{ms}}\right)\end{array}$} & \multicolumn{2}{|c|}{ sEPSC } & \multicolumn{2}{|c|}{ mEPSC } \\
\hline & $\begin{array}{c}\text { NL-4- } \\
\text { WT } \\
(n=21)\end{array}$ & $\begin{array}{c}\text { NL-4- } \\
\text { KO } \\
(n=17)\end{array}$ & $\begin{array}{c}\text { NL-4- } \\
\text { WT } \\
(n=11)\end{array}$ & $\begin{array}{c}\text { NL-4- } \\
\text { KO } \\
(n=14)\end{array}$ \\
\hline $\begin{array}{l}\text { Arithmetisches } \\
\text { Mittel }\end{array}$ & $-31,01$ & $-27,85$ & $-33,20$ & $-27,11$ \\
\hline Median & $-30,81$ & $-25,55$ & $-31,56$ & $-25,55$ \\
\hline $\begin{array}{l}\text { Standardab- } \\
\text { weichung }\end{array}$ & 4,68 & 5,04 & 6,45 & 4,71 \\
\hline Standardfehler & 1,02 & 1,22 & 1,95 & 1,26 \\
\hline$p$-Wert & \multicolumn{2}{|c|}{0,016} & \multicolumn{2}{|c|}{0,005} \\
\hline
\end{tabular}

Tabelle 7.5:

Anstiegszeit exzitatorischer Neurone

\begin{tabular}{l|c|c|c|c} 
& \multicolumn{2}{|c|}{ sEPSC } & \multicolumn{2}{c}{ mEPSC } \\
$\begin{array}{l}\text { Anstiegszeit } \\
(\mathrm{ms})\end{array}$ & $\begin{array}{c}\text { NL-4- } \\
\text { WT } \\
(\mathrm{n}=21)\end{array}$ & $\begin{array}{c}\text { NL-4- } \\
\text { KO } \\
(\mathrm{n}=17)\end{array}$ & $\begin{array}{c}\text { NL-4- } \\
\text { WT } \\
(\mathrm{n}=11)\end{array}$ & $\begin{array}{c}\text { NL-4- } \\
\text { KO } \\
(\mathrm{n}=14)\end{array}$ \\
\hline $\begin{array}{l}\text { Arithmetisches } \\
\text { Mittel }\end{array}$ & 2,35 & 2,44 & 2,36 & 2,47 \\
$\begin{array}{l}\text { Median } \\
\begin{array}{l}\text { Standardab- } \\
\text { weichung }\end{array}\end{array}$ & 2,35 & 2,39 & 2,37 & 2,51 \\
$\begin{array}{l}\text { Standardfehler } \\
0,04\end{array}$ & 0,20 & 0,14 & 0,28 \\
\hline \multicolumn{2}{|c|}{0,05} & 0,04 & 0,08 \\
\hline
\end{tabular}


Tabelle 7.6:

Amplitude exzitatorischer Neurone

\begin{tabular}{|c|c|c|c|c|}
\hline \multirow[b]{2}{*}{$\begin{array}{l}\text { Amplitude } \\
(p A)\end{array}$} & \multicolumn{2}{|c|}{ sEPSC } & \multicolumn{2}{|c|}{ mEPSC } \\
\hline & $\begin{array}{c}\text { NL-4- } \\
\text { WT } \\
(n=21)\end{array}$ & $\begin{array}{c}\mathrm{NL}-4- \\
\mathrm{KO} \\
(\mathrm{n}=17)\end{array}$ & $\begin{array}{c}\text { NL-4- } \\
\text { WT } \\
(n=11)\end{array}$ & $\begin{array}{c}\mathrm{NL}-4- \\
\mathrm{KO} \\
(\mathrm{n}=14)\end{array}$ \\
\hline $\begin{array}{l}\text { Arithmetisches } \\
\text { Mittel }\end{array}$ & $-6,51$ & $-5,87$ & $-6,51$ & $-5,73$ \\
\hline Median & $-6,26$ & $-5,88$ & $-6,42$ & $-5,77$ \\
\hline $\begin{array}{l}\text { Standardab- } \\
\text { weichung }\end{array}$ & 1,19 & 0,85 & 1,19 & 0,98 \\
\hline Standardfehler & 0,26 & 0,21 & 0,36 & 0,26 \\
\hline $\mathrm{p}$-Wert & \multicolumn{2}{|c|}{0,159} & \multicolumn{2}{|c|}{0,163} \\
\hline
\end{tabular}

Tabelle 7.7:

Frequenz exzitatorischer Neurone

\begin{tabular}{|c|c|c|c|c|}
\hline \multirow[b]{2}{*}{$\begin{array}{l}\text { Frequenz } \\
\qquad\left(\frac{1}{s}\right)\end{array}$} & \multicolumn{2}{|c|}{ sEPSC } & \multicolumn{2}{|c|}{ mEPSC } \\
\hline & $\begin{array}{l}\text { NL-4- } \\
\text { WT } \\
(n=21)\end{array}$ & $\begin{array}{c}\mathrm{NL}-4- \\
\mathrm{KO} \\
(n=17)\end{array}$ & $\begin{array}{c}\text { NL-4- } \\
\text { WT } \\
(n=11)\end{array}$ & $\begin{array}{c}\mathrm{NL}-4- \\
\mathrm{KO} \\
(n=14)\end{array}$ \\
\hline $\begin{array}{l}\text { Arithmetisches } \\
\text { Mittel }\end{array}$ & 5,90 & 5,91 & 4,52 & 5,09 \\
\hline Median & 5,24 & 6,04 & 2,80 & 5,00 \\
\hline $\begin{array}{l}\text { Standardab- } \\
\text { weichung }\end{array}$ & 4,08 & 1,84 & 3,87 & 2,05 \\
\hline Standardfehler & 0,89 & 0,45 & 1,17 & 0,55 \\
\hline$p$-Wert & \multicolumn{2}{|c|}{0,428} & \multicolumn{2}{|c|}{0,147} \\
\hline
\end{tabular}

Tabelle 7.8:

Halbwertszeit exzitatorischer Neurone

\begin{tabular}{l|c|c|c|c} 
& \multicolumn{2}{|c|}{ sEPSC } & \multicolumn{2}{c}{ mEPSC } \\
$\begin{array}{l}\text { Halbwerts- } \\
\text { zeit (ms) }\end{array}$ & $\begin{array}{c}\text { NL-4- } \\
\text { WT } \\
(n=21)\end{array}$ & $\begin{array}{c}\text { NL-4- } \\
\text { KO } \\
(n=17)\end{array}$ & $\begin{array}{c}\text { NL-4- } \\
\text { WT } \\
(n=11)\end{array}$ & $\begin{array}{c}\text { NL-4- } \\
\text { KO } \\
(n=14)\end{array}$ \\
\hline $\begin{array}{l}\text { Arithmetisches } \\
\text { Mittel }\end{array}$ & 1,77 & 2,02 & 1,40 & 1,82 \\
$\begin{array}{l}\text { Median } \\
\begin{array}{l}\text { Standardab- } \\
\text { weichung }\end{array}\end{array}$ & 0,85 & 0,63 & 0,81 & 0,68 \\
$\begin{array}{l}\text { Standardfehler } \\
0,19\end{array}$ & 0,15 & 0,25 & 0,18 \\
\hline p-Wert & \multicolumn{3}{|c|}{0,252} & \multicolumn{2}{c}{0,059}
\end{tabular}

Tabelle 7.9:

Fläche exzitatorischer Neurone

\begin{tabular}{l|c|c|c|c} 
& \multicolumn{2}{|c|}{ sEPSC } & \multicolumn{2}{c}{ mEPSC } \\
$\begin{array}{l}\text { Fläche } \\
(\mathrm{pA} * \mathrm{~ms})\end{array}$ & $\begin{array}{c}\text { NL-4- } \\
\text { WT } \\
(\mathrm{n}=21)\end{array}$ & $\begin{array}{c}\text { NL-4- } \\
\text { KO } \\
(n=17)\end{array}$ & $\begin{array}{c}\text { NL-4- } \\
\text { WT } \\
(\mathrm{n}=11)\end{array}$ & $\begin{array}{c}\text { NL-4- } \\
\text { KO } \\
(n=14)\end{array}$ \\
\hline $\begin{array}{l}\text { Arithmetisches } \\
\text { Mittel }\end{array}$ & $-48,85$ & $-43,68$ & $-49,27$ & $-42,84$ \\
$\begin{array}{l}\text { Median } \\
\begin{array}{l}\text { Standardab- } \\
\text { weichung }\end{array}\end{array}$ & $-45,72$ & $-42,26$ & $-45,43$ & $-43,00$ \\
$\begin{array}{l}\text { Standardfehler } \\
10,04\end{array}$ & 7,39 & 9,69 & 4,57 \\
\hline \multicolumn{2}{|c|}{2,19} & 1,79 & 2,92 & 1,22 \\
\hline
\end{tabular}




\subsection{Isolierte Auswertung bedornter Sternzellen}

Tabelle 7.10:

Abfallszeit bedornter Sternzellen

\begin{tabular}{l|c|c|c|c} 
& \multicolumn{2}{|c|}{ sEPSC } & \multicolumn{2}{c}{ mEPSC } \\
$\begin{array}{l}\text { Abfallszeit } \\
(\mathrm{ms})\end{array}$ & $\begin{array}{c}\text { NL-4- } \\
\text { WT } \\
(\mathrm{n}=9)\end{array}$ & $\begin{array}{c}\text { NL-4- } \\
\text { KO } \\
(\mathrm{n}=12)\end{array}$ & $\begin{array}{c}\text { NL-4- } \\
\text { WT } \\
(\mathrm{n}=5)\end{array}$ & $\begin{array}{c}\text { NL-4- } \\
\text { KO } \\
(\mathrm{n}=10)\end{array}$ \\
\hline $\begin{array}{l}\text { Arithmetisches } \\
\text { Mittel }\end{array}$ & 5,24 & 6,12 & 4,94 & 6,01 \\
$\begin{array}{l}\text { Median } \\
\begin{array}{l}\text { Standardab- } \\
\text { weichung }\end{array}\end{array}$ & 5,07 & 6,25 & 4,89 & 5,94 \\
$\begin{array}{l}\text { Standardfehler } \\
0,57\end{array}$ & 0,55 & 0,31 & 0,70 \\
\hline p-Wert & \multicolumn{2}{|c|}{0,006} & 0,14 & 0,22 \\
\hline
\end{tabular}

Tabelle 7.11:

Halbwertszeit bedornter Sternzellen

\begin{tabular}{l|c|c|c|c} 
& \multicolumn{2}{|c|}{ sEPSC } & \multicolumn{2}{c}{ mEPSC } \\
$\begin{array}{l}\text { Halbwerts- } \\
\text { zeit (ms) }\end{array}$ & $\begin{array}{c}\text { NL-4- } \\
\text { WT } \\
(n=9)\end{array}$ & $\begin{array}{c}\text { NL-4- } \\
\text { KO } \\
(n=12)\end{array}$ & $\begin{array}{c}\text { NL-4- } \\
\text { WT } \\
(n=5)\end{array}$ & $\begin{array}{c}\text { NL-4- } \\
\text { KO } \\
(n=10)\end{array}$ \\
\hline $\begin{array}{l}\text { Arithmetisches } \\
\text { Mittel }\end{array}$ & 1,26 & 2,05 & 0,96 & 1,84 \\
$\begin{array}{l}\text { Median } \\
\begin{array}{l}\text { Standardab- } \\
\text { weichung }\end{array}\end{array}$ & 0,48 & 0,66 & 0,21 & 0,77 \\
Standardfehler & 0,16 & 0,19 & 0,09 & 0,24 \\
\hline \begin{tabular}{l} 
p-Wert \\
\hline
\end{tabular} & \multicolumn{2}{|c|}{0,030} & \multicolumn{2}{c}{0,006}
\end{tabular}

Tabelle 7.12:

Maximales Gefälle bedornter Sternzellen

\begin{tabular}{l|c|c|c|c} 
& \multicolumn{2}{|c|}{ sEPSC } & \multicolumn{2}{c}{ mEPSC } \\
$\begin{array}{l}\text { maximales } \\
\text { Gefälle }\left(\frac{\mathrm{pA}}{\mathrm{ms}}\right)\end{array}$ & $\begin{array}{c}\text { NL-4- } \\
\text { WT } \\
(\mathrm{n}=9)\end{array}$ & $\begin{array}{c}\text { NL-4- } \\
\text { KO } \\
(\mathrm{n}=12)\end{array}$ & $\begin{array}{c}\text { NL-4- } \\
\text { WT } \\
(\mathrm{n}=5)\end{array}$ & $\begin{array}{c}\text { NL-4- } \\
\text { KO } \\
(n=10)\end{array}$ \\
\hline $\begin{array}{l}\text { Arithmetisches } \\
\text { Mittel }\end{array}$ & 35,40 & 30,75 & 38,63 & 30,44 \\
$\begin{array}{l}\text { Median } \\
\begin{array}{l}\text { Standardab- } \\
\text { weichung }\end{array}\end{array}$ & 55,32 & 29,68 & 36,07 & 30,06 \\
$\begin{array}{l}\text { Standardfehler } \\
1,86\end{array}$ & 1,45 & 3,03 & 8,22 & 5,54 \\
\hline p-Wert & \multicolumn{2}{|c|}{0,055} & \multicolumn{2}{c}{0,043}
\end{tabular}

Tabelle 7.13:

Maximale Steigung bedornter Sternzellen

\begin{tabular}{l|c|c|c|c}
$\begin{array}{l}\text { maximale } \\
\begin{array}{c}\text { Steigung } \\
\left(\frac{\mathrm{pA}}{\mathrm{ms}}\right)\end{array}\end{array}$ & $\begin{array}{c}\text { NL-4- } \\
\text { WT } \\
(\mathrm{n}=9)\end{array}$ & $\begin{array}{c}\text { NL-4- } \\
\text { KO } \\
(\mathrm{n}=12)\end{array}$ & $\begin{array}{c}\text { NL-4- } \\
\text { WT } \\
(\mathrm{n}=5)\end{array}$ & $\begin{array}{c}\text { NL-4- } \\
\text { KO } \\
(n=10)\end{array}$ \\
\hline $\begin{array}{l}\text { Arithmetisches } \\
\text { Mittel }\end{array}$ & $-31,90$ & $-27,87$ & $-34,87$ & $-27,88$ \\
$\begin{array}{l}\text { Median } \\
\text { Standardab- } \\
\text { weichung }\end{array}$ & $-30,81$ & $-26,30$ & $-31,56$ & $-26,68$ \\
$\begin{array}{l}\text { Standardfehler } \\
\text { Stand }\end{array}$ & 1,51 & 1,36 & 3,66 & 1,72 \\
\hline \multicolumn{2}{|c|}{0,030} & \multicolumn{2}{c}{0,058}
\end{tabular}


Tabelle 7.14:

Anstiegszeit bedornter Sternzellen

\begin{tabular}{l|c|c|c|c} 
& \multicolumn{2}{|c|}{ sEPSC } & \multicolumn{2}{c}{ mEPSC } \\
$\begin{array}{l}\text { Anstiegszeit } \\
(\mathrm{ms})\end{array}$ & $\begin{array}{c}\text { NL-4- } \\
\text { WT } \\
(\mathrm{n}=9)\end{array}$ & $\begin{array}{c}\mathrm{NL-4} \\
\mathrm{KO} \\
(\mathrm{n}=12)\end{array}$ & $\begin{array}{c}\text { NL-4- } \\
\text { WT } \\
(\mathrm{n}=5)\end{array}$ & $\begin{array}{c}\text { NL-4- } \\
\text { KO } \\
(\mathrm{n}=10)\end{array}$ \\
\hline $\begin{array}{l}\text { Arithmetisches } \\
\text { Mittel }\end{array}$ & 2,38 & 2,44 & 2,32 & 2,40 \\
$\begin{array}{l}\text { Median } \\
\begin{array}{l}\text { Standardab- } \\
\text { weichung }\end{array}\end{array}$ & 0,16 & 0,21 & 0,12 & 0,31 \\
$\begin{array}{l}\text { Standardfehler } \\
0,05\end{array}$ & 0,06 & 0,06 & 0,10 \\
\hline p-Wert & \multicolumn{2}{|c|}{0,500} & \multicolumn{2}{c}{0,582}
\end{tabular}

Tabelle 7.15:

Amplitude bedornter Sternzellen

\begin{tabular}{l|c|c|c|c} 
& \multicolumn{2}{|c|}{ sEPSC } & \multicolumn{2}{c}{ mEPSC } \\
$\begin{array}{l}\text { Amplitude } \\
(\mathrm{pA})\end{array}$ & $\begin{array}{c}\text { NL-4- } \\
\text { WT } \\
(\mathrm{n}=9)\end{array}$ & $\begin{array}{c}\text { NL-4- } \\
\text { KO } \\
(\mathrm{n}=12)\end{array}$ & $\begin{array}{c}\text { NL-4- } \\
\text { WT } \\
(\mathrm{n}=5)\end{array}$ & $\begin{array}{c}\text { NL-4- } \\
\text { KO } \\
(\mathrm{n}=10)\end{array}$ \\
\hline $\begin{array}{l}\text { Arithmetisches } \\
\text { Mittel }\end{array}$ & $-6,68$ & $-6,09$ & $-7,09$ & $-6,04$ \\
$\begin{array}{l}\text { Median } \\
\begin{array}{l}\text { Standardab- } \\
\text { weichung }\end{array}\end{array}$ & $-6,54$ & $-6,29$ & $-6,82$ & $-6,40$ \\
$\begin{array}{l}\text { Standardfehler } \\
\text { p-Wert }\end{array}$ & 0,42 & 0,25 & 0,48 & 0,30 \\
\hline \multicolumn{2}{|c|}{0,456} & \multicolumn{2}{c}{0,159}
\end{tabular}

Tabelle 7.16:

Frequenz bedornter Sternzellen

\begin{tabular}{l|c|c|c|c} 
& \multicolumn{2}{|c|}{ sEPSC } & \multicolumn{2}{c}{ mEPSC } \\
\multicolumn{1}{c|}{$\begin{array}{l}\text { Frequenz } \\
\left(\frac{1}{\mathrm{~s}}\right)\end{array}$} & $\begin{array}{c}\text { NL-4- } \\
\text { WT } \\
(\mathrm{n}=9)\end{array}$ & $\begin{array}{c}\text { NL-4- } \\
\text { KO } \\
(\mathrm{n}=12)\end{array}$ & $\begin{array}{c}\text { NL-4- } \\
\text { WT } \\
(\mathrm{n}=5)\end{array}$ & $\begin{array}{c}\text { NL-4- } \\
\text { KO } \\
(\mathrm{n}=10)\end{array}$ \\
\hline $\begin{array}{l}\text { Arithmetisches } \\
\text { Mittel }\end{array}$ & 3,92 & 5,50 & 3,31 & 4,84 \\
$\begin{array}{l}\text { Median } \\
\begin{array}{l}\text { Standardab- } \\
\text { weichung }\end{array}\end{array}$ & 2,80 & 5,13 & 2,77 & 5,00 \\
$\begin{array}{l}\text { Standardfehler } \\
0,93\end{array}$ & 2,03 & 2,38 & 1,93 \\
\hline p-Wert & \multicolumn{2}{|c|}{0,110} & 1,06 & 0,61 \\
\hline
\end{tabular}

Tabelle 7.17:

Fläche bedornter Sternzellen

\begin{tabular}{l|c|c|c|c} 
& \multicolumn{2}{|c|}{ sEPSC } & \multicolumn{2}{c}{ mEPSC } \\
$\begin{array}{l}\text { Fläche } \\
\left(\mathrm{pA} A^{*} \mathrm{~ms}\right)\end{array}$ & $\begin{array}{c}\text { NL-4- } \\
\text { WT } \\
(\mathrm{n}=9)\end{array}$ & $\begin{array}{c}\text { NL-4- } \\
\text { KO } \\
(\mathrm{n}=12)\end{array}$ & $\begin{array}{c}\text { NL-4- } \\
\text { WT } \\
(\mathrm{n}=5)\end{array}$ & $\begin{array}{c}\text { NL-4- } \\
\text { KO } \\
(\mathrm{n}=10)\end{array}$ \\
\hline $\begin{array}{l}\text { Arithmetisches } \\
\text { Mittel }\end{array}$ & $-47,39$ & $-44,44$ & $-50,44$ & $-43,70$ \\
$\begin{array}{l}\text { Median } \\
\begin{array}{l}\text { Standardab- } \\
\text { weichung }\end{array}\end{array}$ & $-45,59$ & $-43,87$ & $-45,43$ & $-43,81$ \\
$\begin{array}{l}\text { Standardfehler } \\
\text { p-Wert }\end{array}$ & 3,20 & 2,33 & 4,49 & 1,49 \\
\hline \multicolumn{2}{|c|}{0,337} & \multicolumn{2}{c}{0,358}
\end{tabular}




\subsection{AMPA-Rezeptor-vermittelte EPSC}

Tabelle 7.18: Mittelwerte und Verteilung der EPSC-Amplitude unter Kontrollbedingungen und nach Einwaschen von Gabazine für je ein NL-4-WT- und ein NL-4-KO-Neuron

\begin{tabular}{l|c|c|c|c}
\multicolumn{1}{c|}{$\begin{array}{c}\text { Amplitude } \\
\text { (pA) }\end{array}$} & \multicolumn{2}{|c|}{ NL-4-WT } & \multicolumn{2}{c}{ NL-4-KO } \\
\hline $\begin{array}{l}\text { Arithmetisches } \\
\text { Mittel }\end{array}$ & $-5,77$ & $-5,91$ & $-6,32$ & $-6,24$ \\
Median & $-5,61$ & $-5,65$ & $-5,86$ & $-5,83$ \\
$\begin{array}{l}\text { Standardab- } \\
\text { weichung }\end{array}$ & 1,50 & 1,78 & 1,89 & 2,69 \\
$\begin{array}{l}\text { Standardfehler } \\
\text { Stande }\end{array}$ & 0,05 & 0,08 & 0,05 & 0,08
\end{tabular}

Tabelle 7.19: Mittelwerte und Verteilung der EPSC-Anstiegszeit unter Kontrollbedingungen und nach Einwaschen von Gabazine für je ein NL-4-WT- und ein NL-4-KO-Neuron

\begin{tabular}{l|c|c|c|c}
$\begin{array}{c}\text { Anstiegszeit } \\
\text { (ms) }\end{array}$ & \multicolumn{2}{|c|}{ NL-4-WT } & \multicolumn{2}{c}{ NL-4-KO } \\
& Kontrolle & Gabazine & Kontrolle & Gabazine \\
\hline $\begin{array}{l}\text { Arithmetisches } \\
\text { Mittel }\end{array}$ & 2,73 & 2,71 & 2,41 & 2,54 \\
Median & 2,58 & 2,53 & 2,33 & 2,40 \\
$\begin{array}{l}\text { Standardab- } \\
\text { weichung }\end{array}$ & 1,08 & 1,07 & 0,97 & 1,02 \\
$\begin{array}{l}\text { Standardfehler } \\
\text { Stand }\end{array}$ & 0,03 & 0,05 & 0,02 & 0,03
\end{tabular}

Tabelle 7.20: Mittelwerte und Verteilung der maximalen Steigung unter Kontrollbedingungen und nach Einwaschen von Gabazine für je ein NL-4-WT- und ein NL-4-KO-Neuron

\begin{tabular}{|c|c|c|c|c|}
\hline \multirow{2}{*}{$\begin{array}{c}\text { maximale } \\
\text { Steigung } \\
\left(\frac{\mathrm{pA}}{\mathrm{ms}}\right)\end{array}$} & \multicolumn{2}{|c|}{ NL-4-WT } & \multicolumn{2}{|c|}{ NL-4-KO } \\
\hline & Kontrolle & Gabazine & Kontrolle & Gabazine \\
\hline $\begin{array}{l}\text { Arithmetisches } \\
\text { Mittel }\end{array}$ & $-25,15$ & $-25,93$ & $-23,92$ & $-24,10$ \\
\hline Median & $-24,80$ & $-26,30$ & $-23,30$ & $-23,30$ \\
\hline $\begin{array}{l}\text { Standardab- } \\
\text { weichung }\end{array}$ & 6,93 & 7,70 & 5,26 & 5,11 \\
\hline Standardfehler & 0,21 & 0,34 & 0,13 & 0,15 \\
\hline
\end{tabular}


Tabelle 7.21: Mittelwerte und Verteilung der EPSC-Abfallszeit unter Kontrollbedingungen und nach Einwaschen von Gabazine für je ein NL-4-WT- und ein NL-4-KO-Neuron

\begin{tabular}{l|c|c|c|c}
\multicolumn{1}{c|}{$\begin{array}{c}\text { Abfallszeit } \\
\text { (ms) }\end{array}$} & \multicolumn{2}{|c|}{ NL-4-WT } & \multicolumn{2}{c}{ NL-4-KO } \\
& Kontrolle & Gabazine & Kontrolle & Gabazine \\
\hline $\begin{array}{l}\text { Arithmetisches } \\
\text { Mittel }\end{array}$ & 6,73 & 6,47 & 5,87 & 5,97 \\
$\begin{array}{l}\text { Median } \\
\begin{array}{l}\text { Standardab- } \\
\text { weichung }\end{array}\end{array}$ & 6,31 & 6,03 & 5,42 & 5,47 \\
$\begin{array}{l}\text { Standardfehler } \\
\text { Stan }\end{array}$ & 0,10 & 0,15 & 0,07 & 0,09
\end{tabular}

Tabelle 7.22: Mittelwerte und Verteilung des maximalen Gefälles unter Kontrollbedingungen und nach Einwaschen von Gabazine für je ein NL-4-WT- und ein NL-4-KO-Neuron

\begin{tabular}{l|c|c|c|c}
$\begin{array}{l}\text { maximales } \\
\text { Gefälle }\left(\frac{\mathrm{pA}}{\mathrm{ms}}\right)\end{array}$ & \multicolumn{2}{|c|}{ NL-4-WT } & \multicolumn{2}{c}{ NL-4-KO } \\
Kontrolle & Gabazine & Kontrolle & Gabazine \\
\hline $\begin{array}{l}\text { Arithmetisches } \\
\text { Mittel }\end{array}$ & 27,91 & 28,50 & 26,37 & 26,90 \\
Median & 27,80 & 28,56 & 26,30 & 26,30 \\
$\begin{array}{l}\text { Standardab- } \\
\text { weichung }\end{array}$ & 7,21 & 8,38 & 5,39 & 4,72 \\
Standardfehler & 0,23 & 0,40 & 0,14 & 0,15
\end{tabular}

\subsection{Analyse der Netzwerkaktivität - TTX-sensitive EPSC}

Tabelle 7.23: Frequenz und Intervall TTX-sensitiver EPSC

\begin{tabular}{l|c|c|c|c}
\multirow{2}{*}{ TTX-sensitive EPSC } & \multicolumn{2}{|c|}{ Frequenz $\left(\frac{1}{s}\right)$} & \multicolumn{2}{c}{ EPSC-Intervall (s) } \\
& $\begin{array}{c}\text { NL-4-WT } \\
(n=10)\end{array}$ & $\begin{array}{c}\text { NL-4-KO } \\
(n=13)\end{array}$ & $\begin{array}{c}\text { NL-4-WT } \\
(n=9)\end{array}$ & $\begin{array}{c}\text { NL-4-KO } \\
(n=13)\end{array}$ \\
\hline Arithmetisches Mittel & 0,027 & 0,060 & 45,85 & 40,03 \\
Median & 0,012 & 0,024 & 41,28 & 24,26 \\
Standardabweichung & 0,025 & 0,092 & 37,92 & 57,99 \\
Standardfehler & 0,008 & 0,026 & 12,64 & 16,08 \\
\hline p-Wert & \multicolumn{2}{|c|}{0,352} & \multicolumn{2}{|c}{0,285}
\end{tabular}




\section{LITERATURVERZEICHNIS}

Armstrong-James M, Fox K und Das-Gupta A (1992): Flow of excitation within rat barrel cortex on striking a single vibrissa. J Neurophysiol $\underline{68}, 1345-1358$

Barrow SL, Constable JR, Clark E, El-Sabeawy F, McAllister AK und Washbourne P (2009): Neuroligin1: a cell adhesion molecule that recruits PSD-95 and NMDA receptors by distinct mechanisms during synaptogenesis. Neural Dev $\underline{4}, 17$ (elektronische Publikation)

Bear MF, Connors BW und Paradiso MA: Neuroscience: Exploring the Brain, 3. Auflage; Lippincott Williams \& Wilkins, Baltimore 2007

Bernardo KL und Woolsey TA (1987): Axonal trajectories between mouse somatosensory thalamus and cortex. J Comp Neurol 258, 542-564

Biederer T und Südhof TC (2000): Mints as adaptors. Direct binding to neurexins and recruitment of munc18. J Biol Chem 275, 39803-39806

Blasi F, Bacchelli E, Pesaresi G, Carone S, Bailey AJ und Maestrini E (2006): Absence of coding mutations in the X-linked genes neuroligin 3 and neuroligin 4 in individuals with autism from the IMGSAC collection. Am J Med Genet 141B, 220-221

Bolliger MF, Frei K, Winterhalter KH und Gloor SM (2001): Identification of a novel neuroligin in humans which binds to PSD-95 and has a widespread expression. Biochem J $\underline{356}, 581-588$

Bonora E, Lamb JA, Barnby G, Sykes N, Moberly T, Beyer KS, Klauck SM, Poustka F, Bacchelli E, Blasi F, Maestrini E, Battaglia A, Haracopos D, Pedersen L, Isager T, Eriksen G, Viskum B, Sorensen EU, Brondum-Nielsen K, Cotterill R, Engeland $H$, Jonge $M$, Kemner $C$, Steggehuis K, Scherpenisse M, Rutter M, Bolton PF, Parr JR, Poustka A, Bailey AJ und Monaco AP (2005): Mutation screening and association analysis of six candidate genes for autism on chromosome 7q. Eur J Hum Genet 13, 198-207

Budreck EC und Scheiffele P (2007): Neuroligin-3 is a neuronal adhesion protein at GABAergic and glutamatergic synapses. Eur J Neurosci 26, 1738-1748

Chen L, Chetkovich DM, Petralia RS, Sweeney NT, Kawasaki Y, Wenthold RJ, Bredt DS und Nicoll RA (2000): Stargazin regulates synaptic targeting of AMPA receptors by two distinct mechanisms. Nature $408,936-943$ 
Cho CH, St-Gelais F, Zhang W, Tomita S und Howe JR (2007): Two families of TARP isoforms that have distinct effects on the kinetic properties of AMPA receptors and synaptic currents. Neuron $\underline{55}$, 890-904

Cho KO, Hunt CA und Kennedy MB (1992): The rat brain postsynaptic density fraction contains a homolog of the Drosophila discs-large tumor suppressor protein. Neuron $\underline{9}, 929-$ 942

Connors BW und Gutnick MJ (1990): Intrinsic firing patterns of diverse neocortical neurons. Trends Neurosci $\underline{13}, 99-104$

Conti F und Weinberg RJ (1999): Shaping excitation at glutamatergic synapses. Trends Neurosci 22, 451-458

Danielson E, Zhang N, Metallo J, Kaleka K, Shin SM, Gerges N und Lee SH (2012): SSCAM/MAGI-2 is an essential synaptic scaffolding molecule for the GluA2-containing maintenance pool of AMPA receptors. J Neurosci $\underline{32}, 6967-6980$

Deng F, Price MG, Davis CF, Mori M und Burgess DL (2006): Stargazin and other transmembrane AMPA receptor regulating proteins interact with synaptic scaffolding protein MAGI-2 in brain. J Neurosci 26, 7875-7884

Diamond JS und Jahr CE (1995): Asynchronous release of synaptic vesicles determines the time course of the AMPA receptor-mediated EPSC. Neuron 15, 1097-1107

Durand CM, Betancur C, Boeckers TM, Bockmann J, Chaste P, Fauchereau F, Nygren G, Rastam M, Gillberg IC, Anckarsater H, Sponheim E, Goubran-Botros H, Delorme R, Chabane N, Mouren-Simeoni MC, de Mas P, Bieth E, Roge B, Heron D, Burglen L, Gillberg C, Leboyer $M$ und Bourgeron T (2007): Mutations in the gene encoding the synaptic scaffolding protein SHANK3 are associated with autism spectrum disorders. Nat Genet 39, 25-27

Ehrlich I und Malinow R (2004): Postsynaptic density 95 controls AMPA receptor incorporation during long-term potentiation and experience-driven synaptic plasticity. J Neurosci 24, 916-927

El-Husseini AE, Schnell E, Chetkovich DM, Nicoll RA und Bredt DS (2000): PSD-95 involvement in maturation of excitatory synapses. Science $\underline{290}, 1364-1368$

Etherton MR, Tabuchi K, Sharma M, Ko J und Südhof TC (2011): An autism-associated point mutation in the neuroligin cytoplasmic tail selectively impairs AMPA receptor-mediated synaptic transmission in hippocampus. EMBO J $\underline{30}$, 2908-2919 
Fatt P und Katz B (1952): Spontaneous subthreshold activity at motor nerve endings. J Physiol $\underline{117}, 109-128$

Feldmeyer D, Brecht M, Helmchen F, Petersen CC, Poulet JF, Staiger JF, Luhmann HJ und Schwarz C (2012): Barrel cortex function. Prog Neurobiol (im Druck; elektronisch bereits verfügbar)

Feng J, Schroer R, Yan J, Song W, Yang C, Bockholt A, Cook EH, Jr., Skinner C, Schwartz CE und Sommer SS (2006): High frequency of neurexin 1beta signal peptide structural variants in patients with autism. Neurosci Lett $\underline{409}, 10-13$

Fox K: Barrel Cortex, Cambridge University Press, Cambridge (UK) 2008

Freitag CM (2007): The genetics of autistic disorders and its clinical relevance: a review of the literature. Mol Psychiatry 12, 2-22

Futai K, Kim MJ, Hashikawa T, Scheiffele P, Sheng M und Hayashi Y (2007): Retrograde modulation of presynaptic release probability through signaling mediated by PSD-95neuroligin. Nat Neurosci 10 , 186-195

Gerrow K, Romorini S, Nabi SM, Colicos MA, Sala C und El-Husseini A (2006): A preformed complex of postsynaptic proteins is involved in excitatory synapse development. Neuron $\underline{49}$, 547-562

Graf ER, Zhang X, Jin SX, Linhoff MW und Craig AM (2004): Neurexins induce differentiation of GABA and glutamate postsynaptic specializations via neuroligins. Cell $\underline{119}, 1013-1026$

Hamill OP, Marty A, Neher E, Sakmann B und Sigworth FJ (1981): Improved patch-clamp techniques for high-resolution current recording from cells and cell-free membrane patches. Pflugers Arch 391, 85-100

Hashimoto K, Fukaya M, Qiao X, Sakimura K, Watanabe M und Kano M (1999): Impairment of AMPA receptor function in cerebellar granule cells of ataxic mutant mouse stargazer. J Neurosci $\underline{19}, 6027-6036$

Hata Y, Butz S und Südhof TC (1996): CASK: a novel dlg/PSD95 homolog with an N-terminal calmodulin-dependent protein kinase domain identified by interaction with neurexins. J Neurosci $\underline{16}$, 2488-2494 
Heine M, Thoumine O, Mondin M, Tessier B, Giannone G und Choquet D (2008): Activityindependent and subunit-specific recruitment of functional AMPA receptors at neurexin/neuroligin contacts. Proc Natl Acad Sci USA 105, 20947-20952

Hille B: Ion channels of excitable membranes, 3. Auflage; Sinauer, Sunderland (USA) 2001

Hirao K, Hata Y, Ide N, Takeuchi M, Irie M, Yao I, Deguchi M, Toyoda A, Südhof TC und Takai $Y$ (1998): A novel multiple PDZ domain-containing molecule interacting with N-methyl-Daspartate receptors and neuronal cell adhesion proteins. J Biol Chem $\underline{273}, 21105-21110$

Hoon M, Soykan T, Falkenburger B, Hammer M, Patrizi A, Schmidt KF, Sassoe-Pognetto M, Lowel S, Moser T, Taschenberger H, Brose N und Varoqueaux F (2011): Neuroligin-4 is localized to glycinergic postsynapses and regulates inhibition in the retina. Proc Natl Acad Sci USA $\underline{108}, 3053-3058$

Hutcheson HB, Olson LM, Bradford Y, Folstein SE, Santangelo SL, Sutcliffe JS und Haines JL (2004): Examination of NRCAM, LRRN3, KIAA0716, and LAMB1 as autism candidate genes. BMC Med Genet $\underline{5}, 12$

Ichtchenko K, Hata Y, Nguyen T, Ullrich B, Missler M, Moomaw C und Südhof TC (1995): Neuroligin 1: a splice site-specific ligand for beta-neurexins. Cell $\underline{81}$, 435-443

Ichtchenko K, Nguyen T und Südhof TC (1996): Structures, alternative splicing, and neurexin binding of multiple neuroligins. J Biol Chem 271, 2676-2682

lida J, Hirabayashi S, Sato Y und Hata Y (2004): Synaptic scaffolding molecule is involved in the synaptic clustering of neuroligin. Mol Cell Neurosci 27, 497-508

Irie M, Hata Y, Takeuchi M, Ichtchenko K, Toyoda A, Hirao K, Takai Y, Rosahl TW und Südhof TC (1997): Binding of neuroligins to PSD-95. Science 277, 1511-1515

Jamain S, Quach H, Betancur C, Rastam M, Colineaux C, Gillberg IC, Soderstrom H, Giros B, Leboyer M, Gillberg C und Bourgeron T (2003): Mutations of the X-linked genes encoding neuroligins NLGN3 and NLGN4 are associated with autism. Nat Genet 34, 27-29

Jamain S, Radyushkin K, Hammerschmidt K, Granon S, Boretius S, Varoqueaux F, Ramanantsoa N, Gallego J, Ronnenberg A, Winter D, Frahm J, Fischer J, Bourgeron T, Ehrenreich H und Brose N (2008): Reduced social interaction and ultrasonic communication in a mouse model of monogenic heritable autism. Proc Natl Acad Sci USA 105, 1710-1715 
Jonas P und Spruston N (1994): Mechanisms shaping glutamate-mediated excitatory postsynaptic currents in the CNS. Curr Opin Neurobiol 4, 366-372

Jones EG (1975): Varieties and distribution of non-pyramidal cells in the somatic sensory cortex of the squirrel monkey. J Comp Neurol 160, 205-267

Kandel ER und Siegelbaum SA: Synaptic Transmission; in: Principles Of Neural Science, 5. Auflage; hrsg. v. Kandel ER, Schwartz JH, Jessell TM, Siegelbaum SA und Hudspeth AJ; McGraw-Hill Medical, New York (USA) 2013, 177-188

Killackey HP (1973): Anatomical evidence for cortical subdivisions based on vertically discrete thalamic projections from the ventral posterior nucleus to cortical barrels in the rat. Brain Res $\underline{51}$, 326-331

Killackey HP und Leshin S (1975): The organization of specific thalamocortical projections to the posteromedial barrel subfield of the rat somatic sensory cortex. Brain Res $\underline{86}, 469-472$

Kim HG, Kishikawa S, Higgins AW, Seong IS, Donovan DJ, Shen Y, Lally E, Weiss LA, Najm J, Kutsche K, Descartes M, Holt L, Braddock S, Troxell R, Kaplan L, Volkmar F, Klin A, Tsatsanis K, Harris DJ, Noens I, Pauls DL, Daly MJ, MacDonald ME, Morton CC, Quade BJ und Gusella JF (2008): Disruption of neurexin 1 associated with autism spectrum disorder. Am J Hum Genet $\underline{82}$, 199-207

Kobbert C, Apps R, Bechmann I, Lanciego JL, Mey J und Thanos S (2000): Current concepts in neuroanatomical tracing. Prog Neurobiol 62, 327-351

Korbmacher $\mathbf{C}$ und Greger R: Die Zelle als Grundbaustein; in: Physiologie, 5. Auflage; hrsg. v. Klinke R, Pape HC und Silbernagl S; Thieme, Stuttgart 2005, 13-52

Kott S, Werner M, Korber C und Hollmann M (2007): Electrophysiological properties of AMPA receptors are differentially modulated depending on the associated member of the TARP family. J Neurosci 27, 3780-3789

Krueger DD, Tuffy LP, Papadopoulos T und Brose N (2012): The role of neurexins and neuroligins in the formation, maturation, and function of vertebrate synapses. Curr Opin Neurobiol 22, 412-422

Kuffler SW, Nicholls JG und Martin AR: From Neuron to Brain: A Cellular Approach to the Function of the Nervous System, 2. Auflage; Sinauer, Sunderland (USA) 1984 
Kugler P: Nervensystem: Grundzüge der Organisation; in: Benninghoff, Drenckhahn: Anatomie Band II 16. Auflage; hrsg. v. Drenckhahn D; Elsevier Urban \& Fischer, München 2004, 232-247

Laumonnier F, Bonnet-Brilhault F, Gomot M, Blanc R, David A, Moizard MP, Raynaud M, Ronce N, Lemonnier E, Calvas P, Laudier B, Chelly J, Fryns JP, Ropers HH, Hamel BC, Andres C, Barthelemy C, Moraine C und Briault S (2004): X-linked mental retardation and autism are associated with a mutation in the NLGN4 gene, a member of the neuroligin family. Am J Hum Genet 74, 552-557

Levinson JN, Li R, Kang R, Moukhles H, El-Husseini A und Bamji SX (2010): Postsynaptic scaffolding molecules modulate the localization of neuroligins. Neuroscience $165,782-793$

Lise MF und El-Husseini A (2006): The neuroligin and neurexin families: from structure to function at the synapse. Cell Mol Life Sci $\underline{63}$, 1833-1849

Lu SM und Lin RC (1993): Thalamic afferents of the rat barrel cortex: a light- and electronmicroscopic study using Phaseolus vulgaris leucoagglutinin as an anterograde tracer. Somatosens Mot Res $\underline{10}$, 1-16

Lübke J, Egger V, Sakmann B und Feldmeyer D (2000): Columnar organization of dendrites and axons of single and synaptically coupled excitatory spiny neurons in layer 4 of the rat barrel cortex. J Neurosci 20, 5300-5311

Moessner R, Marshall CR, Sutcliffe JS, Skaug J, Pinto D, Vincent J, Zwaigenbaum L, Fernandez B, Roberts W, Szatmari P und Scherer SW (2007): Contribution of SHANK3 mutations to autism spectrum disorder. Am J Hum Genet 81, 1289-1297

Molleman A: Patch clamping: An Introductory Guide to Patch Clamp Electrophysiology, Wiley, New York (USA) 2003

Mondin M, Labrousse V, Hosy E, Heine M, Tessier B, Levet F, Poujol C, Blanchet C, Choquet D und Thoumine $\mathbf{O}$ (2011): Neurexin-neuroligin adhesions capture surface-diffusing AMPA receptors through PSD-95 scaffolds. J Neurosci 31, 13500-13515

Mulisch M: Immunlokalisation; in: Romeis Mikroskopische Technik, 18. Auflage; hrsg. v. Mulisch M und Welsch U; Spektrum Akademischer Verlag, Heidelberg 2010, 387-418

Nam Cl und Chen L (2005): Postsynaptic assembly induced by neurexin-neuroligin interaction and neurotransmitter. Proc Natl Acad Sci USA 102, 6137-6142 
Narahashi T, Deguchi T, Urakawa N und Ohkubo Y (1960): Stabilization and rectification of muscle fiber membrane by tetrodotoxin. Am J Physiol 198, 934-938

Narahashi T, Moore JW und Scott WR (1964): Tetrodotoxin Blockage of Sodium Conductance Increase in Lobster Giant Axons. J Gen Physiol 47, 965-974

Neher E und Sakmann B (1976): Single-channel currents recorded from membrane of denervated frog muscle fibres. Nature $\underline{260}, 799-802$

Nguyen T und Südhof TC (1997): Binding properties of neuroligin 1 and neurexin 1 beta reveal function as heterophilic cell adhesion molecules. J Biol Chem $\underline{272}$, 26032-26039

Otis TS, Wu YC und Trussell LO (1996): Delayed clearance of transmitter and the role of glutamate transporters at synapses with multiple release sites. J Neurosci $\underline{16}$, 1634-1644

Peca J, Feliciano C, Ting JT, Wang W, Wells MF, Venkatraman TN, Lascola CD, Fu Z und Feng G (2011): Shank3 mutant mice display autistic-like behaviours and striatal dysfunction. Nature $\underline{472}, 437-442$

Petersen CC (2007): The functional organization of the barrel cortex. Neuron $\underline{56}, 339-355$

Rodriguez-Molina VM, Aertsen A und Heck DH (2007): Spike timing and reliability in cortical pyramidal neurons: effects of EPSC kinetics, input synchronization and background noise on spike timing. PLoS One 2, e319 (elektronische Publikation)

Saras J und Heldin CH (1996): PDZ domains bind carboxy-terminal sequences of target proteins. Trends Biochem Sci 21, 455-458

Scheiffele P, Fan J, Choih J, Fetter R und Serafini T (2000): Neuroligin expressed in nonneuronal cells triggers presynaptic development in contacting axons. Cell 101, 657-669

Schubert D, Kotter R und Staiger JF (2007): Mapping functional connectivity in barrel-related columns reveals layer- and cell type-specific microcircuits. Brain Struct Funct 212, 107-119

Simons DJ (1978): Response properties of vibrissa units in rat SI somatosensory neocortex. J Neurophysiol $\underline{41}$, 798-820

Simons DJ und Woolsey TA (1984): Morphology of Golgi-Cox-impregnated barrel neurons in rat Sml cortex. J Comp Neurol 230, 119-132 
Song JY, Ichtchenko K, Südhof TC und Brose N (1999): Neuroligin 1 is a postsynaptic celladhesion molecule of excitatory synapses. Proc Natl Acad Sci USA $\underline{96}$, 1100-1105

Staiger JF, Zilles K und Freund TF (1996): Distribution of GABAergic elements postsynaptic to ventroposteromedial thalamic projections in layer IV of rat barrel cortex. Eur J Neurosci $\underline{8}$, 2273-2285

Staiger JF, Flagmeyer I, Schubert D, Zilles K, Kotter R und Luhmann HJ (2004): Functional diversity of layer IV spiny neurons in rat somatosensory cortex: quantitative morphology of electrophysiologically characterized and biocytin labeled cells. Cereb Cortex $\underline{14}, 690-701$

Sumita K, Sato Y, lida J, Kawata A, Hamano M, Hirabayashi S, Ohno K, Peles E und Hata Y (2007): Synaptic scaffolding molecule (S-SCAM) membrane-associated guanylate kinase with inverted organization (MAGI)-2 is associated with cell adhesion molecules at inhibitory synapses in rat hippocampal neurons. J Neurochem $\underline{100}, 154-166$

Suzuki E, Kessler M und Arai AC (2008): The fast kinetics of AMPA GluR3 receptors is selectively modulated by the TARPs gamma 4 and gamma 8. Mol Cell Neurosci $\underline{38}$, 117-123

Tomita S, Chen L, Kawasaki Y, Petralia RS, Wenthold RJ, Nicoll RA und Bredt DS (2003): Functional studies and distribution define a family of transmembrane AMPA receptor regulatory proteins. J Cell Biol 161, 805-816

Tomita S, Adesnik H, Sekiguchi M, Zhang W, Wada K, Howe JR, Nicoll RA und Bredt DS (2005): Stargazin modulates AMPA receptor gating and trafficking by distinct domains. Nature $\underline{435}, 1052-1058$

Traynelis SF, Wollmuth LP, McBain CJ, Menniti FS, Vance KM, Ogden KK, Hansen KB, Yuan H, Myers SJ und Dingledine R (2010): Glutamate receptor ion channels: structure, regulation, and function. Pharmacol Rev $\underline{62}, 405-496$

Trussell LO, Zhang S und Raman IM (1993): Desensitization of AMPA receptors upon multiquantal neurotransmitter release. Neuron $\underline{10}$, 1185-1196

Turetsky D, Garringer E und Patneau DK (2005): Stargazin modulates native AMPA receptor functional properties by two distinct mechanisms. J Neurosci $\underline{25}, 7438-7448$

Ushkaryov YA, Petrenko AG, Geppert M und Südhof TC (1992): Neurexins: synaptic cell surface proteins related to the alpha-latrotoxin receptor and laminin. Science $257,50-56$ 
Ushkaryov YA, Hata Y, Ichtchenko K, Moomaw C, Afendis S, Slaughter CA und Südhof TC (1994): Conserved domain structure of beta-neurexins. Unusual cleaved signal sequences in receptor-like neuronal cell-surface proteins. J Biol Chem 269, 11987-11992

Varoqueaux F, Aramuni G, Rawson RL, Mohrmann R, Missler M, Gottmann K, Zhang W, Südhof TC und Brose $\mathbf{N}$ (2006): Neuroligins determine synapse maturation and function. Neuron $\underline{51}$, 741-754

Wang X, McCoy PA, Rodriguiz RM, Pan Y, Je HS, Roberts AC, Kim CJ, Berrios J, Colvin JS, Bousquet-Moore D, Lorenzo I, Wu G, Weinberg RJ, Ehlers MD, Philpot BD, Beaudet AL, Wetsel WC und Jiang YH (2011): Synaptic dysfunction and abnormal behaviors in mice lacking major isoforms of Shank3. Hum Mol Genet 20, 3093-3108

Welker C (1971): Microelectrode delineation of fine grain somatotopic organization of (Sml) cerebral neocortex in albino rat. Brain Res $\underline{26}$, 259-275

Welker C und Woolsey TA (1974): Structure of layer IV in the somatosensory neocortex of the rat: description and comparison with the mouse. J Comp Neurol 158, 437-453

Welker E, Armstrong-James M, Van der Loos H und Kraftsik R (1993): The mode of activation of a barrel column: response properties of single units in the somatosensory cortex of the mouse upon whisker deflection. Eur J Neurosci $\underline{5}, 691-712$

Welsch U: Enzymhistochemie; in: Romeis Mikroskopische Technik, 18. Auflage; hrsg. v. Mulisch M und Welsch U; Spektrum Akademischer Verlag, Heidelberg 2010, 371-386

WHO: ICD-10 - International Statistical Classification of Diseases and Related Health Problems - Internationale statistische Klassifikation der Krankheiten und verwandter Gesundheitsprobleme, 10. Revision; hrsg. v. Deutschen Institut für Medizinische Dokumentation und Information im Auftrag des Bundesministeriums für Gesundheit; o. Verl., Ort 2011

Wittenmayer N, Korber C, Liu H, Kremer T, Varoqueaux F, Chapman ER, Brose N, Kuner T und Dresbach T (2009): Postsynaptic Neuroligin1 regulates presynaptic maturation. Proc Natl Acad Sci USA 106, 13564-13569

Woolsey TA und Van der Loos H (1970): The structural organization of layer IV in the somatosensory region (SI) of mouse cerebral cortex. The description of a cortical field composed of discrete cytoarchitectonic units. Brain Res 17, 205-242 
Yamazaki M, Ohno-Shosaku T, Fukaya M, Kano M, Watanabe M und Sakimura K (2004): A novel action of stargazin as an enhancer of AMPA receptor activity. Neurosci Res $\underline{50}$, 369-374

Yan J, Oliveira G, Coutinho A, Yang C, Feng J, Katz C, Sram J, Bockholt A, Jones IR, Craddock N, Cook EH, Jr., Vicente A und Sommer SS (2005): Analysis of the neuroligin 3 and 4 genes in autism and other neuropsychiatric patients. Mol Psychiatry 10, 329-332 


\section{DANKSAGUNG}

Ich möchte mich herzlich bei allen bedanken, die zur Entstehung dieser Arbeit beigetragen und mich auf dem Weg zu ihrer Fertigstellung in vielfältiger Weise unterstützt und motiviert haben.

Allen voran möchte ich Herrn Prof. Dr. J. Staiger für die Möglichkeit danken, meine Doktorarbeit in der Abteilung Neuroanatomie des Instituts für Anatomie unter seiner Leitung durchführen zu dürfen. Seine kontinuierliche, stets hilfsbereite und fachkompetente Betreuung war für mich eine große Unterstützung.

Darüber hinaus gilt mein Dank Herrn Prof. Dr. N. Brose und der von ihm geleiteten Arbeitsgruppe des Göttinger Max-Planck-Instituts für Experimentelle Medizin. Ohne die Bereitstellung der NL-4Modellmäuse sowie die wertvollen Hinweise im Rahmen lehrreicher und informativer Besprechungen wäre die vorliegende Arbeit nicht möglich gewesen.

Besonderen Dank möchte ich Herrn Dr. M. Witte und Herrn Dr. M. Möck aussprechen, auf deren elektrophysiologisch erhobene Rohdaten ich im Rahmen dieser Arbeit zurückgreifen durfte und deren intensive Betreuung und jederzeit konstruktive Unterstützung stets eine große Hilfe war.

Bei Frau Patricia Sprysch und Frau Anna Lao möchte ich mich für die tatkräftige Unterstützung und die geduldige Anleitung im Rahmen der anfallenden Laborarbeiten herzlich bedanken.

Alvar Prönneke gilt für die Einweisung im Umgang mit dem Videomikroskop und seine Unterstützung im Rahmen der morphologischen Dokumentation der untersuchten Schnittpräparate großer Dank.

Für das Korrekturlesen dieser Arbeit und die damit verbundenen, konstruktiven Verbesserungsvorschläge möchte ich nochmals ausdrücklich Prof. Dr. J. Staiger und Dr. M. Witte ein herzliches Dankeschön aussprechen.

Darüber hinaus möchte ich mich bei allen Mitarbeitern der Abteilung Neuroanatomie für die freundliche Aufnahme, die angenehme, durch Hilfsbereitschaft geprägte Arbeitsatmosphäre sowie den wertvollen Dialog bedanken.

Göttingen, April 2013

Stephen Olt 